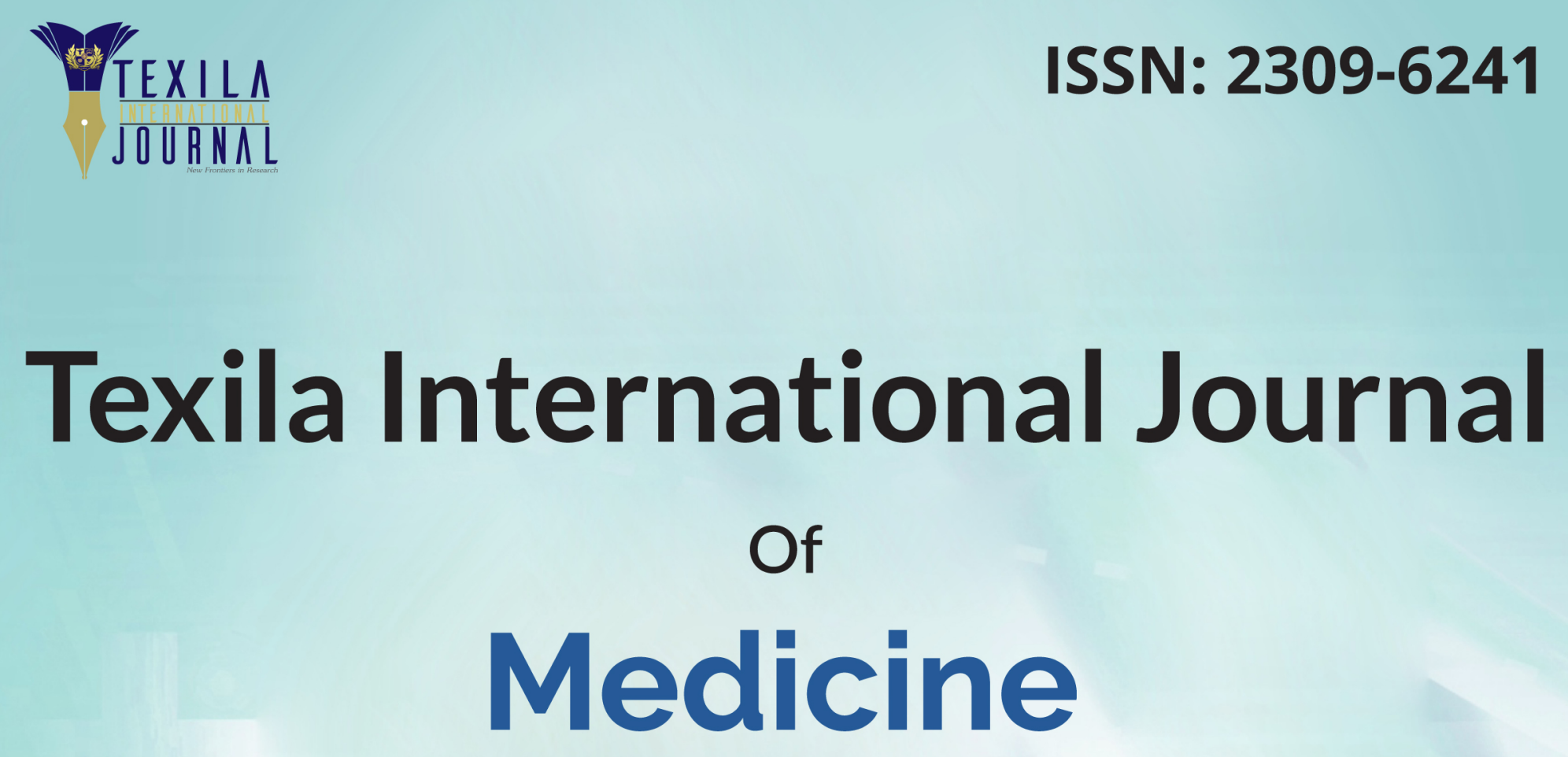




\section{EDITORIAL POLICY}

Papers must be submitted with the understanding that they have not been published elsewhere (except in the form of an abstract or as part of a published lecture, review, or thesis) and are not currently under consideration by another journal published or any other publisher. The submitting (Corresponding) author is responsible for ensuring that the article's publication has been approved by all the other coauthors. It is also the authors' responsibility to ensure that the articles coming from a particular institution are submitted with the approval of the necessary institution. Only an acknowledgment from the editorial office officially establishes the date of receipt. It is a condition for submission of a paper that the authors permit editing of the paper for readability. All enquiries concerning the publication of accepted papers should be addressed to ejournal.assist@tau.edu.gy. 


\section{ABOUT PLAGIARISM}

Plagiarism is the use or close imitation of the language and ideas of another author and representation of them as one's own original work. Duplicate publication, sometimes called self plagiarism, occurs when an author reuses substantial parts of his or her own published work without providing the appropriate references. This can range from getting an identical paper published in multiple journals, where authors add small amounts of new data to a previous paper.

Plagiarism can be said to have clearly occurred when large chunks of text have been cut and pasted. Such manuscripts would not be considered for publication in TIJBMS Journal. But minor plagiarism without dishonest intent is relatively frequent, for example when an author reuses parts of an introduction from an earlier paper. The editors will judge any case of which they become aware (either by their own knowledge of and reading about the literature, or when alerted by referees) on its own merits.

The paper containing the plagiarism will be obviously returned back to the author's for review, but we earnestly request the authors to avoid submitting plagiarized 


\section{DISCLAIMER}

Texila International Journal of Medicine (TIJMD) make every effort to ensure the accuracy of all the information (the "Content") contained in its publications. However, the TIJMD and its agents make no representations or warranties whatsoever as to the accuracy, completeness or suitability for any purpose of the Content and disclaim all such representations and warranties whether express or implied to the maximum extent permitted by law. Any views expressed in this publication are the views of the authors and are not necessarily the views of the Editor's or Texila International Journal of Medicine. 


\section{TABLE OF CONTENT}

1 ESKAPE Pathogens: Bad Bugs with No Drugs- A Study in Tertiary Care Hospital

Mowna Karthick

2 Hyperglycemia and Glasgow Coma Scale in Pediatric Traumatic Brain Injury in the Emergency Room

Karthick Jayapal

3 Understanding Mortality and Morbidity Meeting at Princess Marina Hospital: 9 Case of Accident and Emergency Department (April 2014 to March 2015)

Kabongo Leba

4 Knowledge, Attitude and Practice of Medical Incident Reporting Among Healthcare Professionals: A Study of Midigo Health Centre IV

Omona Kizito

5 Effects of diabetic education on blood pressure, blood urea, creatinine and 43 fasting sugarby diabetic patients in central hospital Nampula

Madhumati Varma

6 Efficacy of Sympathetic Radiofrequency in CRPS 1 Satellite Ganglion Block 71 VS T2-T3 Sympathetic Block

Jayesh Thakrar

7 Hematoma Localization under Ultrasound-Guidance for Excision (HUGE) of 81 Impalpable Breast Lesions, a Modification to make Screening Effective in Nigeria: Pilot study

Agodirin SO

8 Duodenal Carcinoid with Cystic Hepatic Metastasis Presenting with Severe Anemia and Heart Failure

Chenna Keshava BG

9 Management of a suspected case of monkeypox at vanga hospital, Kwilu, 91 republic democratic of Congo

Mudji e’kitiak 
Anitha Bobba

11 Compare the Effect of Thiopental and Propofol on Neonatal and Maternal Outcomes after Caesarean Section: Anon-Systematic Review 


\title{
ESKAPE Pathogens: Bad Bugs with No Drugs- A Study in Tertiary Care Hospital
}

\author{
Article by Mowna Karthick \\ Specialist Microbiology, Shri SathyaSai Medical College and Research Institute, \\ India \\ Email: drmowna1818@gmail.com
}

\begin{abstract}
ESKAPE pathogens Enterococcus faecium, Staphylococcus aureus, Klebsiella pneumoniae, Acinetobacter baumanii, Pseudomonas aeruginosa, and Enterobacter species are currently the cause of majority of hospital infections globally and they also effectively "escape" the effects of antibacterial drugs. The UNSTOPPABLE SUCCESS of these SUPERBUGS will lead to UNWINNABLE WAR. It has been suggested that resistance by these organisms are due to mutations, modification of LPS. As the crisis of antibiotic resistance continues to grow, the latest IDSA(Infectious disease society of America) "Bad Bugs, No Drugs" report examines the trickle of new antibiotics in the research and development $(R \& D)$ pipeline and proposes steps to tackle the shortage. The aim of the study was to characterize the antimicrobial resistance in ESKAPE pathogens isolated from 430 culture positive clinical sample like urine, pus, blood, wound swab and sputum.. Antibiotic resistance was determined by VITEK 2 and manual Kirby Bauer method. MIC was determined by VITEK 2 and E Test according to Clinical and Laboratory Standards Institute (CLSI). ESKAPE pathogens account for 63\%. Except for S. aureus multiple drug resistance (MDR) index of ESKAPE pathogens revealed an increasing trend. The statistical analysis was done for hospital acquired and community acquired MDR infections. Extended spectrum betalactamase (ESBL), Klebsiellaspp., carbapenem resistant, A. baumannii and $P$. aeruginosa were identified mainly in hospital acquired than in community acquired infections. In conclusion, ESKAPE pathogens are commonly identified in alarming frequency and knowledge of antimicrobial resistance will be aided for empirical treatment.
\end{abstract}

Keywords: Multi drug Resistant, ESKAPE pathogens, Infections, antibiotics.

\section{Introduction}

Infections caused by antibiotic-resistant bacteria continue to challenge physicians from last decade. We face growing resistance among Gram-positive and Gram-negative pathogens that cause infection in the hospital and in the community [1-3]. IDSA (Infectious disease society of America) reported these as the "ESKAPE" pathogens Enterococcus faecium, Staphylococcus aureus, Klebsiella pneumoniae, Acinetobacter baumanii, Pseudomonas aeruginosa, and Enterobacter species) to emphasize that they currently cause the majority of hospital infections and effectively "escape" the effects of antibacterial drugs. Data from the Centers for Disease Control and Prevention (CDC) show rapidly increasing rates of infection due to methicillin-resistant S. aureus (MRSA), vancomycin-resistant E. faecium (VRE), and fluoroquinolone-resistant $P$. aeruginosa [4].

Infections caused by Multi drug resistant organisms have been reported with increasing frequency, thereby limiting the choice of effective antimicrobial agents available to clinicians. In addition the aging population and frequent referrals of patients from and to acute care facilities also add for the prevalence of multi drug resistant organisms.

Multidrug resistant (MDR) organisms especially Gram negative bacilli have become a pivotal of long term care facilities in the hospitals and vice versa[5]. In contemporaneous the aging population and frequent referrals of patients from and to acute care facilities also add as the reservoir for the MDR(1). The unstoppable success of these SUPERBUGS will lead to the 
Texila International Journal of Medicine

Volume 4, Issue 2, Dec 2016

crisis called "UNWINNABLE WAR"[6]. Data from the National Nosocomial Infection Surveillance (NNIS) System (2003 versus 1998- 2002) showed that, in the nine selected antimicrobial-resistant pathogens associated with nosocomial infections in intensive care unit patients, there is increase in the prevalence of resistance to third-generation cephalosporins (either ceftriaxone, cefotaxime or ceftazidime) The recent emergence of resistant organisms to other drug classes serves to highlight the important therapeutic role of polymyxins such as colistin. No new antibiotic classes against multi drug resistant Gram-negative bacteria are expected to be commercially available within the next several years. Even more worrying, the emergence of resistance to colistin, the only available active antibiotic against multidrugresistant Gram-negative bacteria[7]. Our therapeutic options for these pathogens are so extremely limited that clinicians are forced to use older, previously discarded drugs, such as colistin, that are associated with significant toxicity and for which there is a lack of robust data to guide selection of dosage regimen or duration of therapy [8]. The growing number of elderly patients and patients undergoing surgery, transplantation, and chemotherapy and dramatic increases in population in neonatal intensive care units will produce an even greater number of immunocompromised individuals at risk of these infections [9]. MDR organisms are commonly hospital acquired. Hospital acquired infections defined as the infections that was not present nor incubating at the time of admission in the hospital.

The study focuses on the antibiotic resistant organisms. It will be useful in implication of the antibiotic policy and also guide the physicians for treatment.

\section{Methodology}

The research done was applied, analytical type of case study research. The samples were collected by direct observational method. All the ESKAPE PATHOGENS isolated samples was be included in the study (probability sampling).

To avoid multiple entries from a single patient, only the first positive MDR culture for a given patient was included. The patients Identification number, age, sex, type of sample, recent significant treatment history with antibiotics, provisional diagnosis, duration of hospital stay and any other history related to the research was collected in observational design from the administrative data base. All the clinical samples received for Bacteriological culture in Microbiology section of the laboratory were processed and analyzed for the research. All clinical samples(Urine, pus, wound swab, sputum) were inoculated in the respective media and methods as per standard guidelines and incubated. The blood culture bottles will be placed in Bac T/ Alert $3 \mathrm{D}$ and the positive culture bottle will be processed by Grams stain and in routine bacteriological media for inoculation and incubated. The samples with significant growth was processed by VITEK Compact for identification. All the ESKAPE pathogens isolated from all the clinical samples will be subjected for determining the MIC and Sensitivity by Vitek 2 and Kirby Bauer method as per CLSI

Isolates that were collected within 2 days after admission were considered to be acquired prior to the hospitalization, or "nonnosocomial”; Isolates acquired after day 2 were considered "nosocomial.”Total of 1000 samples were included in the study after the ethical committee approval by the institution.

\section{Results}

In total 1000 samples, 430 culture positive clinical sample. Among 430 Positive samples, 271 pathogens were identified as ESKAPE pathogens. The Enterococcus faecium accounted for 28, 72 samples isolated MRSA. In 64 and 39 samples Pseudomonas aeruginosa and acinetobacter were isolated respectively.46 samples isolated Klebsiella pneumonia and 22 isoated Enterobacter.

The samples which were resistant to more than 3 groups of antibiotic were considered as Multidrug Resistant Organisms (MDRO). Out of 1000 samples 6.9\% were MDR. 


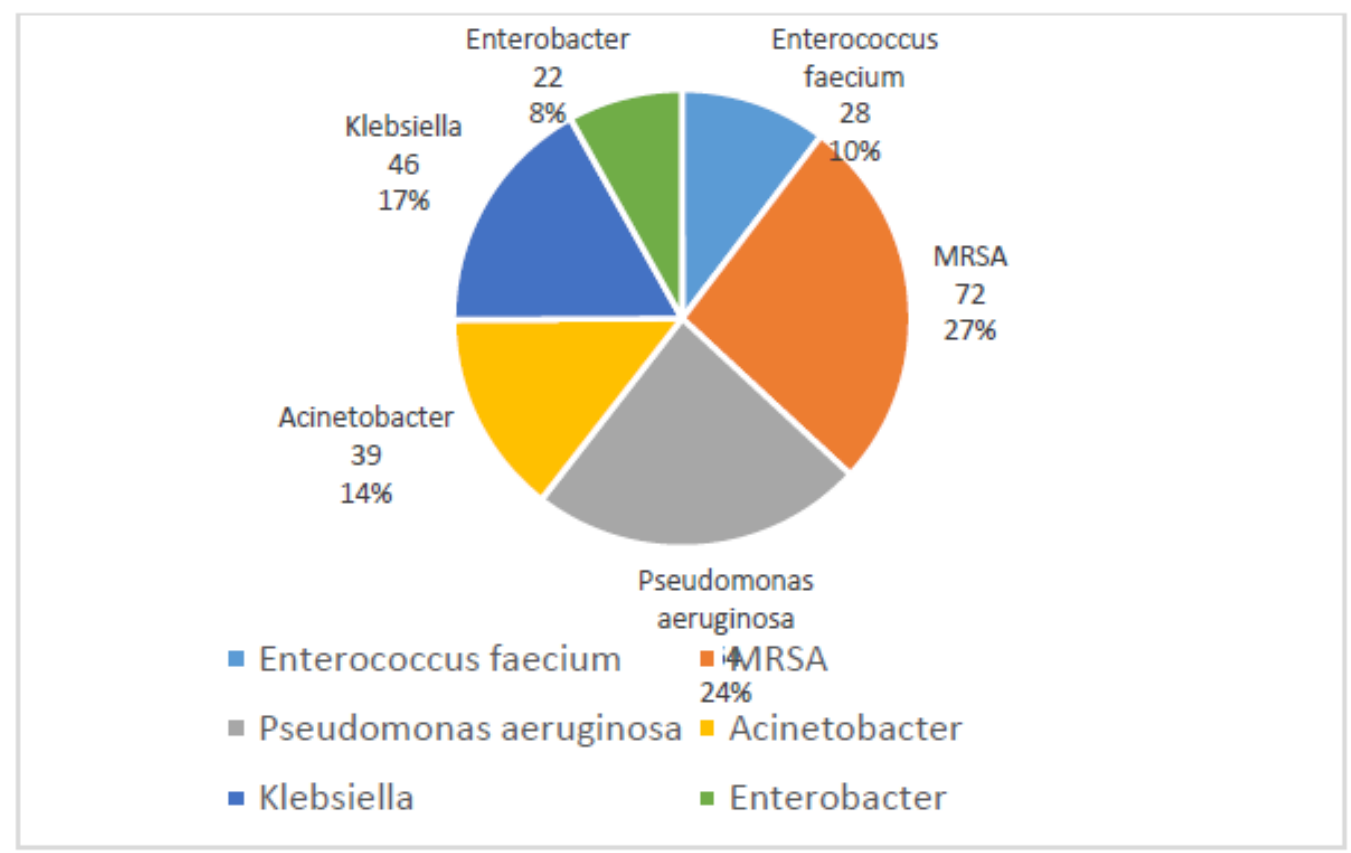

Figure 1. Distribution of ESKAPE

\section{Discussion}

Due to the ability of bacteria to rapidly gain resistance along with overuse and misuse of antibiotics, we are now in an age of multidrug-resistant (MDR) and pan-drug-resistant (PDR) bacterial pathogens leading to the situation like the pre-antibiotic era. This burden of antimicrobial resistance has resulted in increase in the length of hospital stays, patient mortality, and health care costs(10). Of more recent concern is the emergence of MDR Gram negative bacilli (GNB) in long term care facilities; Several studies have shown that the carriage prevalence of MDR GNB has far exceeded that of methicillin-resistant Staphylococcus aureus (MRSA) and vancomycin- resistant enterococci (VRE)(4).

A retrospective study states that there is an increase in the resistance pattern organisms in the past one year. Few studies have been focused on Pandrug resistant organisms especially Acinetobater and Pseudomonas species. Acinetobacter baumannii, Pseudomonas and Enterobacteriaceae were considered to be Pan drug resistant (PDR) if isolates were resistant to all classes of anti pseudomonal agents $(11,12)$. This study focuses on the resistance pattern of the most commonly isolated MDR organism and emergence of antimicrobial stewardship to be followed by the physicians. This study has the pervelence of 6.9 of MDR organisms which was similar to other studies.

The Enterococcus species develops drug resistance by chromosomal mediated while Staphylococcus acquires resistance by plamid mediated. The Pseudomonas and Acinetobacter species transferred easily from one patient to other and prevalent in ICU patients. In the study it was observed chronic hospitalized patients developed drug resistance to which it was sensitive previously. Many carbapenamase resistant pseudomonas were also been isolated. Enterobacter acquired resistance by Amp C gene and it was found that the patients treated with third generation cephalosporins to Enterobacter developed resistance in few weeks for the same drug due to Amp C production.

\section{Conclusion}

In the study there were significant isolation of MDR organisms. The study mainly concerns of resistance pattern in the ESKAPE pathogens which is the major threat to hospital as well as community acquired infections. There should be a strict antibiotic stewardship to be followed in each hospitals and restricted use of antibiotics as per sensitivity pattern. 
Texila International Journal of Medicine

Volume 4, Issue 2, Dec 2016

\section{Acknowledgements}

I would like to express my gratitude to my professor Dr. Venugopal, for helping me with this study.

\section{References}

[1]. Abdul Ghafur1, Vidyalakshmi PR1, A Murali. Emergence of Pan-drug resistance amongst gram negative bacteria! The First case series from India, Journal of Microbiology and Infectious Diseases / (2014); 4 (3): 86-91 JMID doi: 10.5799/ahinjs

[2]. Anima Poudyal, Benjamin P. Howden In vitro pharmacodynamics of colistin against multidrugresistant Klebsiella pneumonia new Journal of Antimicrobial Chemotherapy (2008) 62, 1311-1318 doi:10.1093/jac/dkn425 Advance Access publication 15 October (2008)

[3]. Azza Elemam, Joseph Rahimian, and William Mandell. Infection with Panresistant Klebsiella pneumoniae: A Report of 2 Cases and a Brief Review of the Literature Clin Infect Dis. (2009) 49 (2): 271-274. doi: 10.1086/600042

[4]. Brooke A. Napier,a, b Eileen M. Burd, c, f Sarah W. Satola, c, d, e Stephanie M. Cagle, c, e Susan M. Ray,c, e, i Patrick McGann, g Jan Pohl, h Emil P. Lesho, g David S. Weiss a, b, c Clinical Use of Colistin Induces Cross-Resistance to Host Antimicrobials in Acinetobacter baumannii (2013) 4 (3).

[5]. Chua SL, Yam JKH, Sze KS, Yang L (2016).”Selective labelling and eradication of antibiotictolerant bacterial populations in Pseudomonas aeruginosa biofilms". Nat Commun. 7:10750. doi:10.1038/ncomms10750. PMID 26892159.

[6]. Ching Jou Lim, Allen C. Cheng Prevalence of multidrug resistant organisms and risk factors for carriage in long-term care facilities: a nested case-control study. Antimicrob Chemother(2014); 69: 1972-1980 doi:10.1093/jac/dku077 Advance Access publication 7 April 2014

[7]. Rafael López-Rojas,a,c Michael J. McConnell,a,c Manuel Enrique Jiménez-Mejías, Colistin Resistance in a Clinical Acinetobacter baumannii Strain Appearing after Colistin Treatment: Effect on Virulence and Bacterial Fitness. Antimicrobial agents chemother (2013) sep; 57 (9). Federico Perez, Andrea M. Hujer, Kristine M. Hujer, Brooke K. Decker, Philip N. Rather, and Robert A. Bonomo. Global Challenge of Multidrug-Resistant Acinetobacter baumannii ANTIMICROBIAL AGENTS AND CHEMOTHERAPY, Oct. (2007), p. 3471-3484 Vol. 51, No. 10 0066-4804/07/\$08.000 doi:10.1128/AAC.01464-06 Copyright $($ C 2007, American Society for Microbiology.

[8]. Giske CG, Monnet DL, Cars O, Carmeli Y. Clinical and economic impact of common multidrugresistant gram-negative bacilli. Antimicrob Agents Chemother (2009);52:813-21.

[9]. National Nosocomial Infections Surveillance System Report, data summary from January 1992 through June (2004) issued October 2004. Am J Infect Control 2004;32:470-85.

[10]. Rice LB. Federal funding for the study of antimicrobial resistance in nosocomial pathogens: no ESKAPE. J Infect Dis (2009);197:1079-81.

[11]. Spellberg B, Guidos R, Gilbert D The epidemic of antibiotic-resistant infections: a call to action for the medical community from the Infectious Diseases Society of America. Clin Infect Dis (2009);46:155-64. 


\title{
Hyperglycemia and Glasgow Coma Scale in Pediatric Traumatic Brain Injury in the Emergency Room
}

\author{
Article by Karthick Jayapal \\ MBBS, M.D(ped), Fellowship in Pediatric Emergency medicine, Fellowship in \\ Pediatric Trauma, Specialist Pediatric ER, Shri SathyaSai Medical college and \\ Research Institute, India \\ Email: karthickchildcare@gmail.com
}

\begin{abstract}
Introduction: A high blood glucose is common in actually ill neurological patients, even in non-diabetics. A consensus regarding the cut-off blood glucose level that would be related to poor prognosis in children and adolescent with head trauma, which makes the comparison of different studies important. Objective: Prevalence of acute hyperglycemia and Glasgow coma scale (GCS) in Pediatric Traumatic brain injury in the Emergency Room. Method: Prospective cross-sectional study of pediatric head injury patients in the emergency room during one year period. The cut-off value of $150 \mathrm{mg} / \mathrm{dL}$ to define hyperglycemia was considered. Results: A total of 440 children were included and 65 had admission hyperglycemia. Hyperglycemia was present in 11\% of mild head trauma cases; $35 \%$ of those with moderate head trauma and 54\% of severe head trauma. In this study, observed that among children with higher blood glucose levels, 83\% had abnormal findings on cranial computed tomography scans. The prevalence of hyperglycemia is higher in patients with severe head trauma, as well as in those with abnormal findings on CCT scans. Conclusion: Hyperglycemia was more prevalent in severe head trauma (GCS\&8), regardless of etiology of trauma, mode of injury or multiple trauma in children with abnormal findings on head computed tomography scans.
\end{abstract}

Keywords: adolescents, children, head trauma, hyperglycemia, prevalence

\section{Introduction}

Guidelines for diabetes and classification are widely described ${ }^{1,2}$. A high blood glucose is common in actually ill neurological patients, even in non-diabetics. A consensus regarding the cut-off blood glucose level that would be related to poor prognosis in children and adolescent with head trauma, which makes the comparison of different studies imortant ${ }^{3-9}$.

Some authors believe that patients with hyperglycemia general have a low Glasgow Coma Scale (GCS) score 3-6, poor neurological prognosis based on GCS) and a history of severe trauma with significant brain injury ${ }^{6,7}$. It is well known that such acute hyperglycemia is a result of catecholamine effects ${ }^{8,9}$. Some authors, however, disagree on the association of hyperglycemia and poor prognosis, particularly in children and adolescents, as high blood glucose levels are transient and basically reflect a body response after ijury ${ }^{10}$. In the patient study we aimed to verify the prevalence of acute hyperglycemia in pediatric patients with head trauma, according to the severity of head injury.

Purpose of this study is of great importance in pediatric age group, as more study are related with adult population. Early Hyperglycemia in ER, correlates well with the severity of traumatic brain injury irrespective of the mode of trauma, gives the treating physician as one the important tool in assessment and decision making.

\section{Method}

A prospective cross-sectional study was carried out with information derived from medical records of pediatric patients with head trauma. data collected from medical records included age, sex, mechanism of injury, classification of trauma (isolated head trauma or multiple 
Texila International Journal of Medicine

Volume 4, Issue 2, Dec 2016

trauma), GCS score and blood glucose level on admission and cranial computed tomography (CCT) scan results. Medical records of patients aged from 0 to 14 years-old with head trauma presented in the emergency room for 1 year.

World Health organization (WHO) definition for pediatric age was used here ${ }^{11}$. Severity of head trauma was accessed by GCS score on admission, and when necessary the modification for use in children under 2 years ${ }^{12-14}$. Findings on the CCT scan considered to be abnormal included any brain lesion such as brain swelling, diffuse axonal injury and intracranial hemorrhages. The CCT scans were done in the same hospital and at the same model of tomography machine.

The results were checked by experienced radiologists and neurosurgeons. Exclusion criteria included a previous diagnosis of diabetes, absence of GCS score, CCT scan or blood glucose levels on the first $24 \mathrm{~h}$ of admission and hospital stay less than $48 \mathrm{~h}$.

Hyperglycemia Blood glucose levels were determined by capillary blood glucose obtained through fingertips' puncture at hospital admission. The results were shown in digital blood glucose monitor. This same technique was used in every patient. We considered values above $150 \mathrm{mg} / \mathrm{dl}$ as hyperglycemia, like other authors have already claimed ${ }^{3}$.

Ethical concerns and data analyses the study was approved by the Hospital ethics Committee under registration no 06/07. Either parents or other legally responsible signed informed consent before inclusion in the study. No extra exams, besides the ones usually performed in an emergency room, were done.

Categorical data were analyzed by using $\chi^{2}$ analyses and Pearson analysis was used to verify correlation between GCS and blood glucose level on admission.

\section{Results}

A total of 440 patients were eligible for inclusion. Mean age was $9.8( \pm 6)$ years; $73.2 \%$ were male. Regarding the type of trauma, the most frequent were fall from a height (34.1\%) and vehicle-pedestrian accidents (18.2\%). regarding the GCS classification, 295 (72.1\%) patients had mild head trauma (GCS 13-15), 70 (13.5\%) had moderate head trauma (GCS 912), whereas 74(14.4\%) suffered severe head trauma (GCS 3-8). Concerning blood glucose levels on admission, 65 (17.6\%) patients had hyperglycemia. Hyperglycemia was found in $73.3 \%$ of male patients and $55 \%$ of traffic accidents victims.

The prevalence of hyperglycemia increased proportionally to the head trauma severity: $11 \%$ in mild head trauma, $35 \%$ in moderate head trauma ( $<<0.01$ when compared to mild head trauma) and $54 \%$ in cases considered severe $(\mathrm{p}<0.01$ when compared to mild head trauma). An inverse relationship between admission glucose levels and GCS score was found, using Pearson analysis ( $\mathrm{r}=0.32 ; \mathrm{p}=0.01)$.

Regarding the cases of isolated head trauma or multiple traumas, in those with isolated head injury we observed hyperglycemia in $15 \%$ versus $20 \%$ of the other group $(p=0.28)$. Brain swelling (32\%), and intracranial hemorrhages (20\%) were the most important abnormal findings on CCT scan.

Among hyperglycemic patients, 83\% had abnormal brain parenchymal findings. However only $35.6 \%$ of the normoglycemic patients had abnormal brain parenchymal findings according CCT scans results.

\section{Discussion}

In accordance with previous studies ${ }^{15}$, our findings showed the predominance of male sex and falls in pediatric head trauma victims. We did not observe statistical differences in hyperglycemia prevalence regarding sex $(\mathrm{p}=0.98)$ and type of trauma. Regarding the GCS classification, we find a preponderance of mild head trauma victims, which is also widely described in previous studies. It is important to notice that patients with mild head trauma generally stay in hospital for short periods of time, have less severe or no brain damage and do not suffer a meaningful metabolic response related to trauma ${ }^{16}$, so it is not usual to diagnose hyperglycemia in those patients. 
Hyperglycemia is indeed more frequently observed in severe head trauma victims and in those that suffered multiple trauma, according to some studies ${ }^{3,4,6,17,18}$. The explanation would be that these patients have a more important metabolic response to injury due to the effects of cortisol, glucagon and epinephrine release, causing intracellular acidosis, lactate accumulation, high blood glucose levels and neuronal injury ${ }^{6,19-21}$.

Therefore, our data are in accordance with the results from other authors who correlate the head trauma severity and the metabolic response to trauma, particularly higher blood glucose levels ${ }^{7,22,23}$. Some studies show that hyperglycemia is associated with a worse outcome, regardless of injury characteristics ${ }^{24}$. We did not observe statistically significant differences in blood glucose levels in patients with isolated head injury and in the ones with multiple traumas. The probable cause might be that we considered multiple trauma any kind of injury associated with head trauma, regardless of the degree of injury. We could have overestimated the amount of multiple trauma victims.

The observation of abnormal CCT findings was more frequent in hyperglycemic patients. Such an association was also described by previous studies and possible explanations would be that brain injury evokes a metabolic response that results in hyperglycemia and/or that hyperglycemia itself is responsible for more meaningful brain lesions on CCT scans ${ }^{25,26}$. Our knowledge up to now does not permit to conclude if a high blood glucose level is a mediator or a marker of brain injury.

Inclusion the prevalence of hyperglycemia is higher in patients with severe head trauma, as well as in those with abnormal findings on CCT scans. All these variables are generally associated with significant brain tissue lesion. We cannot conclude if the higher blood glucose levels are responsible for poorer outcomes in the present observation. The meaning of hyperglycemia in the outcomes of children and adolescents with severe head trauma will be analyzed in a future study.

The most common classification system for TBI severity is based on GCS score determined at the time of injury. The GCS is a 3- to 15-point scale used to assess a patient's level of consciousness and level of neurologic functioning. It consists of 3 sections, each of which is scored: best motor response, best verbal response, and eye opening. A total score of 3-8 for the 3 sections indicates severe TBI, a score of 9-12 indicates moderate TBI, and a score of 13-15 indicates mild TBI.

The above data obtained, act as a one of the early significant tool in ER for severity of pediatric traumatic brain injury and decision making even in mild and moderate head trauma. Hyperglycemia correlates well with drop in GCS in accordance with severity of brain injury.

\section{Conclusion}

Hyperglycemia was more prevalent in severe head trauma (GCS $\leq 8$ ), regardless of etiology of trauma, mode of injury or multiple trauma in children with abnormal findings on head computed tomography scans

\section{Acknowledgements}

I would like express my gratitude to my professor Vijayarangan MD for helping me with this study.

\section{References}

[1]. Bochicchio GV, Sung J, Joshi M. Persistent hyperglycemia is predictive of outcome in critically ill trauma patients. J Trauma (2005); 58; 921-924.

[2]. Bochicchio GV, Joshi M, Bochicchio KM. Early hyperglycemic control is important in critically injured trauma patients. J Trauma (2007); 63; 1353-1358.

[3]. Chiaretti A, De BR, Langer A. Prognostic implications of hyperglycaemia in paediatric head injury. Childs NervSyst (1998); 14:455-459.

[4]. Chiaretti A, Piastra M, Pulitano S. Prognostic factors and outcome of children with severe head injury: an 8-year experience. Childs NervSyst (2002); 18:129-136. 
Texila International Journal of Medicine

Volume 4, Issue 2, Dec 2016

[5]. Cochran A, Scaife ER, Hansen KW, Downey EC. Hyperglycemia and outcomes from pediatric traumatic brain injury. J Trauma (2003); 55: 1035-1038.

[6]. Durr JA, Hoffman WH, Sklar AH, Steinhart CM. Correlates of brain edema in uncontrolled IDDM. Diabetes (1992); 41; 627-632.

[7]. Epstein J, Breslow MJ. The stress response of critical illness. Crit Care Clin (1999); 15; 17-33. 20. Hirsch IB.

[8]. Jeremitsky E, Omert LA, Dunham CM, Wilberger J, Rodriguez A. The impact of hyperglycemia on patients with severe brain injury. J Trauma (2005); 58; 47-50.

[9]. Kuzuya T, Nakagawa S, Satoh J. Report of the Committee on the classification and diagnostic criteria of diabetes mellitus. Diabetes Res ClinPract (2002); 55:65-85.

[10]. Kushner M, Nencini P, Reivich M. Relation of hyperglycemia early in ischemic brain infarction to cerebral anatomy, metabolism, and clinical outcome. Ann Neurol (1990); 28: 129-135.

[11]. Lam AM, Winn HR, Cullen BF, Sundling N. Hyperglycemia and neurological outcome in patients with head injury. J Neurosurg (1991); 75: 545-551.

[12]. Laird AM, Miller PR, Kilgo PD, Meredith JW, Chang MC. Relationship of early hyperglycemia to mortality in trauma patients. J Trauma (2004); 56; 1058-1062.

[13]. Marcoux KK. Management of increased intracranial pressure in the critically ill child with an acute neurological injury. AACN Clin Issues (2005); 16:212-231.

[14]. Melo JR, Santana DL, Pereira JL, Ribeiro TF. [Traumatic brain injury in children and adolescents at Salvador City, Bahia, Brazil]. Arq Neuropsiquiatr (2006); 64:994-996.

[15]. Melo JR, Silva RA, Moreira ED Jr. [Characteristics of patients with head injury at Salvador City (Bahia--Brazil)]. Arq Neuropsiquiatr (2004); 62;711-714.

[16]. In-patient hyperglycemia--are we ready to treat it yet? J ClinEndocrinolMetab (2002);87; 975977.

[17]. Orliaguet GA, Meyer PG, Baugnon T. Management of critically ill children with traumatic brain injury. PaediatrAnaesth (2008); 18 :455-461.

[18]. Parish RA, Webb KS. Hyperglycemia is not a poor prognostic sign in head-injured children. J Trauma (1988);28:517-519.

[19]. Parejo P, Stahl N, Xu W, Reinstrup P, Ungerstedt U, Nordstrom CH. Cerebral energy metabolism during transient hyperglycemia in patients with severe brain trauma. Intensive Care Med (2003); 29; 544-550.

[20]. Sung J, Bochicchio GV, Joshi M, Bochicchio K, Tracy K, Scalea TM. Admission hyperglycemia is predictive of outcome in critically ill trauma patients. J Trauma (2005); 59:80-83.

[21]. Schelp AO, Burini RC. [Cerebral glucose metabolism in craniocerebral trauma: an evaluation]. Arq Neuropsiquiatr (1995);53:698-705.

[22]. Teasdale G, Jennett B. Assessment of coma and impaired consciousness. A practical scale. Lancet (1974)13; 7872; 81-84.

[23]. Tominaga M. Diagnostic criteria for diabetes mellitus]. RinshoByori (1999); 47:901-908.

[24]. Umpierrez GE, Isaacs SD, Bazargan N, You X, Thaler LM, Kitabchi AE. Hyperglycemia: an independent marker of in-hospital mortality in patients with undiagnosed diabetes. J ClinEndocrinolMetab (2002); 87; 978-982.

[25]. Yamaguchi N. Sympathoadrenal system in neuroendocrine control of glucose: mechanisms involved in the liver, pancreas and adrenal gland under hemorrhagic and hypoglycemic stress. Can J PhysiolPharmacol (1992);70:167-206.

[26]. World Health Organization. Child and adolescent health and development. Available at (http:///www.who.int/en/) Accessed November 01, (2007). 


\title{
Understanding Mortality and Morbidity Meeting at Princess Marina Hospital: Case of Accident and Emergency Department (April 2014 to March 2015)
}

\author{
Article by Kabongo Leba \\ MBChB (UNILU), Accident and emergency department, Princess Marina Hospital, \\ M.Sc Clinical Research, Texila American University, Congo \\ Email: lebsbabs1984@gmail.com
}

\begin{abstract}
Background: The incidence and spectrum of mortality and morbidity in Botswana are not well established. Mortality data can be provided through the hospital records and documentation.

Objectives: Based on the importance given to accident and emergency at princess marina hospital by both the leaders and the entire population in Botswana, it was opportune to conduct this study. The major objective is to establish some epidemiological markers of death in our facility and therefore to provide factors surrounding death and solutions to reduce mortality.

Methods: A retrospective study has been conducted, based on monthly mortality and morbidity report provided by different doctors within the department.

Results: 27361 patients were seen during the said period with about 111 deaths (0.41\%). A total number of 10041(36.7 \%) patients were admitted to different wards for in-patients management. A couple of patients were brought in death after sudden collapse at home or being involved in road traffic accident. Roughly 9 patients died in accident and emergency each month with a mean of 2280 patients monthly attending the department. $56 \%$ of patient died with an internal medicine condition. $51 \%$ of died in accident and emergency were young adult on the range of $14-49$ year old. No significance value concerning the difference in gender.

Conclusion: The study provided details and a preliminary answer to cause of death grossly. Despite of comorbidities and the high number of HIV patients at the age ranging between 14 and 49 year old, having a high percentage of patients adults dying in accident and emergency is alarming and suggestions had been given to shrink this number.
\end{abstract}

Keywords: mortality, morbidity, mortality and morbidity, princess marina hospital, accident and emergency department, brought in dead, died in casualty,

\section{Introduction}

\section{Background}

The realization that errors play a significant role in mortality and morbidity in accident and emergency department together with poor triaging of the patients has generated interest and needs of quality improvement initiatives that took directly into human errors.

After initially updating the triage tool in 2009 and implementing it in 2010, and In order to provide high quality care, medical staff members in accident and emergency department at princess marina hospital engage quarterly, if possible, in an objective, non-judgmental review of adverse events and outcomes happened during the management of some selective patients .

Generally, the mortality and morbidity meeting will give a statistical report followed by a clear discussion concerning some selected cases of patients who died after being seen in the department or during their stay in the department. 
Texila International Journal of Medicine

Volume 4, Issue 2, Dec 2016

The choice of these cases depends upon several criteria including, but not limited to, presenter's judgment, poor management (delayed attendance, treatment given, protocols followed...), lessons learned and improvement for the future.

\section{Definition of concept}

- The free Dictionary defines "mortality" as the quality and condition of being mortal. "Mortal" is considered to be a group like "human race".

- Morbidity is a term used to describe how often a disease occurs in a specific area or is a term used to describe a focus on death.

- Mortality and morbidity meeting is a conference where regularly the staff take an indepth , franc and opened analysis of some incidents which happened during the management of some patients leading to death or near death; with the purpose of learning and improvement.

\section{Objective of mortality and morbidity ( $M$ and $M$ )}

Mortality and morbidity meeting is one of the key component of workplace-based learning, providing an opportunity to the medical staff in accident and emergency to discuss errors and adverse events which occur in the department during a certain period of time. The discussion is always done in a very friendly and open manner.

During the meeting, the staff will answer to some specific questions:

- What happened?

- Why did it occur?

- How could the issue have been prevented or better managed?

- What are the key learning points?

\section{Methodology}

This is a retrospective study. An archival data collection and archival compilation were done to collect all the data for this report. Generally a Medical officer in accident and emergency in collaboration with Healthcare auxiliaries' staff conduct the data collection under the supervision of the medical officer.

Some tools will be used to collect data:

- Departmental admission book: this book recorded all the patients seen in the department.

- "Died in Accident and emergency" book: this book records all the patients died while in the department.

- "Brought in dead" book: for all death before arrival to the department.

- Nursing mortality and morbidity statistics

- Accident and emergency triage form: containing nurses and doctors 'notes.

- Medical record information store room.

After collecting all the data, the medical staff assigned for the M\&M at a specific period compiles all the data.

After selecting cases for discussions, the concerned officer goes through the Notes (doctors and nurses) as well as outpatient cards if available and admitting department if reported.

During this report, we will give a statistical report of all the patients seen and died in Accident and emergency during the specific of time given. This will be followed by the presentation of some interesting case which was discussed by the department.

A discussion will be conducted generating conclusion and recommendation for the future at the end of the report.

\section{Results and discussion}

\section{Presentation of the department}

- Princess marina hospital is the biggest referral hospital with nearly 500 beds. It situated in the center of Gaborone, the capital city of Botswana. It is a specialized hospital running a multidisciplinary department, as teaching and tertiary hospital. 
- The accident and emergency department is one of the units of the Hospital. It is the major entrance to the hospital. It is situated by the entrance of the hospital with an emergency gate, opposite to the transport office for ambulances. The accident and emergency department is divided into different areas including

1. Head of department office:

2. Triage office:

3. Patient Waiting area

4. Family waiting area

5. Bays(1 to 10$)$ and corridors(1 to 7$)$

6. Resuscitation room

7. Side laboratory

8. Kitchen

9. Sister in charge office

10. Store room

11. Disaster room

12. Doctors station

13. Nurse's station.

14. Isolation room.

- At the time this data were collected, the medical staff comprises the head of department, one emergency specialist under University of Botswana, 10 medical officers, 4 residents, and 2 visiting residents.

- The nurse's staff comprises the matron and sister in charge of the unit, 15 nurses, and 7 health care auxiliaries.

- A private company provides pottering services and cleaning services.

- The accident and emergency department only admits to the ward or discharge to the referring hospital or home. The department does not contain an observation ward.

- The Accident and emergency department has the mandate to manage and stabilize efficiently and effectively trauma and critically ill patients.

\section{Presentation of the results and interpretation}

Table 1. Summary of patients attended in Accident and emergency (A/E) from 01.04.2014 to 31.03.2015

\begin{tabular}{|l|l|l|l|l|}
\hline & Died in A/E & BID & Admission & Total \\
\hline April14 & 8 & 27 & 804 & 2210 \\
\hline May14 & 13 & 22 & 757 & 2136 \\
\hline June14 & 9 & 17 & 757 & 2035 \\
\hline July14 & 6 & 30 & 820 & 2301 \\
\hline august14 & 18 & 28 & 855 & 2318 \\
\hline September14 & 8 & 25 & 889 & 2419 \\
\hline October14 & 7 & 13 & 833 & 2440 \\
\hline November14 & 6 & 17 & 823 & 2277 \\
\hline December14 & 10 & 11 & 752 & 1966 \\
\hline January15 & 7 & 8 & 732 & 2083 \\
\hline February15 & 7 & 8 & 763 & 2574 \\
\hline March15 & 12 & 11 & 1256 & 2602 \\
\hline Total & 111 & 214 & 10041 & 27361 \\
\hline percentage & 0.41 & 0.78 & 36.7 & 100 \\
\hline
\end{tabular}

The table above represents the summary of all the patients seen and recorded according to their outcomes. For the period of April 2014 to march 2015, 27361 patients seek medical care in accident and emergency department at our facility. $36.7 \%$ were admitted, while $0.41 \%$ died within the department. We still have quite a high number of brought in dead cases, despite of different information given to the public. 
Texila International Journal of Medicine

Volume 4, Issue 2, Dec 2016

Table 2. Summary of patient died in Accident and Emergency (A/E) per month

Table 2.1. patients died in A/E during april2014

\begin{tabular}{|l|l|l|l|l|}
\hline Month & Disease & Gender & Age & $\begin{array}{l}\text { Source of } \\
\text { referral }\end{array}$ \\
\hline & $\begin{array}{l}\text { Cancer breast } \\
\text { with } \\
\text { hyperglycemia }\end{array}$ & $\mathrm{F}$ & 55 & Local clinic \\
\hline & $\begin{array}{l}\text { Per } \\
\text { Vaginalbleeding? } \\
\text { malignancy }\end{array}$ & $\mathrm{F}$ & 85 & Local clinic \\
\hline APRIL & $\begin{array}{l}\text { Traditional } \\
\text { medicine } \\
\text { intoxication }\end{array}$ & $\mathrm{M}$ & 47 & EMS \\
\hline & $\begin{array}{l}\text { PCP } \\
\text { Hepatomegaly } \\
\text { ?cause }\end{array}$ & $\mathrm{F}$ & 50 & EMS \\
\hline & $\begin{array}{l}\text { Intestinal } \\
\text { obstruction }\end{array}$ & $\mathrm{F}$ & 60 & Local clinic \\
\hline & HI/RTA & $\mathrm{F}$ & 40 & $\begin{array}{l}\text { District } \\
\text { hospital }\end{array}$ \\
\hline & AIDS & $\mathrm{F}$ & 31 & EMS \\
\hline
\end{tabular}

During April 2014, 8 patients died while still in the unit. More than half of them were on the range of 14-49 years old and only one male patient among all.

Table 2.2. patients died in A/E in May 2014

\begin{tabular}{|c|c|c|c|c|}
\hline Month & Disease & Gender & Age & $\begin{array}{l}\text { Source of } \\
\text { referral }\end{array}$ \\
\hline & PTB/Renal failure & $\mathrm{M}$ & 35 & $\begin{array}{l}\text { District } \\
\text { hospital }\end{array}$ \\
\hline & $\begin{array}{l}\text { Advanced breast } \\
\text { Cancer }\end{array}$ & $\mathrm{F}$ & 33 & EMS \\
\hline & Collapse ?cause & $\mathrm{F}$ & 33 & EMS \\
\hline & RTA/Polytrauma & $\mathrm{M}$ & 32 & local hospital \\
\hline & Hematuria?cause & $\mathrm{M}$ & 72 & Local clinic \\
\hline \multirow[t]{8}{*}{ May14 } & $\begin{array}{l}\text { Hepatorenal } \\
\text { failure with } \\
\text { electrolyte } \\
\text { imbalance }\end{array}$ & F & 82 & Local clinic \\
\hline & PTB & $\mathrm{F}$ & 55 & EMS \\
\hline & $\begin{array}{l}\text { Acute respiratory } \\
\text { distress?cause }\end{array}$ & F & 39 & Local clinic \\
\hline & PTB & $\mathrm{M}$ & 43 & EMS \\
\hline & $\begin{array}{l}\text { Hepatorenal } \\
\text { syndrome }\end{array}$ & F & 37 & $\begin{array}{l}\text { Local } \\
\text { hospital }\end{array}$ \\
\hline & $\begin{array}{l}\text { Aspiration } \\
\text { pneumonia }\end{array}$ & $\mathrm{M}^{\prime}$ & 3 & $\begin{array}{l}\text { Local } \\
\text { hospital }\end{array}$ \\
\hline & $\begin{array}{l}\text { Renal failure/HIV } \\
\text { encephalitis }\end{array}$ & $\mathrm{M}$ & 32 & Local clinic \\
\hline & $\begin{array}{l}\text { Stevens } \\
\text { Johnson's } \\
\text { syndrome }\end{array}$ & $\mathrm{M}$ & 39 & Local clinic \\
\hline
\end{tabular}


13 patients died in May 2014 with a pediatric patient who came from a referring hospital. Mostly Female patients died during the course of this month. About $77 \%$ were young adult. Among them only 1 has a road traffic accident. The remaining has some medical condition.

Table 2.3. patients died in A/e in June 2014

\begin{tabular}{|l|l|l|l|l|}
\hline Month & Disease & Gender & Age & $\begin{array}{l}\text { Source of } \\
\text { referral }\end{array}$ \\
\hline & $\begin{array}{l}\text { Hemoperitoneum } \\
\text { post blunt } \\
\text { abdominal trauma }\end{array}$ & M & 32 & $\begin{array}{l}\text { Local } \\
\text { hospital }\end{array}$ \\
\hline $\begin{array}{l}\text { Severe } \\
\text { pneumonia/PCP }\end{array}$ & F & 40 & Local clinic \\
\hline & $\begin{array}{l}\text { Severe pneumonia } \\
\text { with CCF } \\
\text { exacerbation }\end{array}$ & F & 43 & Local clinic \\
& $\begin{array}{l}\text { Severe } \\
\text { pneumonia/septic } \\
\text { shock }\end{array}$ & F & 48 & Self-referral \\
\hline & $\begin{array}{l}\text { Severe RTI } \\
\text { Pleural effusion }\end{array}$ & F & 59 & EMS \\
\hline & $\begin{array}{l}\text { Aspiration } \\
\text { pneumonia }\end{array}$ & F & 29 & $\begin{array}{l}\text { Local } \\
\text { hospital }\end{array}$ \\
\hline & PCP & F & 31 & Local clinic \\
\hline & PTB & M & 48 & EMS clinic \\
\hline
\end{tabular}

9 deaths were recorded in June. All were adult with a $78 \%$ of female and $22 \%$ male. Except the old lady with severe RTI all the remaining are ranging between 14-49 years old.

Table 2.4. patients died in A/E in July 2014

\begin{tabular}{|l|l|l|l|l|}
\hline & Diseases & Gender & Age & $\begin{array}{l}\text { Source of } \\
\text { referral }\end{array}$ \\
\hline & PTB & F & 33 & Local clinic \\
\hline & $\begin{array}{l}\text { Hepatic } \\
\text { encephalopathy }\end{array}$ & $\mathrm{F}$ & 38 & Local clinic \\
\hline July & $\begin{array}{l}\text { Subdural } \\
\text { hemorrhage }\end{array}$ & $\mathrm{M}$ & 42 & $\begin{array}{l}\text { Local } \\
\text { hospital }\end{array}$ \\
\hline & CVA & $\mathrm{F}$ & 70 & EMS \\
\hline & AIDS & $\mathrm{M}$ & 53 & EMS \\
\hline & $\begin{array}{l}\text { Ruptured } \\
\text { aneurysm }\end{array}$ & $\mathrm{F}$ & 54 & $\begin{array}{l}\text { Local } \\
\text { hospital }\end{array}$ \\
\hline
\end{tabular}

6 patients recorded dead. Oneunusual diagnosis of ruptured aneurysm had been reported as well. 2 third are female.

Table 2.5. patients died in A/E in august 2014

\begin{tabular}{|l|l|l|l|l|}
\hline & Diseases & Gender & Age & $\begin{array}{l}\text { Source of } \\
\text { referral }\end{array}$ \\
\hline & Renal failure & M & 55 & Self \\
\hline & $\begin{array}{l}\text { Severe } \\
\text { Gastroenteritis }\end{array}$ & F & 5 months & Local clinic \\
\hline & $\begin{array}{l}\text { Severe } \\
\text { pneumonia }\end{array}$ & M & 76 & EMS \\
\hline & Urosepsis & M & 53 & EMS \\
\hline
\end{tabular}


Texila International Journal of Medicine

Volume 4, Issue 2, Dec 2016

\begin{tabular}{|c|c|c|c|c|}
\hline & PTB & $F$ & 32 & Local clinic \\
\hline & $\begin{array}{l}\text { Anemia with } \\
\text { CCF }\end{array}$ & $\mathrm{M}$ & 81 & Local clinic \\
\hline & $\begin{array}{l}\text { Severe } \\
\text { pneumonia }\end{array}$ & Male & 37 & EMS \\
\hline \multirow[t]{11}{*}{ august } & $\begin{array}{l}\text { Severe } \\
\text { malnutrition }\end{array}$ & $\mathrm{M}$ & 10months & Local clinic \\
\hline & $\begin{array}{l}\text { Crypto } \\
\text { meningitis }\end{array}$ & $\mathrm{M}$ & 17 & Local clinic \\
\hline & $\begin{array}{l}\text { Incarcerated } \\
\text { hernia }\end{array}$ & $\mathrm{M}$ & 70 & Local clinic \\
\hline & $\begin{array}{l}\text { Polytrauma post } \\
\text { RTA }\end{array}$ & $\mathrm{M}$ & 53 & EMS \\
\hline & $\begin{array}{l}\text { Crypto } \\
\text { meningitis }\end{array}$ & $F$ & 48 & EMS \\
\hline & CVA & $\mathrm{M}$ & 57 & $\begin{array}{l}\text { Local } \\
\text { hospital }\end{array}$ \\
\hline & $\begin{array}{l}\text { Massive } \\
\text { intracranial } \\
\text { hemorrhage }\end{array}$ & $\mathrm{M}$ & 36 & Local clinic \\
\hline & Pneumonia & $\mathrm{M}$ & 36 & $\begin{array}{l}\text { Local } \\
\text { hospital }\end{array}$ \\
\hline & CCF & $\mathrm{M}$ & 80 & Local clinic \\
\hline & $\begin{array}{l}\text { Head injury } \\
\text { post assault }\end{array}$ & $F$ & 80 & $\begin{array}{l}\text { Local } \\
\text { hospital }\end{array}$ \\
\hline & CRF & $M$ & 50 & Local clinic \\
\hline
\end{tabular}

The highest number of death. 2 infants died in a/e during this period. There was a very unusually assault; an 80 years old female who died with head injury. $78 \%$ of deaths were male. About $60 \%$ deaths beyond 50 years old.

Table 2.6. patients died in A/E in September 2014

\begin{tabular}{|l|l|l|l|l|}
\hline & Diseases & Gender & Age & $\begin{array}{l}\text { Source of } \\
\text { referral }\end{array}$ \\
\hline & $\begin{array}{l}\text { Electrolyte } \\
\text { imbalance with } \\
\text { renal failure }\end{array}$ & F & 46 & $\begin{array}{l}\text { Local } \\
\text { hospital }\end{array}$ \\
\hline & $\begin{array}{l}\text { Hemorrhagic } \\
\text { CVA }\end{array}$ & F & 65 & Local clinic \\
\hline September & $\begin{array}{l}\text { Hypovolemic } \\
\text { shock post } \\
\text { trauma }\end{array}$ & $\mathrm{M}$ & 81 & $\begin{array}{l}\text { Local } \\
\text { hospital }\end{array}$ \\
\hline & $\begin{array}{l}\text { Urosepsis with } \\
\text { urinary retention }\end{array}$ & $\mathrm{M}$ & 49 & Local clinic \\
\hline & Severe sepsis & $\mathrm{M}$ & 73 & Local clinic \\
\hline & $\begin{array}{l}\text { PCP } \\
\text { Acute } \\
\text { abdomen(uterine } \\
\text { perforation) }\end{array}$ & $\mathrm{F}$ & 40 & Local clinic \\
\hline & & 39 & $\begin{array}{l}\text { Local } \\
\text { hospital }\end{array}$ \\
\hline
\end{tabular}

8 patients died in A/E. $63 \%$ were ranging 14-49 years old. 
Table 2.7. patients died in A/E in October 2014

\begin{tabular}{|c|c|c|c|c|}
\hline & Diseases & Gender & Age & $\begin{array}{l}\text { Sources of } \\
\text { referral }\end{array}$ \\
\hline & $\begin{array}{l}\text { Tension } \\
\text { pneumothorax } \\
\text { post stab wound }\end{array}$ & $\mathrm{M}$ & 39 & Ems \\
\hline & $\begin{array}{l}\text { Severe } \\
\text { dehydration } \\
\text { /gastroenteritis }\end{array}$ & F & 3 months & Local clinic \\
\hline & $\begin{array}{l}\text { Severe } \\
\text { pneumonia }\end{array}$ & F & 22 & Local clinic \\
\hline \multirow[t]{4}{*}{ October } & $\begin{array}{l}\text { Advanced cancer } \\
\text { of oral cavity }\end{array}$ & $\mathrm{M}$ & 69 & Local hospital \\
\hline & Hypoglycemia & $\mathrm{F}$ & 41 & Local clinic \\
\hline & $\begin{array}{l}\text { Sepsis/anemia } \\
\text { post infected } \\
\text { bedsores }\end{array}$ & F & 38 & Local clinic \\
\hline & $\begin{array}{l}\text { Pulmonary } \\
\text { edema/CCF }\end{array}$ & $\mathrm{M}$ & 81 & Local clinic \\
\hline
\end{tabular}

7 patients died during this period. The patient with Tension pneumothorax died due to a delay in management. 1 infant died due to a diarrheal disease and $57 \%$ of patients were middle age. $57 \%$ of dead were female.

Table 2.8. patients died in A/E in November 2014

\begin{tabular}{|l|l|l|l|l|}
\hline & Diseases & Gender & Age & $\begin{array}{l}\text { Sources of } \\
\text { referral }\end{array}$ \\
\hline & PTB & M & 30 & Local clinic \\
\hline November & $\begin{array}{l}\text { Lower GI } \\
\text { bleeding }\end{array}$ & M & 54 & Local clinic \\
\hline & Sepsis & F & 29 & Local clinic \\
\hline & $\begin{array}{l}\text { Hypovolemic } \\
\text { shock }\end{array}$ & F & 66 & $\begin{array}{l}\text { Local } \\
\text { hospital }\end{array}$ \\
\hline $\begin{array}{l}\text { Severe head } \\
\text { injury post RTA }\end{array}$ & M & 8 & $\begin{array}{l}\text { Local } \\
\text { hospital }\end{array}$ \\
\hline & $\begin{array}{l}\text { Metastatic liver } \\
\text { cancer }\end{array}$ & M & 73 & EMS \\
\hline
\end{tabular}

6 deaths recorded. 2 third were female. $50 \%$ of dead were beyond 50 years old and under age died due after being involved into a Road traffic accident.

Table 2.9. patients died in A/E in December 2014

\begin{tabular}{|l|l|l|l|l|}
\hline & $\begin{array}{l}\text { Severe respiratory } \\
\text { syndrome? cause }\end{array}$ & $\mathrm{M}$ & 51 & Local clinic \\
\hline & Hypokalemia & $\mathrm{F}$ & 74 & Self \\
\hline & $\begin{array}{l}\text { Ruptured } \\
\text { esophageal } \\
\text { varicose }\end{array}$ & $\mathrm{M}$ & 23 & Local clinic \\
\hline & Hi post RTA & $\mathrm{F}$ & $8 \mathrm{months}$ & $\begin{array}{l}\text { Local } \\
\text { hospital }\end{array}$ \\
\hline & $\begin{array}{l}\text { Bilateral subdural } \\
\text { hematoma }\end{array}$ & $\mathrm{M}$ & 59 & $\begin{array}{l}\text { Local } \\
\text { hospital }\end{array}$ \\
\hline & Polythrauma post & $\mathrm{M}$ & 23 & Local \\
\hline
\end{tabular}


Texila International Journal of Medicine

Volume 4, Issue 2, Dec 2016

\begin{tabular}{|l|l|l|l|l|}
\hline & RTA & & & hospital \\
\hline & Severe pneumonia & $\mathrm{F}$ & 29 & Local clinic \\
\hline December & $\begin{array}{l}\text { Mouth lower lip } \\
\text { ulcer/abscess }\end{array}$ & $\mathrm{M}$ & 47 & EMS \\
\hline & Cancer blood & $\mathrm{M}$ & 29 & $\begin{array}{l}\text { Local } \\
\text { hospital }\end{array}$ \\
\hline & $\begin{array}{l}\text { Internal bleeding } \\
\text { post RTA }\end{array}$ & $\mathrm{M}$ & 69 & Local clinic \\
\hline
\end{tabular}

10 deaths, upon which 70\% were male and $30 \%$ female including a female infant involved in road traffic accident. $50 \%$ of death was middle age.

Table 2.10. Patients died in A/e in January 2015

\begin{tabular}{|l|l|l|l|l|}
\hline & Diseases & Gender & Age & $\begin{array}{l}\text { Sources of } \\
\text { referral }\end{array}$ \\
\hline & Meningitis & F & 57 & Local clinic \\
\hline & $\begin{array}{l}\text { Intestinal } \\
\text { obstruction }\end{array}$ & F & 59 & $\begin{array}{l}\text { Local } \\
\text { hospital }\end{array}$ \\
\hline January15 & $\begin{array}{l}\text { Severe } \\
\text { dehydration post } \\
\text { GE }\end{array}$ & M & 6 & $\begin{array}{l}\text { Local } \\
\text { hospital }\end{array}$ \\
\hline & Anemia & F & 4 & Local clinic \\
\hline & CCF & M & 71 & Local clinic \\
\hline & Stab wound & M & 25 & EMS \\
\hline & Anorectal sinus & F & 69 & EMS \\
\hline
\end{tabular}

7 patients died including 2 pediatrics patients which have some medical conditions. 57\%were female. And $57 \%$ were beyond 50 years old.

Table 2.11. Patients died in A/E in February 2015

\begin{tabular}{|l|l|l|l|l|}
\hline & Disease & Gender & Age & $\begin{array}{l}\text { Sources of } \\
\text { referral }\end{array}$ \\
\hline & $\begin{array}{l}\text { Head injury } \\
\text { post RTA }\end{array}$ & $\mathrm{M}$ & 46 & EMS \\
\hline $\begin{array}{l}\text { Head injury } \\
\text { post assault }\end{array}$ & $\mathrm{M}$ & 19 & $\begin{array}{l}\text { Local } \\
\text { hospital }\end{array}$ \\
\hline $\begin{array}{l}\text { DKA with } \\
\text { severe } \\
\text { metabolic } \\
\text { acidosis }\end{array}$ & $\mathrm{M}$ & 50 & EMS \\
\hline February & $\begin{array}{l}\text { Sepsis } \\
\text { Acute kidney } \\
\text { injury with } \\
\text { metabolic } \\
\text { acidosis }\end{array}$ & $\mathrm{M}$ & 43 & $\begin{array}{l}\text { Local } \\
\text { hospital }\end{array}$ \\
\hline & PTB & $\mathrm{M}$ & $\begin{array}{l}\text { Local } \\
\text { hospital }\end{array}$ \\
\hline & PCP & $\mathrm{M}$ & 46 & EMS \\
\hline
\end{tabular}

7 deaths. All were male and $85 \%$ of them ranged between 14 and 49 years old. 
Table 2.12. Patients died in A/e in March 2015

\begin{tabular}{|c|c|c|c|c|}
\hline & Disease & Gender & Age & $\begin{array}{l}\text { Source of } \\
\text { referral }\end{array}$ \\
\hline & $\begin{array}{l}\text { End stage renal } \\
\text { failure/HTA/DM }\end{array}$ & $\mathrm{M}$ & 67 & $\begin{array}{l}\text { Local } \\
\text { clinic }\end{array}$ \\
\hline & $\begin{array}{l}\text { Sepsis with hepatic } \\
\text { failure }\end{array}$ & $\mathrm{F}$ & 36 & EMS \\
\hline & $\begin{array}{l}\text { Acute pulmonary } \\
\text { edema }\end{array}$ & $\mathrm{F}$ & 32 & $\begin{array}{l}\text { Local } \\
\text { clinic }\end{array}$ \\
\hline & PCP & $\mathrm{M}$ & 2months & $\begin{array}{l}\text { Local } \\
\text { hospital }\end{array}$ \\
\hline \multirow[t]{8}{*}{ March } & Hypokalemia/anemia & $F$ & 54 & $\begin{array}{l}\text { Local } \\
\text { clinic }\end{array}$ \\
\hline & Bronchiectasis & $F$ & 52 & $\begin{array}{l}\text { Local } \\
\text { hospital }\end{array}$ \\
\hline & $\begin{array}{l}\text { Urosepsis with } \\
\text { hydronephrosis/bph }\end{array}$ & $\mathrm{M}$ & 85 & EMS \\
\hline & Cancer prostate/copd & $\mathrm{M}$ & 67 & EMS \\
\hline & $\begin{array}{l}\text { Advanced } \\
\text { canceresophagus }\end{array}$ & $F$ & 66 & $\begin{array}{l}\text { Local } \\
\text { clinic }\end{array}$ \\
\hline & $\begin{array}{l}\text { Polythrauma post } \\
\text { RTA }\end{array}$ & $F$ & 38 & $\begin{array}{l}\text { Local } \\
\text { hospital }\end{array}$ \\
\hline & $\begin{array}{l}\text { Intracranial } \\
\text { hemorrhage }\end{array}$ & $F$ & 67 & $\begin{array}{l}\text { Local } \\
\text { hospital }\end{array}$ \\
\hline & $\begin{array}{l}\text { Brain mass with ?PE } \\
\text { post DVT/ severe } \\
\text { dehydration }\end{array}$ & $\mathrm{M}$ & 64 & $\begin{array}{l}\text { Local } \\
\text { hospital }\end{array}$ \\
\hline
\end{tabular}

12 patients were recorded death in March 2015 including 1 infant who had severe pneumocystis carinii pneumonia. $67 \%$ had more than 50years old and $58 \%$ were female.

In summary, the previous 12 tables recorded the patients died in Accident and emergency par month. They give us an idea about their ages, genders and the sources of referral. The types of diagnosis are clearly stated. Patients died either from acute or chronic conditions. The next few tables and graphs will expose these deaths with some specificities.

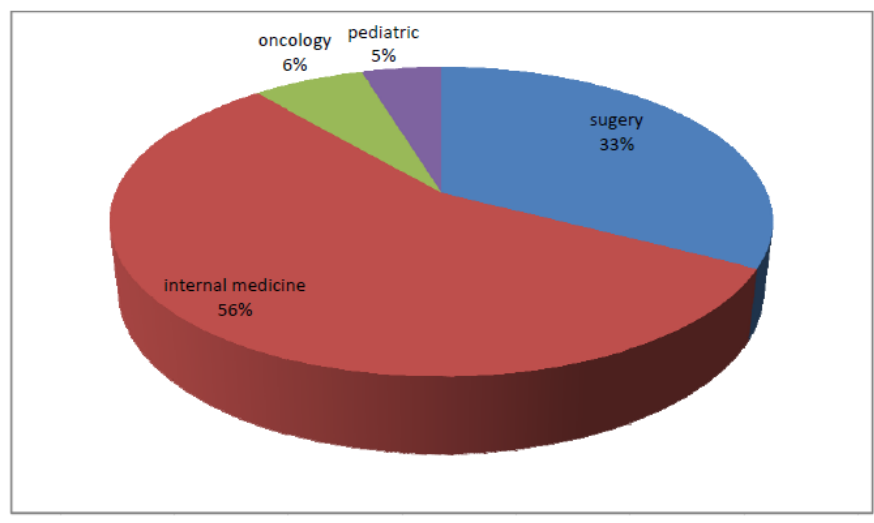

Graph 1. Summary of patients died in A/E by specialty

The above graph shows the patients died based of the specialty of interest. Most patients have an internal medical condition at $56 \%$, 33\% patients had some surgical conditions including traumas. $6 \%$ of patients died from cancer and $5 \%$ was pediatric patients. 
Texila International Journal of Medicine

Volume 4, Issue 2, Dec 2016

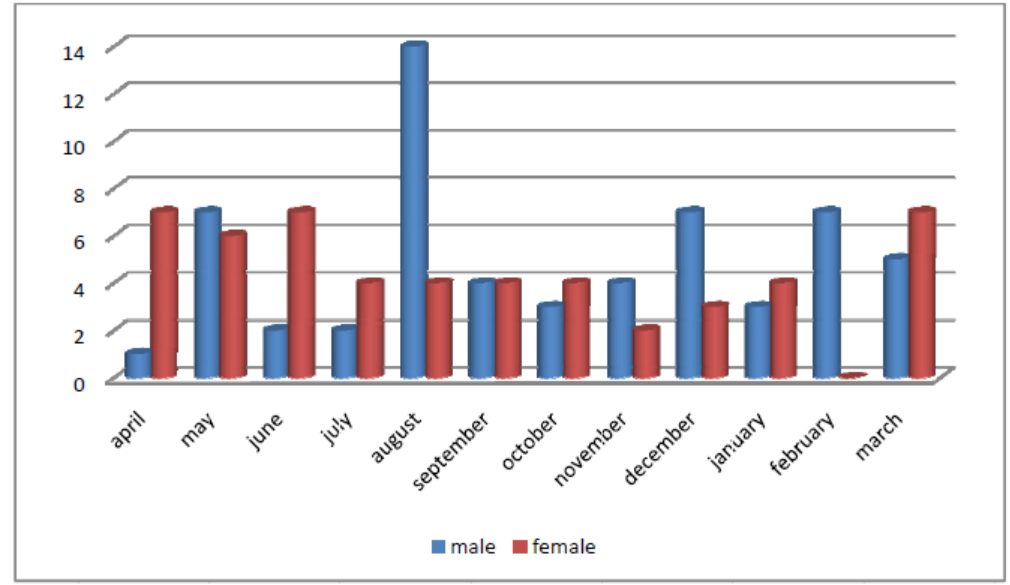

Graph 2. Patients died in A/E by sex

The histogram shows how patients died in a/e were selected per gender. It doesn't show match different in the management of the patients. Overall out of the 111 patients died in A/E, 59 (53\%) were male and 52 (47\%) were female.

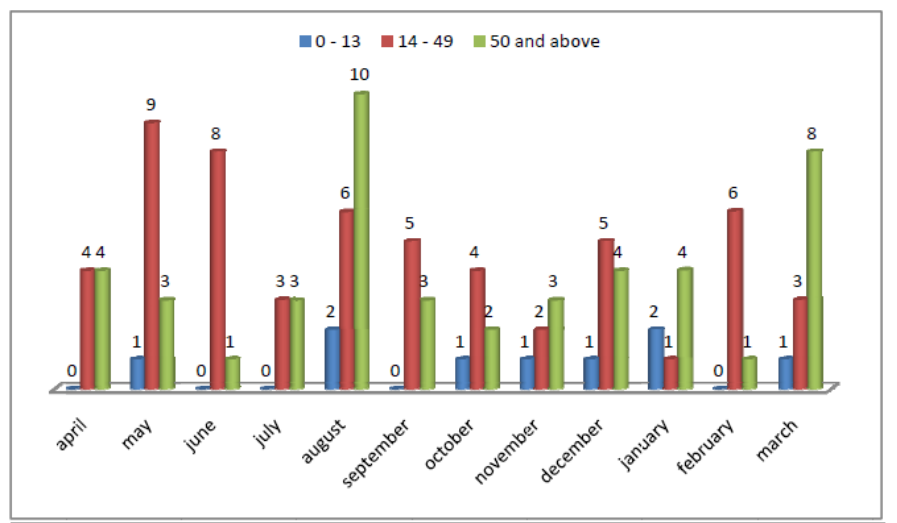

Graph 3. Patients died in A/E by age

Generally, very few pediatric patients died in a/e. young adult and mostly elderly with some chronic disease have shown to be the most patient died in a/e. 9(8\%) children died, 56(51\%) deaths ranged on $13-49$ years and 46(41\%) deaths from 50 years and above.

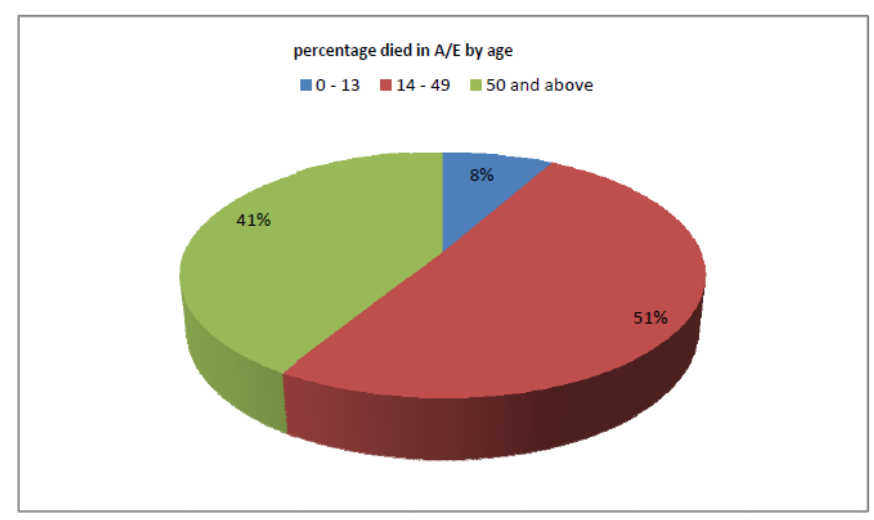

Graph 4. Overall patients died in A/E by age

$51 \%$ of patients died as young adult (14 to 49 ). $41 \%$ were above 50 and pediatric representing $8 \%$. 


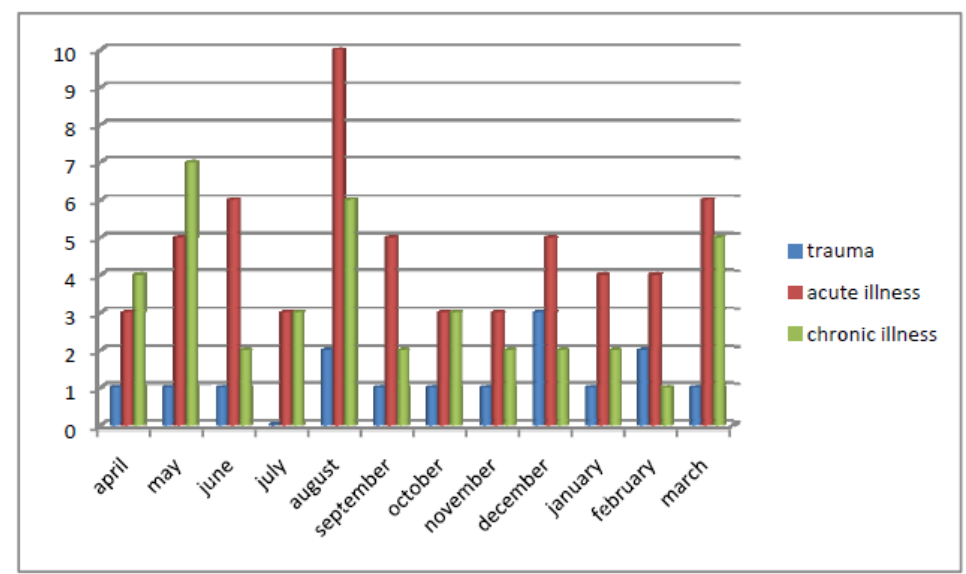

Graph 5. Trauma vs. non traumatic cause of death

The histogram above compares the condition which causes death to some patients each month. In overall, most patients died from acute illness followed by chronic patients. Trauma is not a highest cause of mortality our settings.

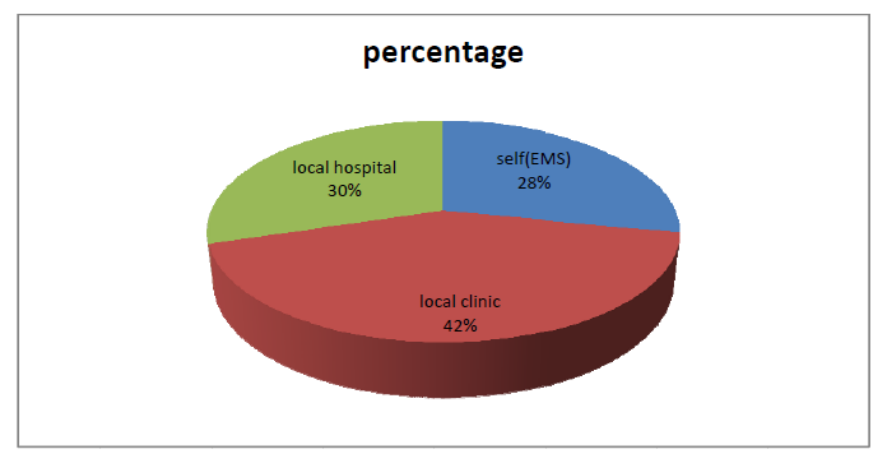

Graph 6. Patients died in A/E per sources of referral

The pi-graph shows the source of referral. $42 \%$ came from local clinic in the same area with the hospital. $30 \%$ from local hospitals while $28 \%$ self-referred.

\section{Case discussion}

We will not close this article without presentation at least on patient died during his stay in our department. Many cases had been reported and discussed during the past meetings due to their interest. Our attention had been retained by a trauma patient presented to the department from local hospital. We are going to report and discuss the issues raised in the management of this patient.

This is a patient M.O., male, 32 year old referred from district hospital with a diagnosis of Polytrauma post road traffic accident( fracture distal Left humerus, Pelvic Left ischio ilio pubic bone, old fracture both tibia/fibula proximal and distal)

The patient arrived in the department of accident and emergency accompanied by a nurse at $01.05 \mathrm{AM}$. The patient was registered at $05.21 \mathrm{AM}$ and attended to by an $\mathrm{A} / \mathrm{E}$ triage nurse 2 minutes later.

At this time, the complaints remain the same with the vital signs as followed: T36.4, RR15, P124, and BP129/93

The patient was codified "orange" as per the triage system used in our setting.

The emergency doctor attended to the patients about 30 minutes later, raising the same complaints like RTA victim who was hit by amoving vehicle and sustained multiple injuries.

The patient was smelling alcohol with blood stained on the clothes. Despite of the pain, the patient was communicating well with a spontaneous breathing. A diagnosis of Polytrauma was made. Some investigations were done and the relevant specialties were informed about the patients. 
Texila International Journal of Medicine

Volume 4, Issue 2, Dec 2016

The general surgeon attended the patient at 9am and planned to review after an abdominal scan is done. The orthopedic medical officer attended the patient at 9.20am and made a diagnosis of multiple fractures. He informed the orthopedic surgeon and prepared the patient for operation.

At 1120, the anesthetist was called. He reported being busy with another patient. He requested that the patient can be prepared for operation.

At 11.30, a new emergency from the surgical ward had been taken to theatre. It was a weekend and there was shortage of staff in theatre.

The patient remains in accident and emergency until when theatre will be free.

At 12.00, the vital sign shows that the patient is in hypovolemic shock.

The patient was called for theatre at 16.05, time when the patient deteriorated.

At 16.07 the 2 surgeons were informed to go to theatre and at 16.15 the patient had a cardiac arrest.

The patient was resuscitated unsuccessfully and was certified death at 17.20.

This case retained our attention due to some multiple issues in management which had been raised.

The patient was a young adult with all his future in front.

Time management and communication were very poor during the follow up of this patient. Despite of the fact that the patient was in shock from arrival, there was a delay in taking the patient to theatre. Also another case from the ward took over a patient with an internal bleeding in accident and emergency. The handling of a hand-over patient: this patient remains in accident and emergency during 3 different shifts. Mostly hand-over patient has a high rate of mortality in accident and emergency worldwide. The shortage of staff and the availability of facilities like theatre room during the weekend should also be considered as risk factors to lose some patients.

\section{Discussion and challenges}

\section{Discussion of result}

During this budgetary year, the accident and emergency department received about 27000 patients. Out of this number, less than 0.5 patients died in the department. This result is equally comparable to the one reported in the 2013 compilation of morbidity and mortality.

Table 2 shows us different diseases which led to death in emergency room. Patients can come in walking or in a stretcher in accident and emergency. Each accident of emergency expects to receive acutely ill patient. But our recorded shows quite significant number of chronically-ill patients. This can be explained by the fact that our setting is the main entrance of the hospital and some chronic patients can have some acute exacerbation of their conditions while other are on end-stage of their disease( e.g. patients with cancers on palliative care).

Table 3 completes the previous one showing the specialty which has the highest number of death. Internal medicine represents almost half of the patient died in the casualty department due partly to the high prevalence of chronically ill condition like HIV/AIDS and cancer as well as some metabolic disorder and cardiovascular disorder.

Looking to the graph 5, generally trauma patients are well managed in our setting. This explains why patients died due to trauma are less in number compare to non- traumatic cause of death (acute and chronic illness together). But an audit in trauma patient is still important. I am refereeing to the case presented previously as an example of a poorly manage patient. But this circumstance was explained by a poor availability of resources.

It was also found that more than half of patients died during that year were between 14 and 49 years old. Considering that chronic diseases have the highest number of death, some questions need to be answered through other researches to try and establish the link between the age and death.

Based on the source of referral, patients were coming from different source. The source of referral should not indicate the severity of the condition. We need to emphasize the 
management of self-referral patients. 28\% patients were self-referred and died in Accident and emergency. this has the same strength of importance with the patient referred from local hospitals (district and primary hospitals). It also means that walk-in patients should receive the same attention as referred patients until proven otherwise.

\section{Challenges}

The management of patients in accident and emergency need skills and teamwork. The challenges will be summarized on

- lack of team work mostly

- Lack of experienced medical and nurse staff

- Shortage of staff

\section{Teamwork:}

To save life especially in a trauma patients need a multidisciplinary approach. Based on the case presented previously, it shows clearly there was miscommunication between teams and specialties.

\section{Experience and inexperienced officers in accident and emergency}

The report shows a pick of death in august. During this period there is movement of medical and nursing staff within the hospital.

\section{Shortage of staff}

In the previous case, the patient was found in cardiac arrest due to the low number of staff in the department.

\section{Conclusion and recommendations}

Accident and emergency at princess marina hospital has remained a center of excellence; and a departmental headlight for the entire hospital as well as the country.

During this report, the accident and emergency shows its capability to contain a high number of patients at a very low rate of death. This is very appreciable for the department. Still some challenges are raised and need to be addressed in goal to reduce the death rate to 0 .

An effort has to be made to help chronically ill patient on the management of their condition. This will improve adherence to treatment and the quality of life for most of them.

Some delays in the management of patients by the admitting team (other specialties) led to dramatic death of some of our patients. This exposed clearly a poor collaboration from other specialty.

Based on the above mentioned findings, we recommend

- Staff training should be provided regularly to improve the quality of care of patient;

- Staff shortage should be resolved as soon as possible;

- Trauma team or multidisciplinary team should be established urgently to allow their continuous presence on the side of the Polytrauma patient;

- Staff should not be transferred in bulk as this reduces the quality of care in the department.

\section{References}

[1] Brennan TA, Leape LL, Laird NM, et al. (1991) Incidence of adverse events and negligence in hospitalized patients: Results of the Harvard Medical Practice Study I. New Engl J Med 324:370-376

[2] "Canadian Institute for Health Information, HSMR: A New Approach for Measuring

[3] Deis JN, Smith KM, Warren MD, Throop PG, Hickson GB, and Joers BJ, et al. (2010) 'Transforming the morbidity and mortality conference into an instrument for system wide improvement'. http://www.ahrq.gov/downloads/pub/ advances2/vol2/Advances-Deis_82.pdf. Accessed May 9, 2010

[4] D.L. Clarcke (2013) "using a structured morbidity and mortality meeting to understand the contribution of human error to adverse surgical events in a south African regional hospital”; 
Texila International Journal of Medicine

Volume 4, Issue 2, Dec 2016

[5] Friedman JN, Pinard MS, Laxer RM. (2005) "The morbidity and mortality conference in university-affiliated pediatric departments in Canada”. J Pediatr; 146:1-2.

[6] Hospital Mortality Trends in Canada (Ottawa: CIHI, 2007)”.

[7] Jed D. Gonzalo, Julius J. Yang, Grace C. Huang (2012) 'Systems-Based Content in Medical Morbidity and Mortality Conferences: A Decade of Change'.

[8] Juliet Higginson and al. (2012) "Mortality and morbidity meetings: an untapped resource for improving the governance of patient safety?” www.patientsafetyfirst.nhs.uk

[9] Kravet SJ, Howell E, Wright SM. (2006)‘Morbidity and mortality conference, grand rounds, and the ACGME’s core competencies’. J Gen Intern Med.; 21(11):1192-1194.

[10] 'Making the Medical Morbidity, Mortality, and Improvement Conference Even Better', J Oncol Pract May 1, 2015:e434-e436

[11] Morbidity and Mortality Revisited: Applying a New Quality Improvement Paradigm in Oncology Daniel G. Stover, and Jessica A. Zerillo, 2015

[12] Orlander JD, Fincke BG. (2003) Morbidity and mortality conference: a survey of academic internal medicine departments. J Gen Intern Med; 18:656-8.

[13] Orlander JD, Barber TW, Fincke BG. (2002) 'the morbidity and mortality conference: the delicate nature of learning from error’. Acad Med.; 77(10):1001-1006.

[14] Pierluissi E, Fischer MA, Campbell AR, et al. (2003) Discussion of medical errors in morbidity and mortality conferences. JAMA; 290:2838-42.

[15] Steven J Kravet and Al. (2006) "morbidity and mortality conference, grand rounds, and the ACGME’s core competencies”, J. Gen Med;

[16] Schwarz D, Schwarz R, Gauchan B, et al. (2011) Implementing a systems-oriented morbidity and mortality conference in remote rural Nepal for quality improvement. BMJ Qual Saf; 20:1082-8.

[17] Szostek JH, Wieland ML, Loertscher LL, Nelson DR, Wittich CM, McDonald FS, et al.(2010) ‘ A systems approach to morbidity and mortality conference’. Am J Med. ;123(7):663-668

[18] Wachter RM, Shojania KG, Saint S, et al. (2002) Learning from our mistakes: quality grand rounds, a new case-based series on medical errors and patient safety. Ann Intern Med; 136:850-2.

[19] Wachter RM, Pronovost PJ (2009) Balancing “no blame” with accountability in patient safety. New Engl J Med 361:1401-1406.

[20] Wachter RM, Pronovost PJ (2009) Balancing “no blame” with accountability in patient safety. New Engl J Med 361:1401-1406. 


\title{
Knowledge, Attitude and Practice of Medical Incident Reporting Among Healthcare Professionals: A Study of Midigo Health Centre IV
}

\author{
Article by Omona Kizito \\ Ph.D in Healthcare Management, Texila American University, Uganda \\ E-mail: kizitoomona@gmail.com
}

\begin{abstract}
Introduction: Medical incident reporting is a key tool for improving patient safety in healthcare, hence improved quality of care. The better the knowledge, attitude and practice of this concept, the better the quality of care. The perceived knowledge, attitude and practice are still low in many Uganda healthcare facilities. Many of the healthcare providers have, therefore, limited their scope to maternal death audit and reporting or perinatal death reporting and to a greater extent Adverse Event Following Immunization (AEFI). This problem of perceived low knowledge, attitude and practice of incident reporting is coupled with the poor institutional culture to persistently and inadequate support healthcare professionals to report incidents. Medical incident reporting is, therefore, the single most powerful tool for developing and maintaining an awareness of risks in healthcare practice, hence a cornerstone to improved patient safety and improved quality of service delivery.

Objectives: The study objectives were as follow; to assess the level of knowledge about medical incident reporting among healthcare professionals, by April, 2016 and determine their attitude towards medical incident reporting. The researcher also set out to ascertain the practice and the extent to which medical incident reporting is practiced in Midigo Health Centre IV, as well as, establishing the factors affecting medical incident reporting in the said healthcare facility.

Methods: The study was a cross sectional study of knowledge, attitude and practice of medical incident reporting among Healthcare Professionals in Midigo health centre IV. It was both qualitative and quantitative; with a sample of 44healthcare professionals interviewed using structured questionnaires. The questionnaire was pre-tested. Analysis of result was done using computer packages called Statistical Package for Social Sciences (SPSS) and Microsoft excel. Ethical considerations in research were observed.

Results: The cadre of the respondents were; Medical officers $-4.5 \%$, Clinical officers $6.8 \%$, Nurses $-43.2 \%$, Midwives $-11.4 \%$, Theatre staffs - 9.1\%, Laboratory staffs $-6.8 \%$ and other staffs $-18.2 \%$. The response rate was $100 \%$. The level of knowledge about medical incident reporting among healthcare professionals in Midigo HC IV was at 84.1\%, by April 2016. Much as there was no statistical significance between cadre of staffs and extent of knowledge, $p$-value $>0.39$, the only cadres that had excellent knowledge on medical incident reporting were nurses (75\%) and clinical officers (25\%). The rest of the staffs either had average knowledge or fair knowledge or no knowledge at all. The healthcare professionals had strong positive attitude towards medical incident reporting and this was at $97.7 \%$. By April, 2016, the practice of medical incident reporting was at $72.6 \%$ with the majority of these respondents (up to 50\%), having participated in reporting three times or more for the last 5years. The major factors that facilitated the respondents to report were; Strong positive feeling to participate and improve patient safety and respondents were knowledgeable (educated) about medical incident reporting. Other minor factors like ability of respondents to get feedback on reported incidents and strong institutional culture of reporting did not make strong contribution towards the practice of reporting. However, the major barriers were; respondents didn't know where and how to report, coupled with weak institutional culture of reporting incidents. Surprisingly, fear of consequence of reporting did not in any
\end{abstract}


Texila International Journal of Medicine

Volume 4, Issue 2, Dec 2016

way hinder any respondent from reporting. In other words, it was not a reason for them not to participate in medical incident reporting.

Conclusion: Medical incident reporting still remains a key tool in improving patient safety. The greater the practice of reporting, the better; as evident by the strong positive feeling towards medical incident reporting, in this research finding. Educating professionals on incident reporting and strong positive individual feeling to improve safety have remained the major factors facilitating medical incident reporting. Likewise, lack of knowledge on where and how to report, coupled with weak institutional culture of reporting have remained the major barriers to practicing medical incident reporting.

\section{Introduction}

This section covers introduction to the study topic, background to the study area, statement of the problem, research question, conceptual framework, research objectives and justification for the study in that order

\section{Introduction to the study topic}

Medical incident reporting in healthcare is presumed to have helped a lot in the reduction of healthcare associated errors/risks. According to British journal of anesthesia, Critical incident reporting, key in improving safety, is under-utilized in healthcare systems (Mahajan, 2010). Anderson Janet E., Naonori Kodate, Rhiannon Walters And Anneliese Dodds (2013) argued that incident reporting is well accepted in safety critical industries such as aviation, as a method for improving safety, and that it is now well established in healthcare in many countries, including the United Kingdom. Medical incident reporting seems to have proven effective in improving patient safety in healthcare. It is presumed that the already over-burden healthcare professionals, in healthcare setting, may not pay keen attention in each and everything in the healthcare setting. One such area that appears to be under looked by many healthcare professionals is medical incident reporting, itself. This argument has been supported by the work of earlier researchers on patient safety and medical errors among Italian hospital Physicians (Domenico, F., Paolo, R., Aida, B., Claudia, P. And Maria, P., 2012).

Studies have shown that Poor staffing levels hinder effective communication amongst health workers, leading to provider fatigue and creating an environment for medical incidents. Similarly, poor organizational safety culture, with resultant under-reporting of medical incidents and predominantly punitive responses to errors by health workers seem to have lowered health workers" attitudes to report (Nabudere, H., Asiimwe, D. and Semakula, D., 2014). The practice of medical incident reporting goes down as the attitude lowers and the end result is that quality of care is compromised.

In their study on the perceived effectiveness of incident reporting in improving safety, among healthcare professionals, Anderson et al (2013) found that indeed incident reporting was perceived to have a positive effect on safety. They further stressed that this positive effect did not only lead to changes in care processes but also change the staff attitudes and knowledge. In fact, they concluded that incident reporting can be a powerful tool for developing and maintaining an awareness of risks in healthcare practice, hence patient safety improvement.

Other studies have shown that healthcare professionals appear reluctant to report adverse incidents to a senior member of staff. Doctors were more unwilling than nurses or midwives to report adverse incidents to a senior staff member. Incident reporting was most likely when the incident involved the deviation from a protocol and when the outcome for the patient was bad (Lawton, R. and Parker, D., 2002). The argument is that reporting must be a routine selfdriven practice among healthcare professionals. Omona (2015, pp.34-35), in his study to determine the level of health workers" engagement in patient safety in Kitgum general hospital, found that the majority of the health workers (77.3\%) never reported the medical incidents they encountered. The major reason (50.8\%) for not reporting was because they did 
not know where to report, owing to poor reporting culture in the health facility. In Uganda, however, the commonly reported medical incidents are limited to maternal death, perinatal death and Adverse Reaction Following Immunization (ARFI) or in emergency out breaks.

\section{Background to the study area}

Midigo health centre IV is a government health facility, located in Yumbe district (West Nile), specifically located in Midigo Sub County. It is the only health centre IV in the district and has a total bed capacity of 73beds ( $\mathrm{MoH}, 2015)$. Midigo Sub County has a total population of 37,100people which is $7.64 \%$ of the total population of Yumbe district of 485,582 persons (UBOS, 2015).

The health centre has been partly supported for a long period of time (about 15years) by a Church based development partner, Calvary Chapel of Midigo. Calvary Chapel contributes about 35\% of the healthcare professional staffs to the health facility, alongside with other supports including monthly procurement of medicines and other medical supplies.

\section{Statement of the problem}

Medical incident reporting appears to be a very important practice in improving patient safety in healthcare. In Uganda, many healthcare professionals appear to be relaxed except in areas of maternal death and perinatal death reporting, adverse event following immunization and a few others, where some reporting is practiced.

The main problems are presumed to be the knowledge gaps, negative attitude towards reporting and low level of practice of actual reporting of medical incidents among healthcare professionals. These problems are presumed to cut across the various health facilities countrywide. Midigo health centre IV is just one of the few health facilities, among others. The cause of these problems are probably; lack of adequate professional medical development (PMD)/Continuous medical education (CME) on the subject matter, fear of punitive consequences of reporting, lack of motivation to do so (poor reporting culture) and perceived lack of time due to understaffing, among others. The solutions to these problems are lying in addressing the mentioned causes.

The effects of these problems are increased healthcare risk for patients and compromised quality of healthcare services. These problems are thought of by the researcher to deserve special attention and have, therefore, prompted the researcher to find out the magnitude of such in the Midigo health centre IV.

\section{Research questions}

This study sought to answer the following research questions;

I. What is the level of knowledge about medical incident reporting among healthcare professionals in Midigo Health Centre IV?

II. What is the attitude of healthcare professionals in Midigo Health Centre IV towards medical incident reporting?

III. To what extend is medical incident reporting practiced in Midigo Health Centre IV?

IV. What are the factors affecting medical incident reporting in Midigo Health Centre IV?

\section{Conceptual framework}

The dependent variable or variable of primary interest, as shown in the model, is medical incident reporting while the independent variables are healthcare professional knowledge, attitude and practice of medical incident reporting. The co-founders affect the out outcome of incident reporting. 


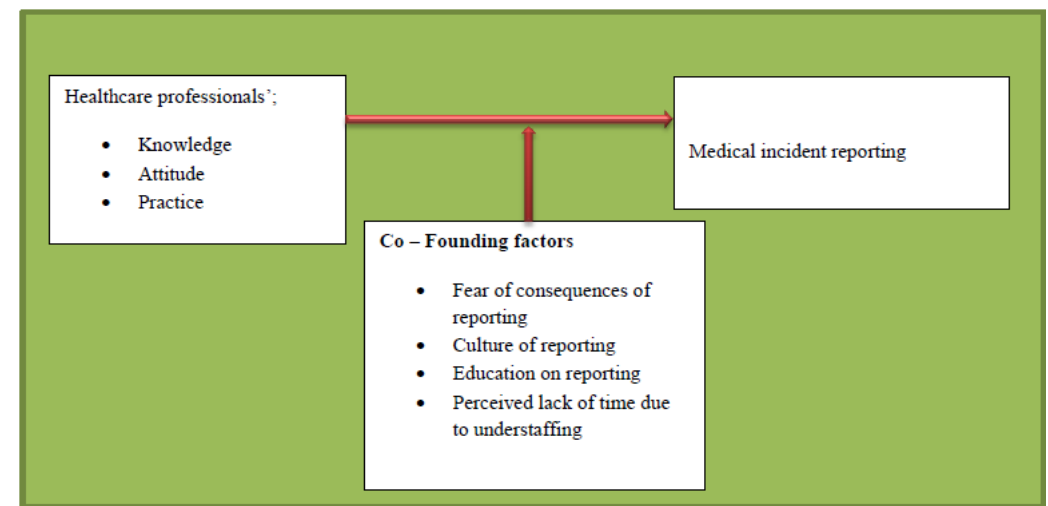

Figure 1: Conceptual model

\section{Objectives of the study}

The study had both broad objective and specific objectives, under sub-sections below;

\section{Broad objectives}

The broad objective is to contribute to improved patient safety in healthcare through creating awareness on the need for medical incident reporting among healthcare professionals in Midigo Health Centre IV

\section{Specific objectives}

There are four specific objectives for this study. These are as below stated;

I. To assess the level of knowledge about medical incident reporting among healthcare professionals in Midigo Health Centre IV, by April 2016

II. To determine the attitude of healthcare professionals in Midigo Health Centre IV towards medical incident reporting, by April 2016.

III. To ascertain the practice and the extent to which medical incident reporting is practiced in Midigo Health Centre IV, by April 2016.

IV. To establish the factors affecting medical incident reporting in Midigo Health Centre IV, by April 2016.

\section{Justification of the study}

However the study findings, if utilized, would help achieve the following;

I. The healthcare stakeholders will appreciate the relationship between patient safety and medical incident reporting. If found to be a positive relationship (that improves patient safety in healthcare), the finding will be used to make decisions to improve the weak areas of the healthcare settings. Some of the weak points could be; the Institution may have a less supportive environment for event reporting that does not protect the privacy of staffs reporting, reports received from a narrow range of personnel, summaries of reported events may not be disseminated in a timely fashion and less structured mechanism for reviewing reports and developing action plans (Agency for Healthcare Research and Quality, 2014)

II. The study will add to the existing body of knowledge as a future reference material and for any researcher who may wish to do similar study elsewhere.

\section{Literature review}

\section{Introduction}

This chapter has been laid down in the following order; Introduction, level of knowledge about medical incident reporting among healthcare professionals, attitude of healthcare professionals towards medical incident reporting, practice and the extent to which medical incident reporting is practiced in healthcare settings and factors affecting medical incident reporting in that order. Conclusion of this chapter was made last in the sub-section. Findings 
of many scholars related to this subject matter were sought and reviewed as per citations in this chapter.

\section{Knowledge about medical incident reporting among healthcare professionals}

World Health Organization (WHO) defined Incident reporting as a process used to document occurrences that are not consistent with routine hospital operation or patient care. Similarly, patient safety was defined as freedom from accidental injuries during the course of medical care; activities to avoid, prevent, or correct adverse outcomes which may result from the delivery of health care (WHO, 2009). Incident reporting is viewed at as a measure to improve patient safety in health care, by many scholars. In fact, WHO argued that for several reasons, the effectiveness of incident reporting is limited. These reasons, among others, include fear of punitive action, reluctance of non-physicians to report incidents involving physicians, lack of understanding of what a reportable incident is and lack of time to report medical incidents (WHO, 2009)

Marilyn, J. K., Sue, M. E., Brian, J. S. and Jesia, G. B. (2004), in their study on attitudes of doctors and nurses towards incident reporting found that knowledge gap was one of the factors that negatively affected incident reporting. They argued that this gap can be adequately addressed through healthcare professional education. Their view was supported in another study. After the study on the effect of incident reporting following patient safety education, it was concluded that patient safety education can have immediate and long-term positive effects on knowledge, skills and attitudes, and modestly influence the reporting behavior of resident healthcare professionals (Jansma, J. D., Cordula, W., Reinier, W. t. K. and Arnold, B. B., 2011).

In a study on healthcare professionals" views of the effectiveness of incident reporting, Anderson et al, (2013), found that incident reporting had a very strong positive effect on patient safety, not only by leading to changes in care processes but also by changing staff attitudes and knowledge. In another study on engagement in patient safety, Omona (2015) found that health workers in Kitgum general hospital were $4.5 \%$ more aware about patient safety than the patients. This awareness did not have strong engagement to improve safety in terms of what health workers do, such as incident reporting.

In a study on factors influencing incident reporting in surgical care, it was found that nurses were more knowledgeable than doctors when it comes to incident reporting (Kreckler, S., Catchpole, K., McCulloch, P. and Handa, A., 2009)

Some knowledge gaps still exist, definitely, in incident reporting systems in many countries. Anja, H., Brunsveld-Reinders, M., Sesmu, A., Rien, D. V. and Evert, D. J., (2015) in their study pointed out that many of the incident reporting systems could not meet WHO criteria. No attention was given to analyzing incidents reported or giving feedback on the reported incidents. This resulted in just a simple administrative report system, rather than the much desired instrument for change of practice and increase of quality of care. Incident reporting system can only effectively contribute to improve patient safety and quality of care if more attention is given to analyzing incidents and feedback.

Again, according to Patient Safety Network (PSNet), a successful incident reporting system should be easy to use and must contain the four components. These are;

- Institution must have a supportive environment for incident reporting that protects the privacy of staff who report occurrences

- Reports should be received from a broad range of personnel

- Summaries of reported events must be disseminated in a timely fashion

- Lastly, a structured mechanism must be in place for reviewing reports and developing action plans

Much as incident reporting utilization can be a cornerstone of a positive safety culture within the institution, such institutions need to resist the temptation to encourage incident reporting without a concrete plan for following up on the reported events (PSNet, 2014) 
Texila International Journal of Medicine

Volume 4, Issue 2, Dec 2016

Therefore, all in all, much as there may be few knowledge gaps in medical incident reporting, the greatest problem is different, as pointed out by other scholars. In a study on Culture of blame in the National Health Service in United Kingdom (UK), it was pointed that 'The single greatest impediment to error prevention is that we punish people for making mistakes' This is what makes incident reporting weak (Radhakrishna, 2016). This view was supported by Vincent (2011) who argued that the culture of blaming and disciplining in case of medical incidents are ineffective responses to most safety problems.

\section{Attitude of healthcare professionals towards medical incident reporting}

In a study on the views of junior doctors on reporting incidents, in United Kingdom (UK), it was noted that these category of healthcare professionals (junior doctors) participated less in incident reporting. This was not because they had negative attitude towards the practice, but it was predominantly due to lack of supporting environment to report (Hooper, P., Kocman, D., Carrl, S. and Tarrant, C., 2015).

This argument was supported by another study on attitudes of doctors and nurses towards incident reporting. It was found that Nurses reported more habitually than doctors as a result of culture which provided directives in the nursing arena as opposed to such environment for doctors (Marilyn et al., 2004).

In fact, according to Jansma et al. (2011), patient safety education can have immediate and long-term positive effects on knowledge, skills and attitudes, and modestly influence the reporting behavior of healthcare professionals.

In a similar study on barriers and motivating factors in reporting incidents of assault, it stated that personal attitudes may affect reporting, especially if individual reporting thinks that reporting is optional or he or she sees reporting as "taking on a battle." Other attitudes such as seeing personal effort to report as not worth, because of the minimal expectation of a positive outcome, was also noted. Again, the fear of being blamed stood out strongly as a perception that deter healthcare professionals from reporting medical incidents (Gifford and Anderson, 2010) Furthermore, they argued that individual attitudes such as; belief that reporting is optional, Self-blame and fear of embarrassment quite often negatively affect incident reporting.

The ultimate goal of incident reporting is to improve on patient safety, by way of reducing medical errors. It has, therefore, been argued that healthcare professionals who get involved in adverse incidents or those who seem to have caused adverse incident, often feel guilty, shameful and develop burnout. This is common among junior healthcare professionals and in a way could negatively affect their attitude towards medical incident reporting (Naonori and Anneliese, 2008). Vincent (2011) argued that the culture of blaming and disciplining healthcare professional on such account is an ineffective response to most safety problems. In another study by Polisena, J., Gagliardi, A., Urbach, D., Tammy, C. and Michelle, F., (2015), findings indicated that fear of punishment, uncertainty of what should be reported and how incident reports will be used and time constraints to incident reporting are common barriers to incident recognition and reporting. For surely, healthcare professionals who have fear of punishment associated with incident reporting, will be negatively affected when it comes to medical incident reporting.

In a study about attitudes and barriers to incident reporting, it was found that both doctors and nurses believe they should report most incidents, but nurses were found to do so more frequently than doctors. In their conclusion, to improve incident reporting, especially among doctors, clarification was needed of which incidents should be reported, the process needed to be simplified and feedback given to the reporters (Evans et al., 2006). In a study on patient safety and medical errors among Italian hospital physicians, Domenico et al., (2012) concluded that greater efforts were needed. These efforts were to facilitate the translation of positive attitudes towards patient safety into appropriate practices that have proven to be effective in the reduction of medical errors (increased patient safety). 


\section{Practice and the extent to which medical incident reporting is carried out in healthcare settings}

The practice of incident reporting needs to be as inclusive as possible, with most of the stakeholders getting involved. In a study on anesthesia related incidents, it was made that post-operatively, quality assurance officer would constitute a team to do the review of what went wrong. In that review meeting, staff members would be encouraged to provide comments and suggestions for improvement. This meeting was regularly done for every morbidity-mortality related cases and the incidents were discussed in detail with the staff members involved in the process describing the sequence of event and suggesting a number of corrective strategies to avoid similar incidents re-occurring (Haller, G., Courvoisier, D. S., Anderson, H. and Myles, P. S., 2011).

The extent of incident reporting depend the level of knowledge and positive attitudes towards patient safety concept, among healthcare professionals. Therefore, the more someone is educated on patient safety, the more the ability and willingness to report incidents. In fact, positive changes in knowledge, skills and attitudes would be paramount after such education course (Jansma et al., 2011)

\section{Factors affecting medical incident reporting}

Medical incident reporting practice is still lower than expected in many Ugandan healthcare facilities. A number of factors are negatively affecting this practice, which would otherwise improve quality of care.

In a similar study, it was found that fear of punishment, uncertainty of what should be reported and how incident reports will be used and time constraints to incident reporting were among the common barriers to incident recognition and reporting. It was concluded that strategies to improve error reporting were; the use of an electronic error reporting system, increased training of healthcare professionals and giving feedback to frontline healthcare professionals about the reported error (Polisena et al., 2015). However, Vincent (2011) argued that the culture of blaming and disciplining in case of medical incidents are ineffective responses to most safety problems. They are ineffective in the sense that they markedly affect improvement strategies but encourage defensive tactics by healthcare professionals.

These findings were not far different from those found by Gifford and Anderson (2010). For them, the major factors were; feeling that reporting was optional, fear of blame and embarrassment, among others. Similarly, Marilyn et al. (2004) found the common barriers to reporting incidents included; time constraints, unsatisfactory processes, deficiencies in knowledge, cultural norms, inadequate feedback, beliefs about risk and a perceived lack of value in the process.

\section{Conclusion}

According to (Julius, C. P., Thierry, G. and Peter, J. P., 2013), Incident Reporting System (IRS) is and will continue to be an important influence on improving patient safety. In their review on IRS, they pointed at four major advantages (uses) of incident reporting as follows;

- To identify local system hazards

- To aggregate experiences for uncommon conditions

- Used to share lessons within and across organizations (health institutions)

- Used to increase patient safety culture

When this concept is not well understood by healthcare professionals, the practice might markedly be affected negatively. Similarly, when it is well understood, the practice would be perfect hence improved patient safety and quality of healthcare. 
Texila International Journal of Medicine

Volume 4, Issue 2, Dec 2016

\section{Research methodology}

\section{Introduction}

This chapter illustrates the study area, study design, study population, study unit, sample size estimation, sampling techniques, the variables for the objectives and their indicators, data collection and study instruments, data analysis and presentation methods, quality controls, ethical considerations, limitations of the study and plans for dissemination of results.

\section{The study area}

The research was done in Midigo Health Centre IV, located in Midigo sub county, in Yumbe district (West Nile region), Uganda.

\section{Study duration}

The study took a period of three months (February - April), in the year 2016

\section{The study type/design}

This was a descriptive, cross sectional study of Knowledge, attitude and practice of medical incident reporting among healthcare professionals in Midigo Health Centre IV. The study took both qualitative and quantitative dimensions.

\section{Study Population}

The study population was all the healthcare professionals (both medical workers and the support staffs) in Midigo health centre IV.

\section{Study Units}

These were healthcare professionals present in the health facility at the time of the study/during the period of the study.

Inclusion Criteria: All the healthcare professionals present in the health facility at the time of the study were free to participate in the study. This included all those healthcare professionals who directly or indirectly got involved in medical incident reporting.

Exclusion Criteria: All healthcare professionals who were not physically present in the health facility (Such as those on study leave or sick leave) at the time of the study or those who were unwilling to participate in the study were excluded. Again, students who were for internship/industrial training were excluded.

\section{Sample size estimation}

Since the population size of healthcare professionals in Midigo health centre IV was known (49health workers), the formula for calculation of sample size was used to compute the sample size.

Therefore, using the formula;

$$
n=\mathrm{N} /\left[\mathbf{1}+\mathbf{N}(\mathrm{e})^{2}\right]
$$

Where $n$ is the sample size, $\mathrm{N}$ is the population size (Total population of the study), e is the level of precision (level of confidence) and 1 is a constant

Hence; $n=49 /[1+49(0.052)]$

$$
\begin{aligned}
& n=49 / 1.1225 \\
& =43.6526 \\
& \sim 44 \text { health workers }
\end{aligned}
$$

\section{Sampling techniques}

The techniques used were both probability and non-probability sampling. For healthcare professional cadres that were very few in the health facility and yet their knowledge, attitude and practice is key in medical incident reporting, purposive sampling technique was used. These categories of healthcare professionals were medical officers, clinical officers, midwives, theatre staffs and laboratory staffs. The likelihood of missing their views in this 
research was very high because of their low numbers and therefore the researcher purposely selected them to be included in the sample.

Simple random sampling technique was then used to select the remaining categories of staffs such as nurses and nursing assistants, among others. This was done until the entire 44respondents healthcare professionals were obtained.

\section{Variables and Indicators for the objectives}

The variables and indicators for all the four specific objectives have been described in the sub-sections below. The healthcare professionals" knowledge, attitudes and practices were taken as the independent variables while medical incident reporting was the dependent variable. Medical incident reporting was taken to be dependent on whether or not the healthcare workers were knowledgeable about it, have positive attitudes towards it or practice it in their day to day service delivery.

Variables and indicators for objective I: To assess the level of knowledge about medical incident reporting among healthcare professionals in Midigo Health Centre IV.

The variable used for this objective was healthcare professional knowledge of medical incident reporting. The indicator was the „YES" or „No " responses given by the respondent, on whether or not they knew about the subject matter. This was used as a proxy measure of the respondents" knowledge on the subject matter.

Variables and Indicators for objective II: To determine the attitude of healthcare professionals in Midigo Health Centre IV towards medical incident reporting

The independent variables for this objective are healthcare professionals " attitudes (categorized as negative or positive). The indicators were as follows; the respondents who accepted that medical incident reporting should be removed from healthcare practice were taken as those with negative attitude towards the practice. Similarly, those who want the practice to continue, even at higher level, were taken as respondents with positive attitudes towards the practice.

Variables and Indicators for objective III: To ascertain the practice and the extent to which medical incident reporting is practiced in Midigo Health Centre IV

The independent variables for this objective were „the practice of incident reporting " and the „extend of this practice." This was measured against the number of respondents who had ever practiced any incident reporting within a period of one year. Similarly, the extent of the practice was measured against the frequency of such practice.

Variables and Indicators for objective IV: To establish the factors affecting medical incident reporting in Midigo Health Centre IV

For the respondents who practiced medical incident reporting in Midigo HC IV, the variables were the stated factors which made them to do so. Similarly, for those who did practice reporting, the stated factors that prevented them from doing so were considered as variables.

\section{Data collection tools and techniques}

The data collection tool used in this study was purely questionnaires. Whereas, the data collection techniques were used in was self-administering of semi-structured questionnaires to the respondents. Reasonable amount of time to fill the questionnaire was agreed upon between the research assistant and the respondent.

\section{Data entry, analysis and presentation methods}

Data entry and analysis was made using two computer softwares; Statistical Package for Social Sciences (SPSS) and Microsoft excel. The researcher did the data entry and analysis by himself, in consultation with an experienced data analyst.

Pie charts, tables, bar graphs and descriptive methods for the qualitative components were used as data presentation methods for this research. Simple frequency tables and cross tabulations were drawn to present results. 
Texila International Journal of Medicine

Volume 4, Issue 2, Dec 2016

\section{Quality controls}

For quality assurance purpose, the following quality control measures were employed;

I. Pre-testing of the questionnaires was done before actual data collection was made. Changes to the questionnaires were made as appropriate, after the pre-testing exercise.

II. Other ways used to improve quality of data included; training of the research assistant, close field supervision by the researcher and a careful data validation at the point entry and analysis. The researcher took particular interest in doing this validation and personally did the analysis.

\section{Ethical considerations}

The following ethical considerations were taken care of;

I. Permission was sought from office of the District Health Officer (DHO), of Yumbe district local government, as well as the In-Charge of Midigo HC IV.

II. Informed consents from the respondents were sought before engaging them. Confidentiality of data collected was maintained.

III. Participation of the respondents was purely voluntary. Respondents were free to pull out of the study, for whatever reason(s) and their decisions to do so were highly respected.

\section{Limitations to the study}

The study had the following limitations;

I. The researcher, at the time of the study, was a high profile healthcare professional in the same health facility (Midigo HC IV). Therefore, his direct involvement could induce respondents" bias in filling the questionnaires. To solve this concern, an independent research assistant was used to collect data.

II. Not all the healthcare professionals who participated in the study were directly/equally exposed to medical incident reporting. Therefore, their level of knowledge in the subject matter varied markedly from the others who were exposed. To address this concern, key terms used were defined in the introduction to the questionnaire, to help them understand the subject matter before filling their questionnaires. Examples were also given about certain key terms.

\section{Plan for dissemination of results}

The result of this study was disseminated to all the staffs of Midigo HC IV. Part of it was shared with the office of District Health Officer (DHO), the District Health Team (DHT) and office of the Chief Administrative Officer (CAO) of Yumbe district local government. This work is also planned for dissemination across Uganda and the world at large, by way of publishing it.

\section{Results, analysis and presentation}

\section{Introduction}

The results of the analysis of this study have been discussed as under. Tables, pie charts and bar graphs were used. Percentages and frequencies were also used to present results. The respondents were healthcare professionals working in Midigo health centre IV, in Yumbe district, in the year 2016.

Socio-demographic characteristics of the respondents: There were 44respondent healthcare professionals, with response rate of $100 \%$. The male respondents were 26 in number, constituting $59.1 \%$ of the total respondent whereas the female respondents were 18 in number (40.9\%). The majority of the respondents, 52.3\%, were of older age group (More than 35years old). $45.5 \%$ of the respondents were in the middle age group (25-35years old) while $2.3 \%$ were in the younger age group, less than 25years old.

The cadre of the respondents were as follows; Medical officers $-4.5 \%$, Clinical officers $6.8 \%$, Nurses $-43.2 \%$, Midwives $-11.4 \%$, Theatre staffs $-9.1 \%$, Laboratory staffs $-6.8 \%$ 
and other staffs $-18.2 \%$. Therefore, nurses were the majority followed by the other category of staffs (Cleaners, Security officers, Public health specialist, recorder staffs, store assistants and others).

\section{Level of knowledge about medical incident reporting among respondents healthcare professionals}

The knowledge of the respondents was first assessed on medical incident reporting. Later, the extent of this knowledge was assessed for each respondent who knew about it.

To assess the level of knowledge of the about medical incident reporting in the healthcare facility, the respondents were asked whether or not they knew medical incident reporting before the study. „Yes" or "No" responses were given. The result has been shown in the table below.

Table1: Whether respondent knew about medical incident reporting or not

\begin{tabular}{|c|l|l|l|l|l|}
\hline \multicolumn{6}{|c|}{ Respondent knew about Medical Incident Reporting } \\
\hline Valid & Yes & Frequency & Percent & Valid Percent & Cumulative Percent \\
\hline & No & 7 & $84.1 \%$ & $84.1 \%$ & 84.1 \\
\hline & Total & 44 & $15.9 \%$ & $15.9 \%$ & 100.0 \\
\hline
\end{tabular}

From table 1 above, the majority of the respondents, $84.1 \%$ knew about medical incident reporting before the study. Only 7respondents, constituting $15.9 \%$ did not know about the subject matter.

Based on this, the researcher concluded the level of knowledge about medical incident reporting among healthcare professionals in Midigo HC IV to be 84.1\%, by April 2016.

Extent of the knowledge among respondents who knew about medical incident reporting: The respondents who knew about medical incident reporting were then categorized into three; category one were those who had excellent knowledge, category two were those who had average knowledge while category three were those who had fair knowledge. The results of the findings were as presented in figure below.

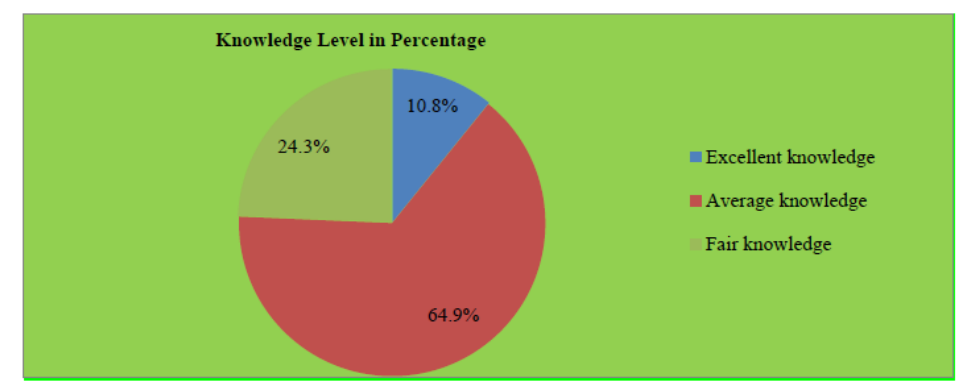

Figure 2: Level of knowledge among respondents who knew about medical incident reporting

Figure 2 above shows that out of the $84.1 \%$ respondents who knew about medical incident reporting; only $10.8 \%$ had excellent knowledge. The majority $(64.9 \%)$ had average knowledge.

A cross tabulation between extent of knowledge and cadre of staff was done. The summary results are shown in table 2 below. 
Texila International Journal of Medicine

Volume 4, Issue 2, Dec 2016

Table 2: Cross tabulation of extent of knowledge versus cadre of the respondents who knew about medical incident reporting

Cross tabulation of Extent of Knowledge versus Cadre of Respondent

Cadre of Respondent

Total

Medical Clinical Nurses Mid Theatre Laboratory Others

\begin{tabular}{|c|c|c|c|c|c|c|c|c|c|}
\hline \multirow{5}{*}{$\begin{array}{l}\text { Extent of } \\
\text { Knowledge }\end{array}$} & \multirow{3}{*}{$\begin{array}{l}\text { Excellent } \\
\text { Knowledge }\end{array}$} & \multirow{2}{*}{$\begin{array}{l}\text { officers } \\
0 \%\end{array}$} & \multicolumn{2}{|l|}{ officers } & \multirow{3}{*}{$\begin{array}{l}\text { wives } \\
0 \%\end{array}$} & \multirow{3}{*}{$\begin{array}{l}\text { staffs } \\
0 \%\end{array}$} & \multicolumn{2}{|l|}{ staffs } & \multirow{3}{*}{$100 \%$} \\
\hline & & & $25 \%$ & $75 \%$ & & & $0 \%$ & $0 \%$ & \\
\hline & & & & & & & & & \\
\hline & $\begin{array}{l}\text { Average } \\
\text { Knowledge }\end{array}$ & $8 \%$ & $8 \%$ & $38 \%$ & $21 \%$ & $13 \%$ & $4 \%$ & $8 \%$ & $100 \%$ \\
\hline & Fair Knowledge & $0 \%$ & $0 \%$ & $67 \%$ & $0 \%$ & $0 \%$ & $22 \%$ & $11 \%$ & $100 \%$ \\
\hline
\end{tabular}


From table 2 above, nurses were the single most important cadre of healthcare professionals with excellent knowledge (75\%) followed by clinical officers (25\%). However, this finding was not statistically significant, $X 2(12, N=44)=12.7, p=.39$, it was by chance that these cadres had higher knowledge level. Other factors could have played, including exposure to incident reporting following their previous work environments. Probably, a security officer may not have adequate knowledge about medical incident reporting to the level of a nurse or a midwife, much as they are all health workers. This is because the environment where a security officer works may not give him/her enough exposure.

Most of the staffs in Midigo health centre IV had average knowledge and this cut across all cadres of healthcare professionals in the facility.

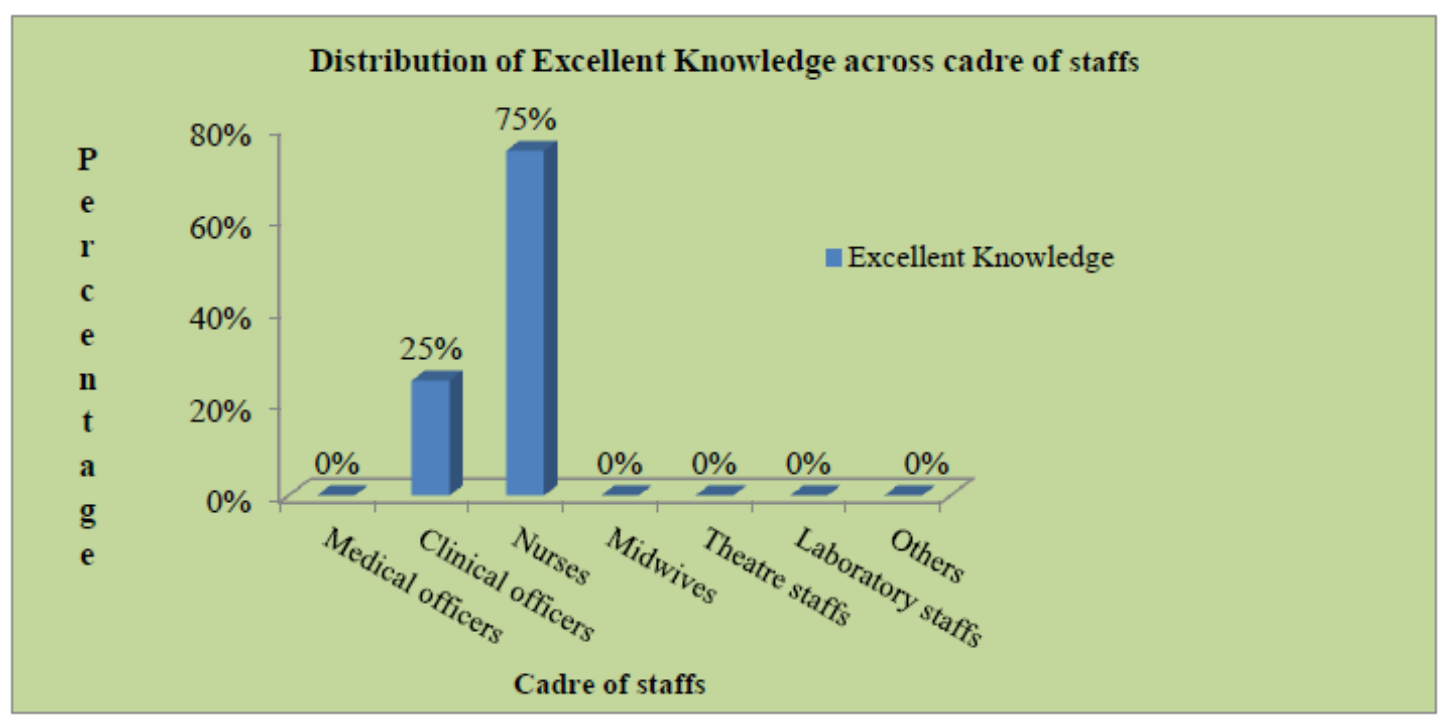

Figure 3: Distribution of excellent knowledge among respondents who knew medical incident reporting

Figure 3 above, shows that a healthcare professional in Midigo health centre IV who excellently knew about medical incident reporting was either a nurse, with $75 \%$ chance or a clinical officer, with $25 \%$ chance respectively.

\section{Attitude of healthcare professionals in Midigo Health Centre IV towards medical incident reporting}

The respondents were asked a strong negative statement and a strong positive statement about the need to used medical incident reporting to improve patient safety. Asking the respondent to state whether incident reporting was a „waste of time, and must be discouraged immediately" showed a strong negative feeling about the exercise. This was taken by the researcher as a negative attitude towards medical incident reporting. Similarly, asking the respondent to state whether incident reporting ,improves patient safety, and therefore must be encouraged" showed a strong positive feeling of the respondent about the exercise. This was taken as a positive attitude towards medical incident reporting.

Table 3: Attitude of healthcare professionals toward medical incident reporting

\begin{tabular}{llllll}
\hline \multicolumn{6}{c}{ Attitude of Respondent About Medical Incident Reporting } \\
\hline & Frequency & Percent & Valid Percent & $\begin{array}{l}\text { Cumulative } \\
\text { Percent }\end{array}$ \\
Valid & & & & 2.3 \\
& Strong Negative Attitude & 1 & 2.3 & 2.3 & 100.0 \\
& Strong Positive Attitude & 43 & 97.7 & 97.7 & \\
\hline & Total & 44 & 100.0 & 100.0 & \\
\hline
\end{tabular}


Texila International Journal of Medicine

Volume 4, Issue 2, Dec 2016

From table 3 above, the majority of the respondents had strong positive attitude toward medical incident reporting, standing at $97.7 \%$. The negative feeling about the practice, herein referred to as attitude, was at $2.3 \%$

This result has been graphically presented as below;

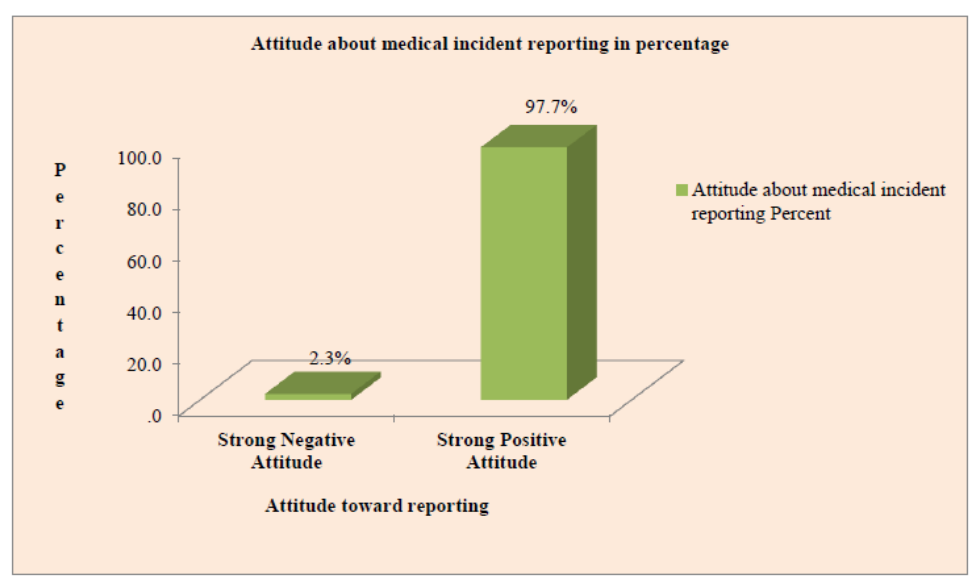

Figure 4: Attitude of healthcare professional in Midigo health centre IV towards medical incident reporting

Figure 4 above showed that positive attitude towards medical incident reporting in Midigo health centre IV was at $97.7 \%$ while negative attitude was at $2.3 \%$.

\section{The practice of medical incident reporting in Midigo Health Centre IV}

The respondents were asked where or not they had ever participated in reporting incident over the last 5years. „Yes" or "No" responses were solicited from them and the researcher based on these responses, as a proxy measure, to ascertain the level of practice of medical incident reporting in the facility. The findings were summarized in graphic form as below.

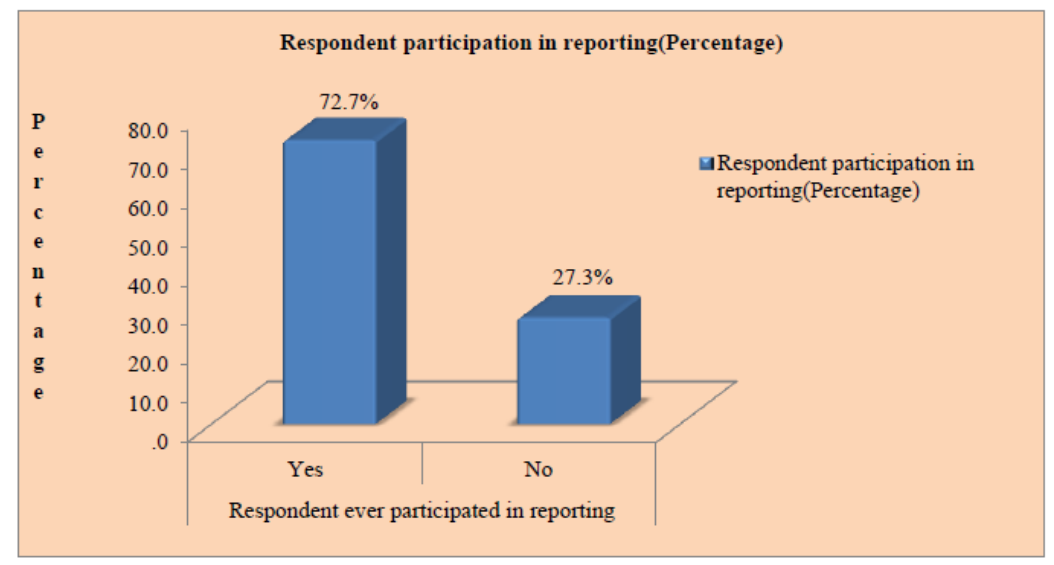

Figure 5: Practice of medical incident reporting over 5years period

From figure 5 above, the majority (72.7\%) of the respondent healthcare professionals in Midigo health centre IV ever participated in the medical incident reporting over the last 5years while $27.3 \%$ never did so. The level of practice was concluded based on the „Yes response, which was $72.7 \%$.

The extent of practice of medical incident reporting among respondents who ever participated in medical incident reporting over the last 5years: The respondents who had ever participated in incident reporting over 5years period were asked how many times they participated within the said time frame. The response categories solicited were; Once, Twice and Three times or more. The results were summarized in figure 6 below. 


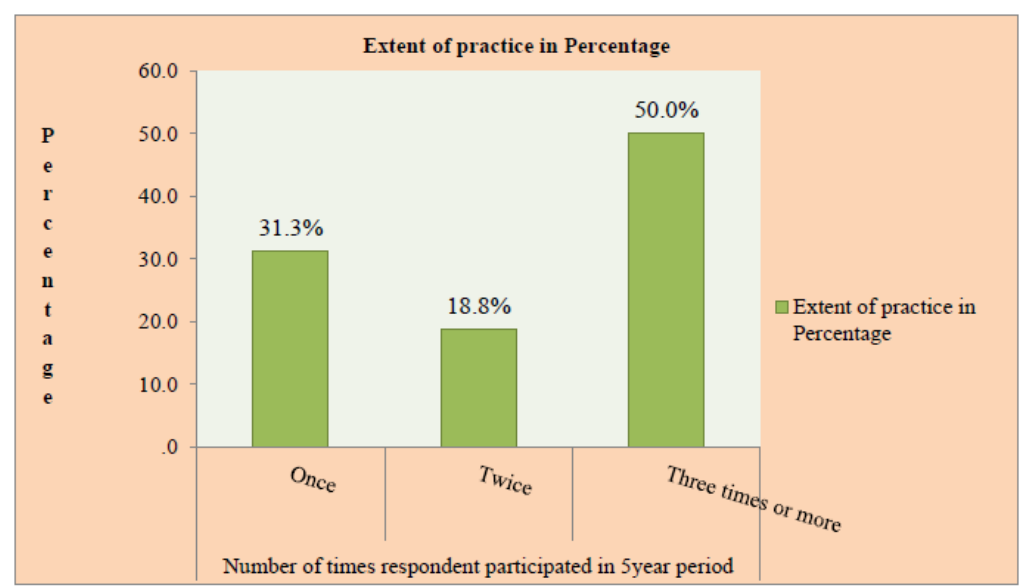

Figure 6: Extent of practice of medical incident reporting in a 5year period

Figure 6 above shows that out of the 72.6\%respondent healthcare professionals who ever participated in incident reporting in a 5year period, the majority $(50.0 \%)$ had participated three times or more. This was followed by those who participated once, constituting 31.3\%.

Relationship between extent of practice of medical incident reporting over a 5year period and cadre of respondent: The researcher proceeded to examine the relationship between extent of practice in a 5year period and cadre of respondent. A cross tabulation was done and the findings were shown figure 7 below

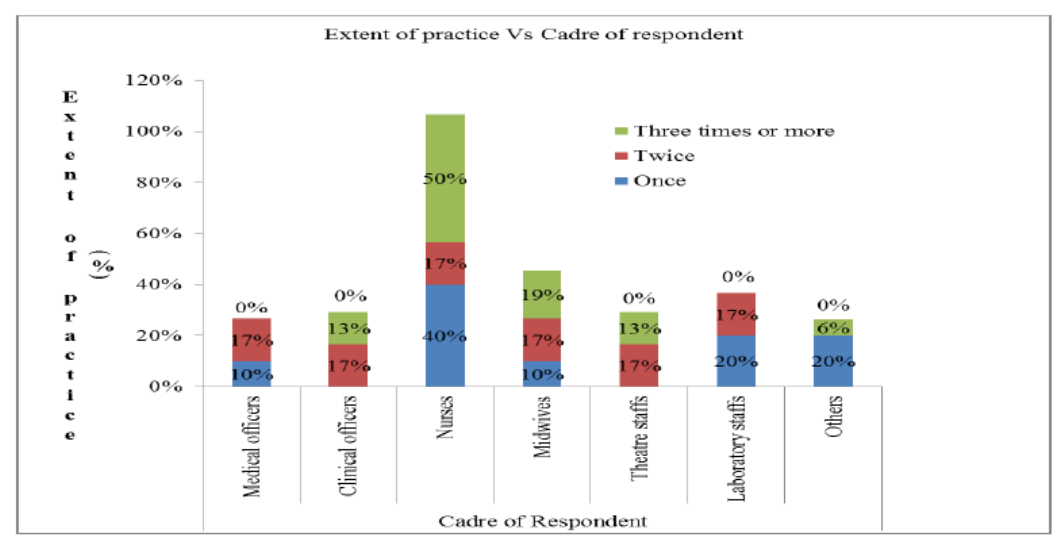

Figure 7: Cross tabulation of extent of practice over 5year period versus cadre of respondent

Figure 7 above shows that the greatest categories of staffs who practiced medical incident reporting three times or more in a 5year period were nurses and midwives, constituting $50 \%$ and $19 \%$ respectively. Therefore, being a nurse or a midwife in Midigo health centre IV gives a healthcare professional better chance of practicing medical incident reporting. However, the researcher is 95\% confident that this finding was by chance, $\mathrm{X} 2(12, \mathrm{~N}=44)=11.64, p=.48$. In other word, there was no significant relationship between the extent to which one practiced medical incident reporting and cadre of the said respondent.

Relationship between knowledge about medical incident reporting and extent of practice over a 5year period: The researcher, again, went ahead to examine the relationship between knowledge about medical incident reporting and extent of practice of medical incident reporting over a 5year period. Cross tabulation of knowledge about reporting and extent of practice was done and the result was as shown in figure 8 below 


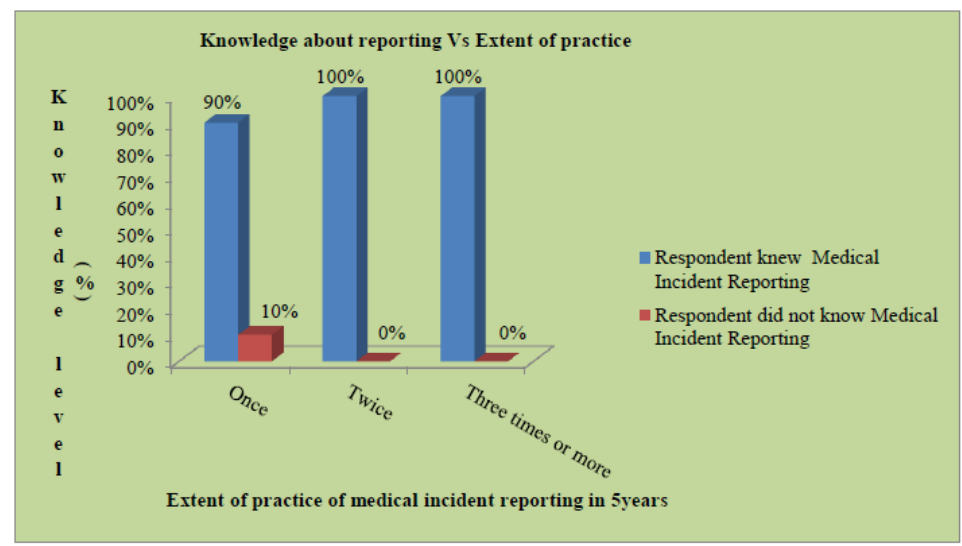

Figure 8: Knowledge of medical incident reporting versus extend of practice

Figure 8 shows that under the category of those who practiced (participated in) medical incident reporting once in 5years, only $10 \%$ did not know medical incident reporting. $90 \%$ of this category of respondents knew about the subject matter. For the categories that practiced (participated in) more than once, they all knew medical incident reporting. Much as knowledge on medical incident reporting appears to be high with increase in the extent of practice, there was no evidence to justify this trend, $X 2(2, N=44)=2.27, p=.32$.

\section{Factors affecting medical incident reporting in Midigo Health Centre IV}

The factors affecting medical incident reporting were listed in two categories. The first categories were those factors which facilitated the respondent to participate in reporting over the last 5years. The second categories were those factors which hindered the respondent from participation over a 5year period. These were called barriers, by the researcher. The respondent was allowed to select any many factors as possible for the respective category he/she falls.

Factors that facilitated the practice of affecting medical incident reporting: The factors which facilitated the practice varied from one respondent to the next. They were summarized in table 4 below;

Table 4: Factors that facilitated the practice of medical incident reporting

\begin{tabular}{lll}
\hline Factors for participation & Frequency & Percentage \\
\hline $\begin{array}{l}\text { Respondent was Knowledgeable(educated) about } \\
\text { reporting }\end{array}$ & 23 & $71.9 \%$ \\
$\begin{array}{l}\text { Respondent had strong positive feeling to participate and } \\
\text { improve patient safety }\end{array}$ & 26 & $81.3 \%$ \\
$\begin{array}{l}\text { Practice(Culture) of reporting was high in the facility } \\
\begin{array}{l}\text { Respondent was able to get feedback about reported } \\
\text { incidents }\end{array}\end{array}$ & 6 & 11 \\
\hline
\end{tabular}

Total percentage $>100 \%$ because of multiple responses

From table 4 above, out of the $72.7 \%$ of the respondents (reported earlier) who practice incident reporting over a 5year period, the majority (81.3\%) practiced because they had strong feeling to improve patient safety. Therefore, most of the staffs of Midigo health centre IV participated in incident reporting either because strong feeling to improve patient safety or because they were knowledgeable (educated) about reporting (71.9\%). The institutional high culture of reporting and ability to get feedback of reported incidents did not have much impact in their participation.

Barriers to the practice of medical incident reporting over a 5year period: Again, the factors which acted as barriers to the practice of medical incident reporting varied from one respondent to the next. They were summarized in table 5 below; 
Table 5: Barriers to the practice of medical incident reporting

\begin{tabular}{lll}
\hline Barriers & Frequency & Percentage \\
\hline Respondent didn't know how and where to report & 8 & $66.7 \%$ \\
The practice(culture) of reporting was weak(low) & 5 & $41.7 \%$ \\
Fear of consequence of reporting & 0 & $0 \%$ \\
Respondent lacked time to report & 3 & $25 \%$ \\
Other factors & 2 & $16.7 \%$ \\
\hline
\end{tabular}

Total percentage $>100 \%$ because of multiple responses

Table 5 above shows that out of the $27.3 \%$ of respondent who did not participate in medical incident reporting, the majority (66.7\%) did not do so because they didn "t know how and where to report. The practice (culture) of weak institutional reporting also featured as a great barrier, standing at $41.7 \%$. The fear of the consequence of reporting did not contribute in any way to their non-participation in the 5year period.

\section{Discussions, conclusion and recommendations}

\section{Introduction}

This chapter displays the discussion on the findings, conclusion based on this study and recommendation to readers or stakeholders to this research work.

\section{Discussion}

The discussions have been sub-divided into four result areas in accordance with the specific objectives of this study.

Knowledge about medical incident reporting among healthcare professionals: Being knowledgeable about something often influences one"s judgment whether or not be active. Similarly, it is expected that where healthcare professionals are more knowledgeable about medical incident reporting, the practice must be high. In fact Jansma et al. (2011) argued that patient safety education can have immediate and long-term positive effects on knowledge, skills and attitudes, and modestly influence the reporting behavior of resident healthcare professionals.

The finding in this study also showed that the extent of practice of medical incident reporting was highest among those healthcare professionals whose knowledge level was $100 \%$. This is consistent with other studies, including World Health Organization (WHO). WHO argued that for several reasons, the effectiveness of incident reporting is limited. One of such reasons was related to knowledge gap, that is, lack of understanding of what a reportable incident is (WHO, 2009).

Attitude of healthcare professionals towards medical incident reporting: The attitude, in many cases goes hand-in-hand with knowledge deficit on the subject matter, although there may be other aggravating factors. For example, many researchers have found that fear of being punished in case of reported medical incident has negatively affected the practice of reporting in many healthcare settings (Radhakrishna, 2016 and WHO, 2009).

However, in Midigo health centre IV, this factor did not contribute at all to any negative practice. No respondent healthcare professional was able to say he/she did not participate in reporting because he/she feared being punished. The knowledge level of healthcare professionals in Midigo was reasonably high

(84.1\%) and this was coupled with very strong positive attitude (97.7\%) towards medical incident reporting, hence level of practice being $72.7 \%$. Therefore, in terms of fear of being punished for medical incidents, this study was not consistent with other studies.

The practice and the extent to which medical incident reporting is practiced: The extent of incident reporting depended on the level of knowledge and positive attitudes towards patient safety concept, among healthcare professionals. This is consistent with other studies. For that matter, therefore, the more someone is educated on patient safety, the more 
Texila International Journal of Medicine

Volume 4, Issue 2, Dec 2016

the ability and willingness to report incidents. In fact, positive changes in knowledge, skills and attitudes would be paramount after such education course (Jansma et al., 2011)

Factors affecting medical incident reporting: According to Marilyn et al. (2004), the common barriers to reporting incidents included; time constraints, unsatisfactory processes, deficiencies in knowledge, cultural norms, inadequate feedback, beliefs about risk and a perceived lack of value in the process.

In the context of Midigo Health Centre IV, the commonest barriers were; respondents didn't know how and where to report, weak institutional culture of reporting and to a lesser extent the perceived lack of time to report. These factors are not any different from those found by other researchers. Uniquely speaking, fear of punishment following medical incident reporting did not act as a barrier at all in Midigo.

\section{Conclusion}

Medical incident reporting still remains a key tool in improving patient safety. The greater the practice of reporting, the better; as evident by the strong positive feeling towards medical incident reporting, in this study. Educating professionals on incident reporting and strong positive individual feeling to improve safety have remained the major factors facilitating medical incident reporting. Likewise, lack of knowledge on where and how to report, coupled with weak institutional culture of reporting have remained the major barriers to practicing medical incident reporting.

\section{Recommendations}

Following the findings from this study, the researcher would like to make the following recommendations;

I. Let many more researches be done on medical incident reporting in other health facilities, in Yumbe district and beyond, to assess their status regarding such reporting.

II. Let continuous professional development (CPD) / continuous medical education (CME) be done in Midigo health centre IV and other healthcare facilities in and around Yumbe district. This will help to increase patient safety awareness among healthcare professionals.

III. Let healthcare professionals be encouraged and fully facilitated by management of healthcare facilities, district health office (DHO) and development partners such as Calvary Chapel of Midigo, to conduct of healthcare researches in their institutions. This will help to identify and correct problem areas.

\section{Acknowledgement}

I do sincerely acknowledge the contributions of everybody towards the successful completion of this research work. In particular, I want to recognize the supervisory role played by Dr Yayi Alfred, the District Health Officer (DHO) of Yumbe district local government who has been my professional supervisor throughout the course of this research work. I also acknowledge the supervisory roles played by Pastor Jjagwe Charles, the Chief Executive Officer (CEO) of Calvary Chapel of Midigo who doubles as a Public Health Specialist and my immediate supervisor. May God bless them all!

\section{References}

\section{Book}

[1.] Ministry of Health Uganda. (2015). Annual Health Sector Performance Report: Financial Year 2014/2015. Kampala: Ministry of Health Uganda.

\section{Journal article}

[2.] Mahajan, R. P. (2010). Critical incident reporting and learning. British Journal of Anaesthesia,105 (1), 69-75. doi:10.1093/bja/aeq133 


\section{Project report}

[3] Nabudere, H., Asiimwe, D. and Semakula, D. (2014). Improving patient safety for better quality of care. Regional East African Community Health (REACH) Policy Initiative

\section{Journal article}

[4] Anderson, J. E., Naonori, K., Rhiannon, W., and Anneliese, D. (2013). Can incident reporting improve safety? Healthcare practitioners" views of the effectiveness of incident reporting. International Journal for Quality in Health Care, 2013(25), 141-150. doi: 10.1093/intqhe/mzs081

\section{Journal article}

[5] Lawton, R. and Parker, D. (2002). Barriers to incident reporting in a healthcare system. Qual Saf Health Care,11, 15-18. doi: 10.1136/qhc.11.1.15

\section{Journal article}

[6] Evans, S. M., Berry, J. G., Smith, B. J., Esterman, A., Selim, P., O "Shaughnessy, J. and DeWit, M. (2006). Attitudes and barriers to incident reporting: a collaborative hospital study. Qual Saf Health Care, 15, 39-43. doi: 10.1136/qshc.2004.012559

\section{Journal article}

[7] Omona, K. (2015). Patients and Health Workers' Engagement in Patient Safety in Healthcare in Kitgum General Hospital. South American Journal of Management, 1, 1-44.

\section{Journal article}

[8] Domenico, F., Paolo, R., Aida, B., Claudia, P., and Maria, P., (2012). Patient Safety and Medical Errors: Knowledge, Attitudes and Behavior among Italian Hospital Physicians. International journal for quality in healthcare, 2012, 1-8.

\section{Journal article}

[9] Jansma, J. D., Cordula, W., Reinier, W. t. K., \& Arnold, B. B. (2011). Effects on incident reporting after educating residents in patient safety: a controlled study. BMC Health Services Research, 11:335. doi:10.1186/1472-6963-11-335

\section{Article from a reference book}

[10] World Health Organization. (2009). Glossary of Patient Safety Concepts and References. In WHO, World Alliance for Patient Safety Taxonomy (Technical Annex II). Geneva: World Health Organization.

London, UK: Wiley Blackwell.

\section{Journal article}

[11] Kreckler, S., Catchpole, K., McCulloch, P. and Handa, A. (2009). Factors influencing incident reporting in surgical care. Qual Saf Health Care, 18, 116-120 doi:10.1136/qshc.2008.026534

\section{Journal article}

[12] Radhakrishna, S. (2016). Culture of blame in the National Health Service; consequences and solutions. British Journal of Anesthesia, 115, 653-655.

\section{Journal article}

[13] Anja, H., Brunsveld-Reinders, M., Sesmu, A., Rien, D. V. and Evert, D. J. (2015). Incident and error reporting systems in intensive care: a systematic review of the literature. Oxford University Press, 2015, 2-13. doi: http://dx.doi.org/10.1093/intqhc/mzv100

\section{Web page}

[14] Patient Safety Network. (2014). Voluntary Patient Safety Event Reporting (Incident Reporting). Retrieved from https://psnet.ahrq.gov/primers/primer/13/voluntary-patient-safety-event-reportingincident-reporting 
Texila International Journal of Medicine

Volume 4, Issue 2, Dec 2016

\section{Book}

[15] Vincent, C. (2011). The Essentials of Patient Safety, London, UK: Wiley Blackwell.

\section{Journal article}

[16] Gifford, M., L. and Anderson, J., E. (2010). Barriers and Motivating Factors in Reporting Incidents of Assault in Mental Health Care. Journal of the American Psychiatric Nurses Association, 16(5), 288-298. doi: 10.1177/1078390310384862

\section{Journal article}

[17] Naonori, K. and Anneliese, D. (2008). Factors Affecting Willingness to Report Patient Safety Incidents in Hospitals. National Institute for Health Research, 1, 1-38.

\section{Journal article}

[18] Polisena, J., Gagliardi, A., Urbach, D., Tammy, C. and Michelle, F. (2015). Factors that influence the recognition, reporting and resolution of incidents related to medical devices and other healthcare technologies: a systematic review. BioMed Central (2015), 1-11. doi:10.1186/s13643-015-0028-0

\section{Journal article}

[19] Haller, G., Courvoisier, D. S., Anderson, H. and Myles, P. S. (2011). Clinical factors associated with the non-utilization of an anaesthesia incident reporting system. British Journal of Anaesthesia, 107 (2), 171-179. doi:10.1093/bja/aer148

\section{Journal article}

[20] Julius, C. P., Thierry, G. and Peter, J. P. (2013). What to do with healthcare Incident Reporting Systems. Journal of Public Health Research 2013, 2(27), 154-159. doi:10.4081/jphr.2013.e27

\section{Journal article}

[21] Marilyn, J. K., Sue, M. E., Brian, J. S. and Jesia, G. B. (2004). Attitudes of doctors and nurses towards incident reporting: a qualitative analysis. MJA, 36-39.

\section{Journal article}

[22] Hooper, P., Kocman, D., Carrl, S. and Tarrant, C. (2015). Junior doctors" views on reporting concerns about patient safety: a qualitative study. British Medical Journal, 91, 251-256. doi:10.1136/postgradmedj-2014-133045

\section{Book}

[23] Uganda Bureau of Statistic. (2015). National Population and Housing Census 2014. Kampala: Uganda Bureau of Statistic (UBOS). 


\title{
Effects of diabetic education on blood pressure, blood urea, creatinine and fasting sugarby diabetic patients in central hospital Nampula
}

\author{
Article by Madhumati Varma \\ Ph.D in Medicine by Research in Diabetology, India \\ Email: madhumativarma@gmail.com
}

\begin{abstract}
Background: The Global report from the World Health Organization (WHO), published in 2016, estimated that 422 million of the adult population lives with diabetes the number of diabetic patients has dramatically increased 4 times over in the adult population.

Methods: This is Interventional study, 648 of the participants of diabetes mellitus in outpatient diabetic clinic in hospital central Nampula, the participants taken according to inclusion and exclusion criteria, completed the pre-test at baseline and post-test after the second follow up session of education, during each session of education blood pressure, urea, creatinine were recorded. Education commenced with instruction in groups of each session followed by individual advice sessions for each patient with different specialists.

Results: The present study found that educational intervention of diabetes was highly effective to improve blood pressure from baseline mean of 131.02/71.73 $\mathrm{mmHg}$ second follow up 120.95/68.79 $\mathrm{mmHg}$ with standard deviation of baseline $24.35 \mathrm{mmHg} / 14.66 \mathrm{mmHgto}$ second follow up $19.95 \mathrm{mmHg} / 11.33 \mathrm{mmHg}$, blood urea and serum creatinine significantly decreased from baseline in the second follow up $(P<.001)$. A post hoc Turkey test on blood pressure, blood urea and serum creatinine when compared with dependent variable fasting blood sugar found significantly $(P=.05)$ at baseline, at first follow up $(P=.005)$ and at second follow up $(P=$. 005).

Conclusion: The present study found that educational intervention was highly effective in controlling blood pressure, blood urea and creatinine among participants of diabetes mellitus.
\end{abstract}

Keywords: Diabetes Mellitus, blood pressure, blood urea and creatinine, effect education, control, and participants

\section{Introduction}

\section{Background}

\section{Worldwide}

The Global report from the World Health Organization (WHO), published in 2016, estimated that 422 million of the adult population lives with diabetes the number of diabetic patients has dramatically increased 4 times over in the adult population, compared to 108 million in 1980. Diabetes Mellitus is a chronic metabolic disorder, which is caused by partial deficiency or total deficiency of insulin. Diabetic mellitus could be diabetes, which is type 1 complete deficiency of insulin and diabetes type 2, partial deficiency of insulin with receptor of insulin not functioning to facilitate enter glucose into cells for utilization and formation of units of energy. WHO has estimated that the number of diabetic patients will double by 2030. Diabetes is increasing more rapidly in low and medium income groups than higher income groups as well as in, developing countries compared to European countries, where there is less prevalence of diabetes. The top five countries with the highest prevalence of diabetes. Include the following: India, China, USA, UK, Bazile and Indonesia. Diabetes Type 1 most common in Scandinavian populations, Sardines, and Kuwait, and less common in Asia, Latin and European population. 
Texila International Journal of Medicine

Volume 4, Issue 2, Dec 2016

\section{Mozambique}

Mozambique is located on the East coast of Africa (Wikipedia 2016). There are 274,700 diabetic patients and 9716 deaths due to diabetes, according to a report of 2015 (IDF 2015). This country is the setting for this study. There is the prevalence of obesity, poor knowledge regarding diabetes and lack of awareness of complication of diabetes. Most of the population uses traditional healer for treatment of diabetes. There are unhealthy food habits, sedentary lifestyle in urban population and increased economic growth amongst professions related to office work, which is one of the risk factors that causes diabetes and its complications. There are no professional health, diabetes educators and patients have little or no knowledge of selfmanagement, adherence of treatment, awareness of complication. Among the group of patients who seek care in public hospitals, many are poor and cannot afford the cost of medication or healthy foods. There is an 80 dollar expenditure allotted to each patient of diabetes from the country's Ministry of Health and supported by the government. Additionally, the ministry of health provides free medication for all chronic diseases, including diabetes and hypertension. Currently, there is no study that has been done on the effects of education in various modalities of diabetes for patients and its outcome. Accordingly, there is an extreme need to educate patients of diabetes to improve diabetic control and reduce its complication.

\section{Problem}

The population for this study are diabetic patients in the Central Hospital Nampula in Mozambique, who are from low and medium income groups. This group of patients has limited sources of incomes and, completely depends on the diabetic pharmacological treatment of the government hospital pharmacy, which gives medication free of cost. In the country of Africa, there is a generally poor health education regarding the diabetes. There are no professional diabetic health educators and patients receive advice from doctors and dieticians regarding their diets and directions on how to use their prescriptions of medicine so as to continue treatment at home. Due to the large size of patient loads in outpatient consultations of diabetes, it is not possible to sit with each patient and provide specific health education about diabetes. Also, these groups of patients do not access of the internet to seek their own self-education from different sources. It is clear that when diabetic patients only utilize pharmacological treatments that it is not sufficient to control diabetes and complication (Association, 2002).

\section{Objective}

1. There is a need for lifestyle modification, knowledge of diabetes and its complication, as chronic disease,so that patients can ability to detect small symptoms of complication and present physician, adherence of treatment and its important.

2. There are different types, categories, and levels of controlled diabetic patients and the each type requires different types of education, depending on complications and diseases associated with diabetes.

There following are the clinical categories patients:

1. Good control over blood sugar and without complication.

2. Fair/not controlled blood sugar with or without complication.

3. Good control of blood sugar and without complication, but other disease example HIV treatment, CVA etc.

\section{Question statement}

To conduct the study, used dependent variable fasting blood sugar and independent age, body mass index.

Positive hypothesis, the positive correlation of control of fasting blood sugar change of lifestyle modification includes diet and exercise. The positive correlation with control of fasting blood sugar to blood pressure, blood urea and creatinine. The knowledge of diabetes 
could help in controlling diabetes and blood sugar in case implemented knowledge of diabetes in life style.

Null hypothesis, the diabetes more common with age of 45-60 but not uncontrolled by increase of age. The various reasons which can responsible for uncontrolled fasting blood sugar, in case not implemented knowledge of diabetes in life style.

\section{Assumption and limitation}

There is a need to implement before each consultation of control of diabetes for writing the prescription of medicine and controlling complication. There should be a 15 minute session of education to reemphasized, remember to patients to continue habits which helping to control diabetes. It is seen continues education help to keep continue positive habits to control diabetes. As increase period after education, some of patients come back to the same stage as they were started.

There was limitations as Mozambique is developing country as limited resources in hospital. To minimized expenditure, there are available only fasting blood sugar. There is no concept of doing the regular postprandial blood sugar. There were some time none availability of reagent in the laboratory to evaluate blood sugar, blood urea and creatinine during the period of study. That makes statically results different from which was accepted. To choose topic also forced to see available facility in a public hospital.

\section{Method}

This study was conducted on regular patients of the diabetic outpatient department of the Central Hospital of Nampula. The study investigated the effects of three sessions of the diabetes education program (baseline, first follow-up and second follow-up) on each patient at one-month intervals. The inclusion and exclusion criteria for participation in the education program are listed below.

\section{Inclusion and exclusion criteria for the study}

Table 1. Inclusion and exclusion criteria for the study

\begin{tabular}{ll}
\hline Inclusion criteria & Exclusion criteria \\
\hline Diabetic patients who come for & Participation in previous diabetes education \\
outpatient consultations & programs for more than 3 sessions \\
Mozambican citizen & Not willing to participate \\
Any age & Live in a location that makes them unable to \\
& return every month for control \\
\hline
\end{tabular}

\section{Sample number and characteristics}

A sample of 648 participants was taken for this study. The inclusion criteria for participating in the diabetes education program dictated that patients should be in the OPD, willing to participate in the education sessions and willing to give consent to be included in the study. Participants were excluded if they had already completed three sessions of education or if they lived in a district that made it impossible for them to return within one month for the next education session.

\section{Organization of education sessions}

Amongst the group instructors were a diabetologist, dietician, psychologist, physiotherapist, and diabetic nurse. The following tasks had to be performed before each of the sessions:

\section{The baseline session}

The diabetic nurse took consent and accessed the patient's clinical history before conducting a physical examination that included checking vital signs and fasting blood sugar to blood pressure. The physical examination was to be done by a physician. They also noted 
Texila International Journal of Medicine

Volume 4, Issue 2, Dec 2016

the results of a fasting blood sugar, urea and creatinine analysis that tested, which had been conducted 2-3 days prior to the education session.

\section{First follow up}

At the beginning of the session, the diabetic nurse measured the blood pressureand noted the results of the blood analysis that tested for fasting blood sugar, blood urea and creatinine, which had been conducted 2-3 days prior to the education session. The physicians and other specialists also noted the relevant patient information.

\section{Second follow up}

At the beginning of the session, the diabetic nurse measured the blood pressure and noted the results of the blood analysis that tested for fasting blood sugar, blood urea and creatinine, which had been conducted 2-3 days prior to the education session. The physicians and other specialists also noted the relevant patient information.

\section{Method of education}

The education sessions were in the form of a conference with all specialists leading a class in various verbal forms, demonstrating real situations, operating the relevant apparatus and discussing any difficulties at the end of the session.

\section{Description of health education intervention}

\section{Description of the specialists that participated in giving the education sessions}

The different types of specialists involved in the health education intervention were:

1. The psychologist oriented the patients with basic aspects of psychology to help them live with diabetes.

2. The diabetologist provided knowledge about the general concepts of diabetes.

3. The dietician provided information about the specific diet needed for diabetic patients.

4. The physiotherapist demonstrated important exercises that were specifically for sufferers of diabetes and were applicable to all individuals.

\section{Group and individual education sessions}

After a three-hour group education session, individual outpatient consultations were conducted in different rooms with different specialists. These patients could consult a diabetologist, dietician, physiotherapist, or psychologist individually according to the specific needs of each patient.

\section{Organization of health education sessions}

Due to the shortage of separate spaces large enough to accommodate the number of participants in the baseline, first follow-up and second follow-up, sessions were limited to approximately 40-50 participants. To make education sessions more interesting and effective the beginning of each session was realized with baseline participants followed by first followup participants, and then second follow-up participants were taken for education of diabetes. There was no restriction for participants if they wanted to attend the same session twice.

Each session built upon the knowledge gained in the previous session. The health outcomes of each patient were assessed in outpatient service to monitor the implementation of the knowledge imparted in the education sessions in daily life.

\section{Description of educational materials and information provided}

The topics of the sessions were chosen according to local culture, socioeconomic conditions, beliefs, lifestyle, common complications and associated diseases. The aim was to improve the outcomes for diabetes patients and prevent complications. The information was presented in a manner that the participants could easily understand and would motivate them to implement the new information in their daily lives. 


\section{Thetopics of the diabetes education sessions}

- Definition of diabetes and types of diabetes

- Symptoms of hypo- and hyperglycemia, both complications of diabetes

- Management of diabetes by diet and physical activity

- Psychological assistance

- Brief knowledge of medicines that are available in the pharmacy of the hospital

- Management of hypoglycemic medication

- Complications of diabetes and early detection

- Dental and foot care

- Diabetic control in special situations such as during Ramadan or when travelling

- Blood sugar monitoring using a glucometer

- How and where to inject insulin and how to prevent complications

- How to prevent primary and secondary stages of diabetes

- Participation of family members if willing and/or required

\section{Description of the sequence of the diabetes education sessions} In groups:

1. Welcome address to participants from a diabetologist

2. First part of the education session: lessons on diabetes by, taught by a diabetologist

3. Second part of the education session: information on diet and nutrition, taught by a dietician

4. Third part of the education session: information on how to cope psychologically with the disease, taught by a psychologist

5. Fourth part of the education session: the benefits of exercise and demonstrations of general exercises that are applicable to all patients, taught by a physiotherapist

6. Fifth part of the education session: how to inject insulin and use a glucometer, taught by a nurse

\section{On an individual basis:}

7. Sixth part of education session: individual consultations with each patient with a diabetologist, dietician, psychotherapist, or physiotherapist to help participants with particular recommendations based on associated diseases and complications, if needed

\section{Patient interviews}

The patients were interviewed in order to gather the following information:

- Identification details

- Medical history/past clinical history

- Blood pressure, body mass index

- Drug history (type of oral hypoglycemic agents, injectable form antidiabetic agents, drugs to maintain blood pressure and lipids)

- Analysis of fasting blood sugar before each session

- Specific findings, if noted by each specialists

\section{Variables used and their ranges}

\section{Blood pressure (repeated for the baseline, first follow-up, and second follow-up)}

Normal: $<120 / 80 \mathrm{mmHg}$

Pre-hypertension: 121-89 mmHg

Mild: 140/90-159/99 mmHg

Moderate: $>160 / 109 \mathrm{mmHg}$

Severe: >180/110 mmHg

Information not given 
Texila International Journal of Medicine

Volume 4, Issue 2, Dec 2016

Serum Creatinine (repeated for the baseline, first follow-up, and second follow-up)

Normal creatinine (female): $<115 \mathrm{umol} / \mathrm{l}$

Normal creatinine (male): $<88.4 \mathrm{umol} / \mathrm{l}$

Mild creatinine (female): $115-168 \mathrm{umol} / \mathrm{l}$

Mild creatinine (male): 88.4-168 umol/l

Moderate creatinine (both sexes): 176.8-353umol/l

Severe creatinine (both sexes): > 353.6umol/l

Information not given

Blood Urea (repeated for the baseline, first follow-up, and second follow-up)

Normal blood urea: $1.2-3 \mathrm{mmol} / \mathrm{l}$

Mild blood urea: 3-7 mmol/l

Moderate blood urea: 7-11 $\mathrm{mmol} / \mathrm{l}$

Severe blood urea: > $11 \mathrm{mmol} / \mathrm{l}$

Information not given

Fasting blood sugar (repeated for the baseline, first follow-up, and second follow-up)

Hypoglycemic range: $<3.9 \mathrm{mmol} / \mathrm{dl}$

Normal: 4-5.8 mmol/dl

Mild hyperglycemic range: 5.9-11 mmol/dl

Moderate hyperglycemic range: $12-19 \mathrm{mmol} / \mathrm{dl}$

Sever hyperglycemic range: $>20 \mathrm{mmol} / \mathrm{dl}$

Problem with laboratory

Information not given

A Data was analyzed SPSS 17 version, and graphs made in excel software.

Outline of presentation of statically analysis as follows:

\section{A. Descriptive analysis}

1. Frequency and percentage tables of various variables with graphic presentations.

2. Central tendency (Mean), standard deviation (stander scores).

B. Correlation analysis

1. Regression-predictive-ability independent and dependent variable

C. Analyzing difference between groups

1. T-test

2. ANOVA

3. Post hoc Turkey test

4. P-value of less than 0.05 were considered to be significant.

D. Tables and graphs use for results

\section{Results}

A sample of 648 participants was taken for this study. This study was conducted on regular patients of the diabetic outpatient department of the Central Hospital of Nampula. The study investigated the effects of three sessions of the diabetes education program (baseline, first follow-up and second follow-up) on each patient at one-month intervals. The inclusion criteria for participating in the diabetes education program dictated that patients should be in the OPD, willing to participate in the education sessions and willing to give consent to be included in the study. Participants were excluded if they had already completed three sessions of education or if they lived in a district that made it impossible for them to return within one month to the next education session. Amongst the group instructors were a diabetologist, dietician, psychologist, physiotherapist, and diabetic nurse. There were various variables to assess from baseline to second follow up education session. The variables were assessed 
blood pressure, blood urea and creatinine with compare to dependent variable fasting blood sugar of patients of diabetes mellitus.

\section{Descriptive analysis of blood pressure at baseline, first follow up, second follow up}

A sample of 648 patients with diabetes mellitus, those who had participated in educational sessions concerning diabetes mellitus, was taken for study in order to determine the effect of education on improving blood pressure levels in diabetes. The measurement of blood pressure was performed at baseline, at the first follow up and at the second follow up. The results are shown in Table 13, below. Briefly, the percentage of patients with normal $<120 / 80 \mathrm{mmHg}$ increased frombaseline $(40,1 \%)$ to the first follow up $(46.1 \%)$ and decreased at the second follow up (27.2 \%). The percentage of patients with severe rang $>180 / 110 \mathrm{mmHg}$ blood pressure were observed to decrease from baseline $(4.2 \%$ to the first follow up and to the second follow up (0.6 \%).

Table 2. Descriptive analysis of blood pressure of at baseline, first follow up and second follow up

\begin{tabular}{|c|c|c|c|c|c|c|}
\hline \multirow[b]{2}{*}{$\begin{array}{l}\text { Ranges of Blood } \\
\text { pressure }\end{array}$} & \multicolumn{2}{|c|}{ Baseline line } & \multicolumn{2}{|c|}{ First fallow up } & \multicolumn{2}{|c|}{ Second follow up } \\
\hline & Frequency & $\begin{array}{l}\text { Percen } \\
\text { tages } \\
\%\end{array}$ & $\begin{array}{l}\text { Frequen } \\
\text { cy }\end{array}$ & $\begin{array}{l}\text { Percenta } \\
\text { ges \% }\end{array}$ & Frequency & $\begin{array}{l}\text { Percent } \\
\text { ages \% }\end{array}$ \\
\hline $\begin{array}{l}\text { Normal }<120 / 80 \\
\mathrm{mmHg}\end{array}$ & 260 & 40.1 & 299 & 46.1 & 176 & 27.2 \\
\hline $\begin{array}{l}\text { Pre hypertension } \\
121-89 \text { - } \\
\text { 139/89mmhg }\end{array}$ & 118 & 18.2 & 71 & 11.0 & 53 & 8.2 \\
\hline $\begin{array}{l}\text { Mild-140/90- } \\
\text { 159/99 mmHg }\end{array}$ & 156 & 24.1 & 79 & 12.2 & 48 & 7.4 \\
\hline $\begin{array}{l}\text { Moderate }>160 / 109 \\
\text { mmlhg }\end{array}$ & 56 & 8.6 & 32 & 4.9 & 15 & 2.3 \\
\hline $\begin{array}{l}\text { Sever }>180 / 110 \\
\text { mmHg }\end{array}$ & 27 & 4.2 & 4 & .6 & 4 & .6 \\
\hline Not done & 29 & 4.5 & 161 & 24.8 & 350 & 54.0 \\
\hline Total & 646 & 99.7 & 646 & 99.7 & 646 & 99.7 \\
\hline Missing & 2 & .3 & 2 & .3 & 2 & .3 \\
\hline Total & 648 & 100.0 & 648 & 100.0 & 648 & 100.0 \\
\hline
\end{tabular}

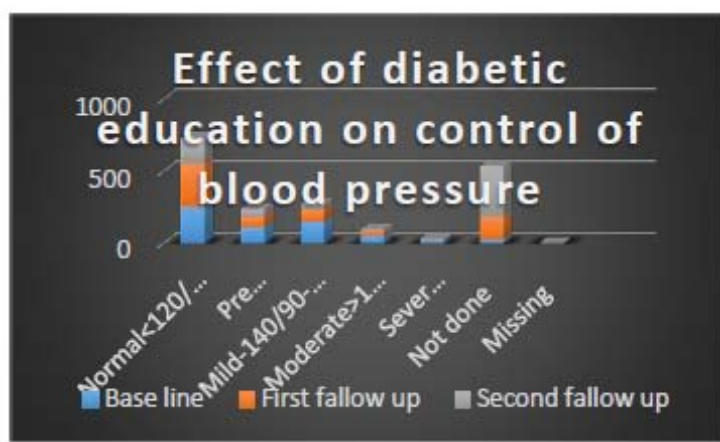

\section{Effect of diabeticn education on control of blood pressure}

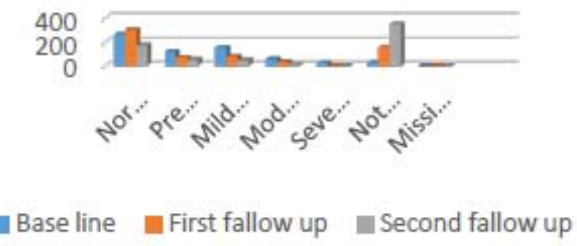




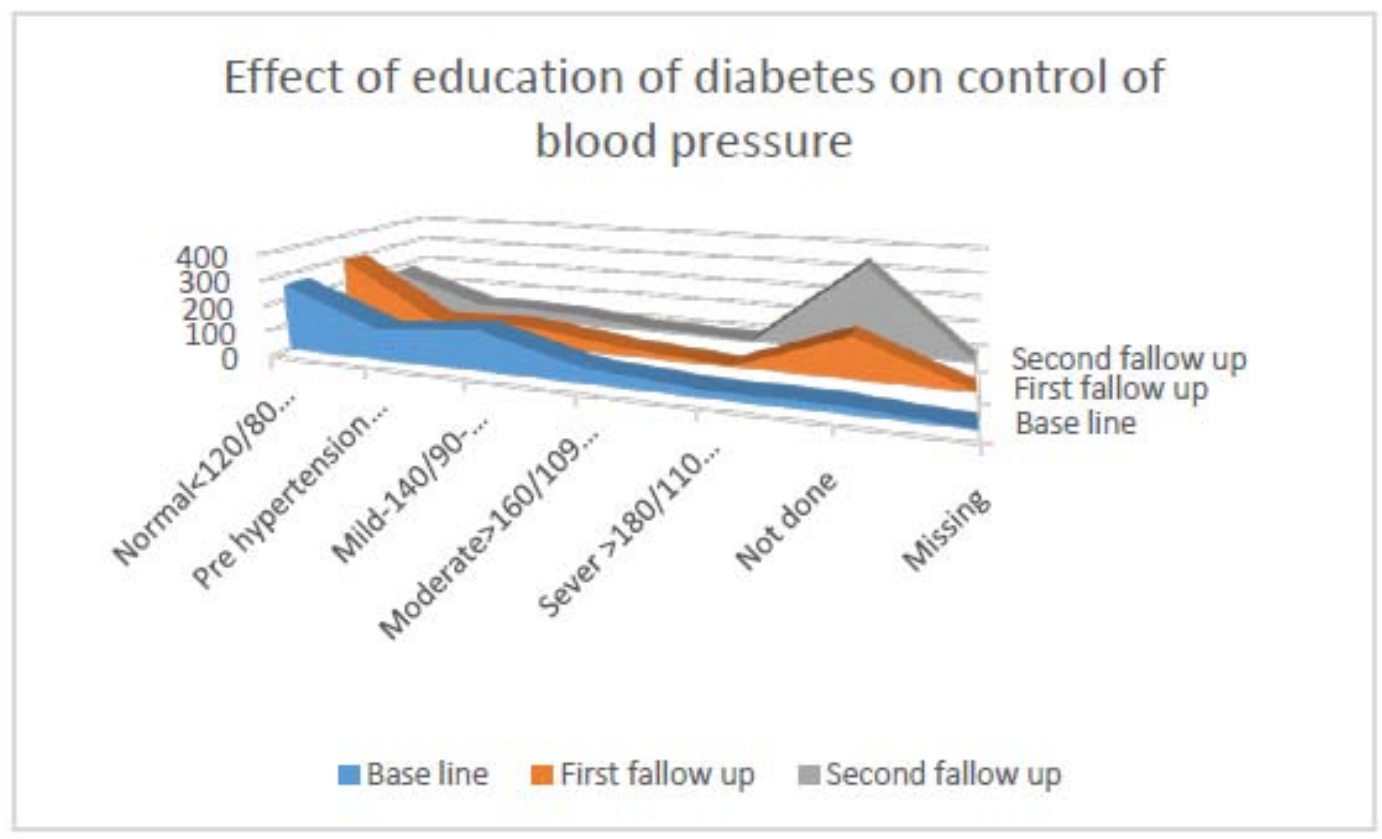

Figures 1. Bar chart and linear chart: In the above charts we see that distribution of the compared blood pressure at baseline, first follow up, and second follow up after diabetes education among participants

\section{Descriptive analysis of blood creatinine concentrations at baseline, first follow up and second follow up}

A sample of 648 patients with diabetes mellitus, who had participated in educational sessions regarding diabetes mellitus, was taken for study in order to determine the effect of education on improving outcomes in diabetes. The analysis for blood creatinine concentration was performed at baseline, at the first follow up and at the second follow up. The results are presented in Table 18, below. Briefly, the percentage of female patients with normal creatinine concentrations of $<115.0 \mathrm{umol} / \mathrm{l}$ decreased from baseline (36.7\%), to the first follow up (31.3\%), to the second follow up (23.1\%). The percentage of male patients with normal creatinine concentrations of $<88.4 \mathrm{umol} / \mathrm{l}$ decreased from baseline $(31.0 \%)$, to the first follow up (24.7\%), to the second follow up (20.4\%). The percentage of female patients with mildly increased creatinine concentrations of 115.0-168.0 umol/l decreased at each follow up from baseline (1.1\%), to the first follow up (1.9\%), to the second follow up (0.6\%). The percentage of male patients with mildly increased creatinine concentrations of 88.4-168.0 umol/l decreased at each follow up from baseline (17.4\%), to the first follow up (15.7\%), to the second follow up (10.0\%). The percentage of patients (male and female) who had moderately increased creatinine concentrations of 176.8-353.0 umol/l decreased at each follow up from baseline (2.2\%), to the first follow up (0.6\%), to the second follow up (0.6\%). The percentage of patients (both male and female) with severely increased creatinine concentrations of $>353.6 \mathrm{umol} / \mathrm{l}$ decreased at each follow up from baseline $(0.5 \%)$, to the first follow up $(0.5 \%)$, to the second follow up $(0.3 \%)$. The percentage of missing values increased from baseline (11.1\%), to the first follow up (25.3\%), to the second follow up (44.9\%). 
Texila International Journal of Medicine Volume 4, Issue 2, Dec 2016

Table 3. Descriptive analysis of serum creatinine at baseline, first follow up and second follow up

\begin{tabular}{|c|c|c|c|c|c|c|}
\hline \multirow[b]{2}{*}{$\begin{array}{l}\text { Ranges of Blood } \\
\text { creatinine }\end{array}$} & \multicolumn{2}{|c|}{ Baseline line } & \multicolumn{2}{|c|}{ First follow up } & \multicolumn{2}{|c|}{ Second follow up } \\
\hline & $\begin{array}{l}\text { Frequenc } \\
\mathrm{y}\end{array}$ & $\begin{array}{l}\text { Percentag } \\
\text { es \% }\end{array}$ & $\begin{array}{l}\text { Frequenc } \\
\mathrm{y}\end{array}$ & $\begin{array}{l}\text { Percentag } \\
\text { es \% }\end{array}$ & $\begin{array}{l}\text { Frequenc } \\
\mathrm{y}\end{array}$ & $\begin{array}{l}\text { Percenta } \\
\text { ges } \%\end{array}$ \\
\hline $\begin{array}{l}\text { Nomal female } \\
\text { creatinine }<115 \text { um } \\
\text { ol/l }\end{array}$ & 238 & 36.7 & 203 & 31.3 & 150 & 23.1 \\
\hline $\begin{array}{l}\text { Normal creatinine } \\
\text { man }<88.4 \text { umol/l }\end{array}$ & 201 & 31.0 & 160 & 24.7 & 132 & 20.4 \\
\hline $\begin{array}{l}\text { Mild creatinine } \\
\text { female 115-168 } \\
\text { umol/l }\end{array}$ & 7 & 1.1 & 12 & 1.9 & 4 & 6 \\
\hline $\begin{array}{l}\text { Mild creatinine } \\
\text { man 88.4-168 } \\
\text { umol/l }\end{array}$ & 113 & 17.4 & 102 & 15.7 & 65 & 10.0 \\
\hline $\begin{array}{l}\text { Moderate } \\
\text { creatinine both } \\
\text { 176.8-353umol/l }\end{array}$ & 14 & 2.2 & 4 & .6 & 4 & 6 \\
\hline $\begin{array}{l}\text { Sever creatinine } \\
\text { both }>353.6 \mathrm{umol} / \mathrm{l}\end{array}$ & 3 & .5 & 3 & .5 & 2 & .3 \\
\hline Not done & 72 & 11.1 & 164 & 25.3 & 291 & 44.9 \\
\hline Total & 648 & 100.0 & 648 & 100.0 & 648 & 100.0 \\
\hline
\end{tabular}
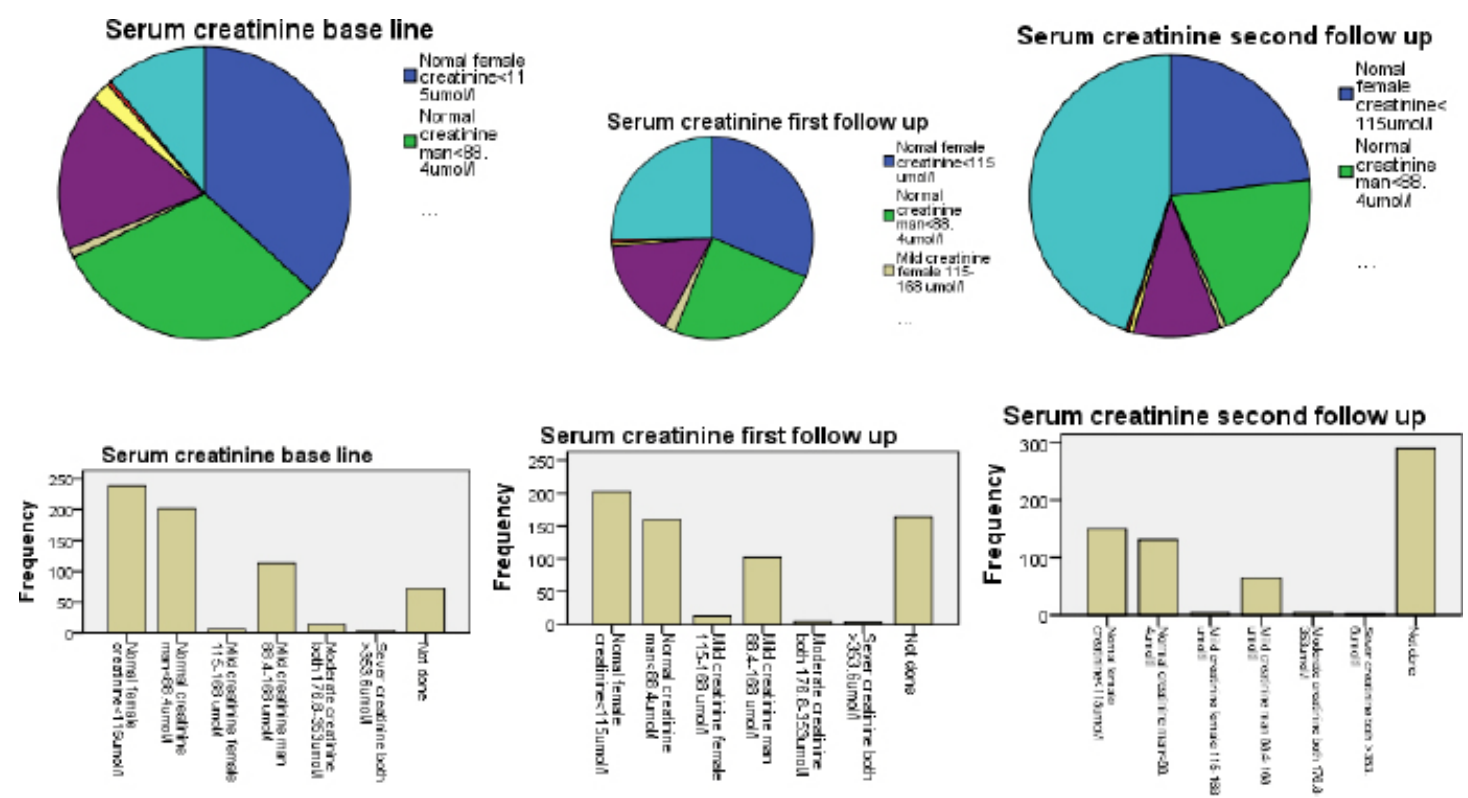
Texila International Journal of Medicine

Volume 4, Issue 2, Dec 2016

\section{Effect of diabetic education on control of s.creatinine}
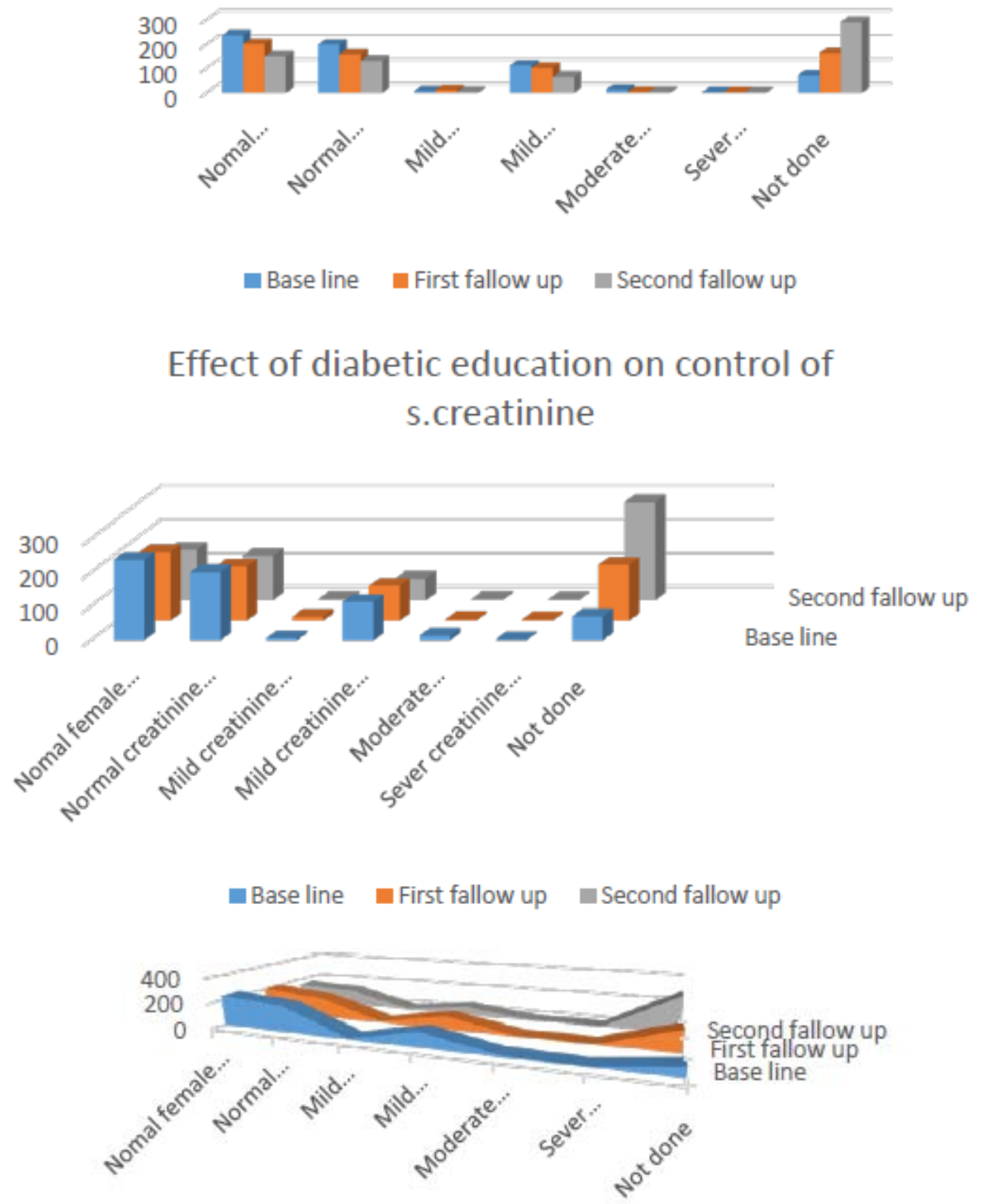

Base line $\quad$ First fallow up Second fallow up 


\section{Creatinine level at different follow up schedule}

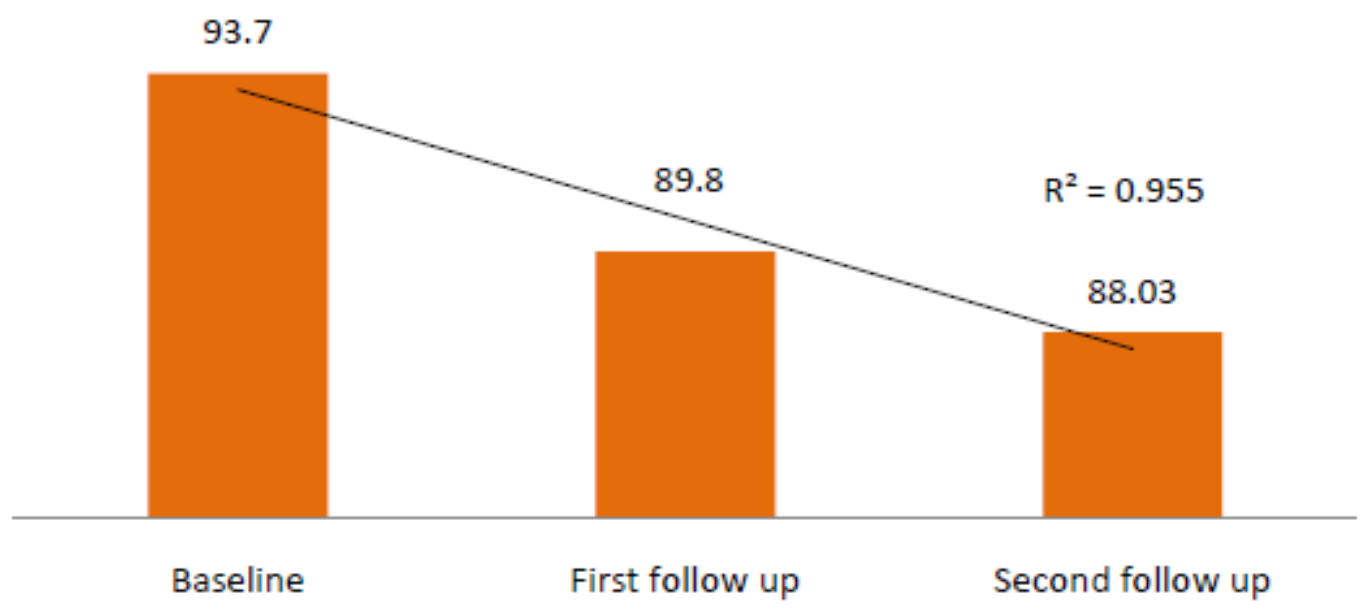

Figures 2. Pie chart, bar chart and linear chart: In the above charts we see the distribution of the compared blood creatinine scores at baseline, first follow up and second follow up after diabetes education among participants.

\section{Descriptive analysis of blood urea concentrations at baseline, first follow up and second follow up}

A sample of 648 patients with diabetes mellitus, who had participated in educational sessions concerning diabetes mellitus, was taken for study in order to see the effect of education on improving the outcomes of diabetes. The analysis performed for blood urea concentrations was done at baseline, at the first follow up and at the second follow up. The results are presented in Table 19, below. Briefly, the percentage of patients with normal blood urea concentrations of 1.2-3.0 mmol/l decreased from baseline (11.7\%), to the first follow up (8.6\%), to the second follow up (4.0\%). The percentage of patients with mildly increased levels of urea of $3.0-7.0 \mathrm{mmol} / \mathrm{l}$ decreased from baseline $(50.5 \%)$, to the first follow up (35.6\%), to the second follow up (16.4\%). The percentage of patients with moderately elevated levels of urea of 7.0-11.0 mmol/l decreased at each follow up from baseline (4.8\%), to the first follow up (3.4\%), to the second follow up (0.9\%). The percentage of patients with severely increased urea concentrations of $>11.0 \mathrm{mmol} / \mathrm{l}$ decreased at each follow up from baseline $(1.9 \%)$, to the first follow up ( $0.9 \%)$, to the second follow up $(0.2 \%)$. The percentage of patients with missing values increased from baseline (31.0\%), to the first follow up (51.2\%), to the second follow up (78.2\%). 
Texila International Journal of Medicine

Volume 4, Issue 2, Dec 2016

Table 4. Descriptive analysis of blood urea at baseline, first follow up and second follow up

\begin{tabular}{lllllll}
\hline \multicolumn{3}{c}{ Baseline line } & \multicolumn{2}{l}{ First follow up } & \multicolumn{2}{l}{ Second follow up } \\
$\begin{array}{l}\text { Ranges of } \\
\text { Blood Urea }\end{array}$ & Frequency & $\begin{array}{l}\text { Percentages } \\
\%\end{array}$ & Frequency & $\begin{array}{l}\text { Percentages } \\
\%\end{array}$ & Frequency & $\begin{array}{l}\text { Percentages } \\
\%\end{array}$ \\
\hline $\begin{array}{l}\text { Normal } \\
\text { Blood Urea }\end{array}$ & 76 & 11.7 & 56 & 8.6 & 26 & 4.0 \\
$\begin{array}{l}1.2-3 \\
\text { mmol/l }\end{array}$ & & & & & & \\
Mildl Blood & 327 & 50.5 & 231 & 35.6 & 106 & 16.4 \\
$\begin{array}{l}\text { Urea 3-7 } \\
\text { mmol/l }\end{array}$ & & & & & & \\
moderate & 31 & 4.8 & 22 & 3.4 & 6 & .9 \\
$\begin{array}{l}\text { Blood Urea } \\
7-11 \text { mmol/1 }\end{array}$ & & & & & & \\
$\begin{array}{l}\text { Sever Blood } \\
\text { Urea }>11\end{array}$ & 12 & 1.9 & 6 & .9 & 1 & .2 \\
mmol/l & & & & & & \\
Not done & 201 & 31.0 & 332 & 51.2 & 507 & 78.2 \\
$\begin{array}{l}\text { Total } \\
\text { Missing }\end{array}$ & 647 & 99.8 & 647 & 99.8 & 646 & 99.7 \\
Total & 1 & .2 & 1 & .2 & 2 & .3 \\
\hline
\end{tabular}
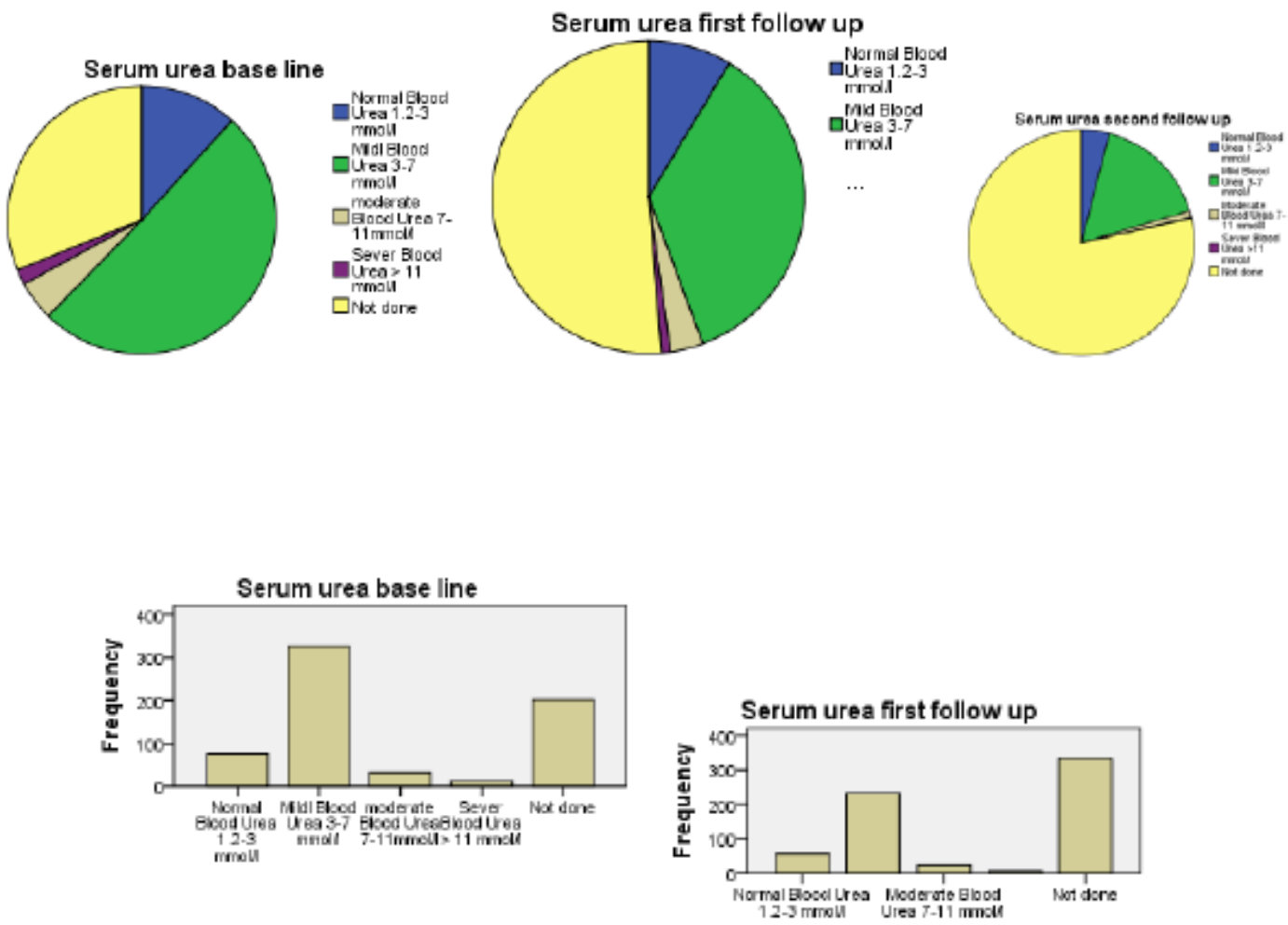
Effect of diabetic education on control of S.urea
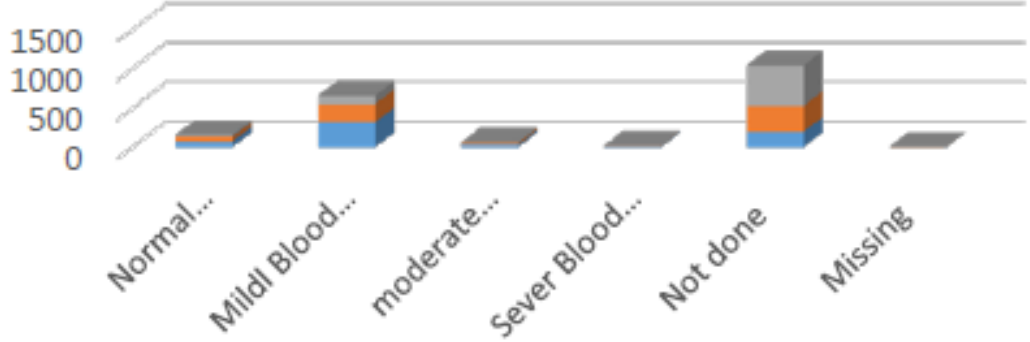

Base line $\square$ First fallow up $\square$ Second fallow up

Effect of diabetic education on control of s.

urea

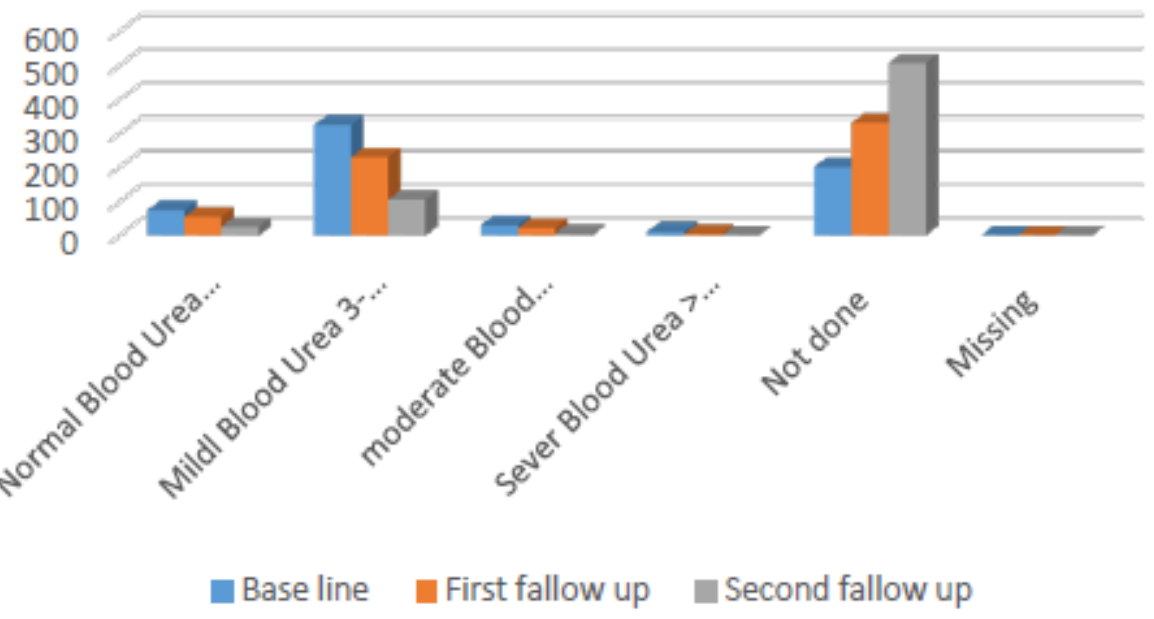

Effect of diabetic education on control of s.urea

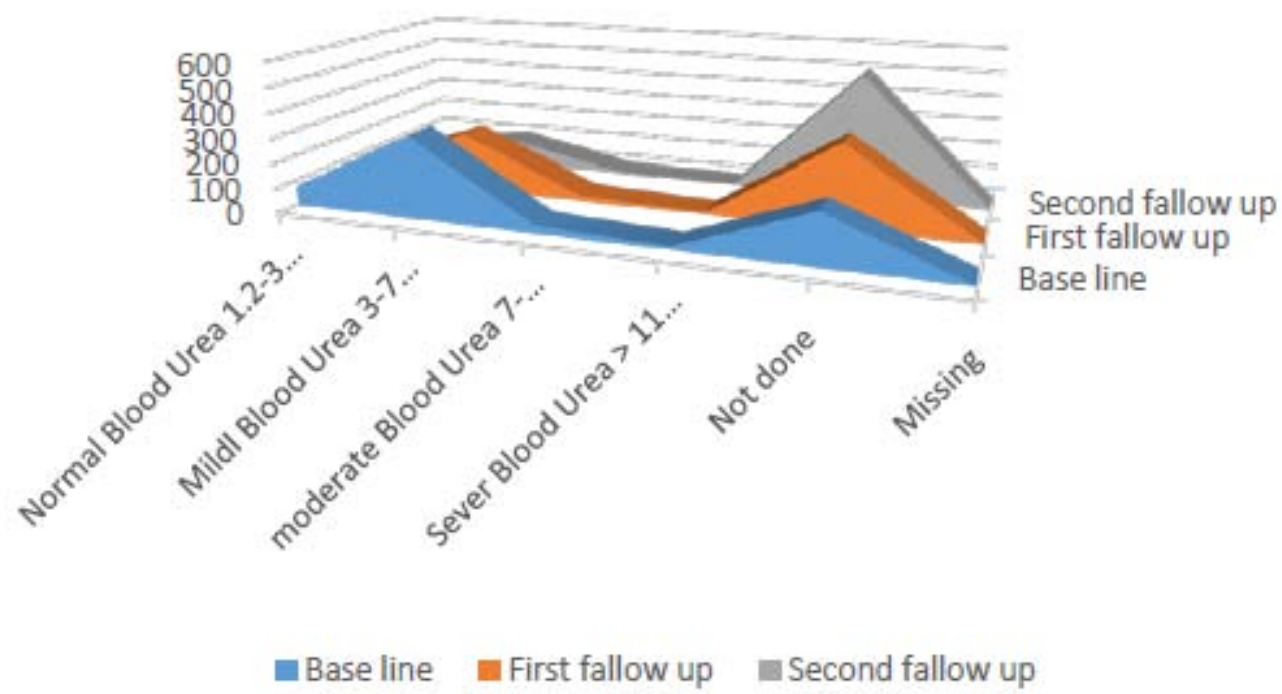


Texila International Journal of Medicine

Volume 4, Issue 2, Dec 2016

\section{Urea level at different follow up schedule}

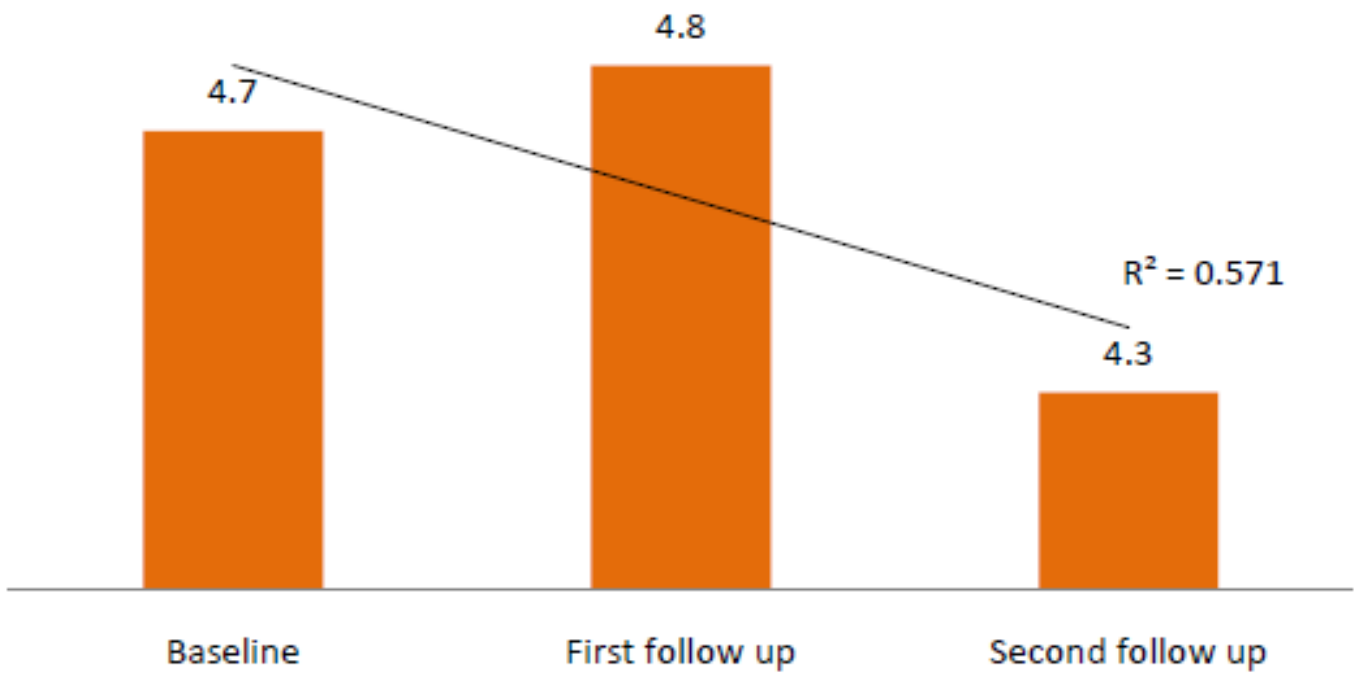

Figures 3. Pie chart, bar chart and linear chart: In the above charts we see the distribution of the compared blood urea scores at baseline, first follow up, and second follow up after diabetes education diabetes among participants.

Table 5. Descriptive analysis of fasting blood sugar at baseline, first follow up and second follow up

\begin{tabular}{lcccccc}
\hline & \multicolumn{2}{l}{ Baseline line } & \multicolumn{2}{l}{ First follow up } & \multicolumn{2}{l}{ Second follow up } \\
$\begin{array}{l}\text { Ranges of Blood } \\
\text { Sugar }\end{array}$ & $\begin{array}{l}\text { Frequen } \\
\text { cy }\end{array}$ & $\begin{array}{l}\text { Percentag } \\
\text { es \% }\end{array}$ & $\begin{array}{l}\text { Frequenc } \\
\text { y }\end{array}$ & $\begin{array}{l}\text { Percentag } \\
\text { es \% }\end{array}$ & $\begin{array}{l}\text { Frequen } \\
\text { cy }\end{array}$ & $\begin{array}{c}\text { Percent } \\
\text { ages \% }\end{array}$ \\
\hline $\begin{array}{l}\text { Hypoglycaemic }<3.9 \\
\text { mmol/dl }\end{array}$ & 31 & 4.8 & 27 & 4.2 & 33 & 5.1 \\
Normal 4-5.8 mmol/dl & 141 & 21.8 & 123 & 19.0 & 97 & 15.0 \\
Mild hyperglycaemic & 268 & 41.4 & 240 & 37.0 & 183 & 28.2 \\
$\begin{array}{l}\text { 5.9-11 mmol/dl } \\
\text { Moderate }\end{array}$ & 144 & 22.2 & 116 & 17.9 & 81 & 12.5 \\
hyperglycaemic 12-19 & & & & & & \\
mmol/dl & & & & & & \\
Sever hyperglycaemic & 51 & 7.9 & 29 & 4.5 & 21 & 3.2 \\
$>$ 20 mmol/dl & & & & & & \\
Problem laboratory & 1 & .2 & 12 & 1.9 & 29 & 4.5 \\
Not done & 10 & 1.5 & 99 & 15.3 & 202 & 31.2 \\
Total & 646 & 99.7 & 646 & 99.7 & 646 & 99.7 \\
Missing & 2 & .3 & 2 & .3 & 2 & .3 \\
Total & 648 & 100.0 & 648 & 100.0 & 648 & 100.0 \\
\hline
\end{tabular}




\section{Bar chart}
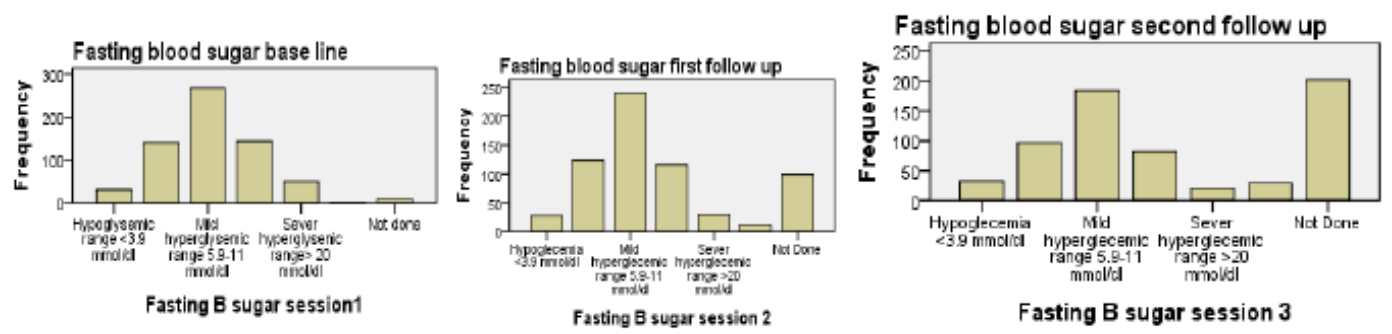

\section{Pie chart}

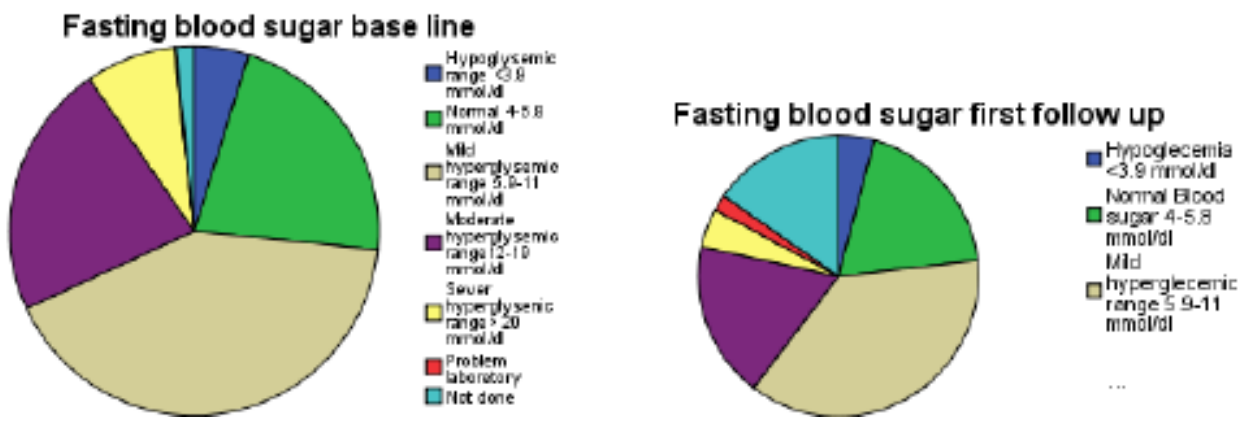

\section{Effect of education diabetes and control of}

b. Sugar

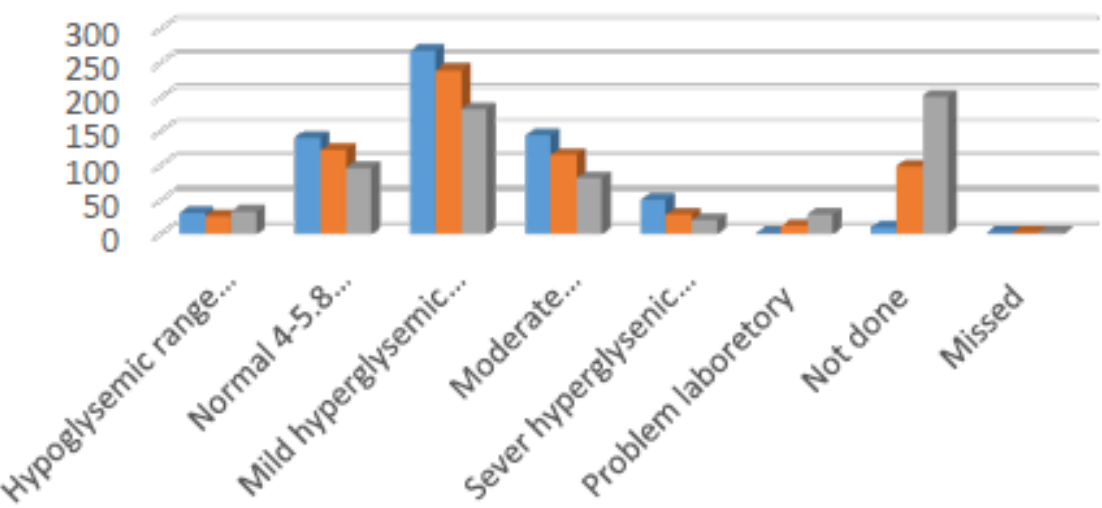

Base line Fallow up 1 Fallow up 2 
Texila International Journal of Medicine

Volume 4, Issue 2, Dec 2016

\section{Effect of education of diabetes on control of}
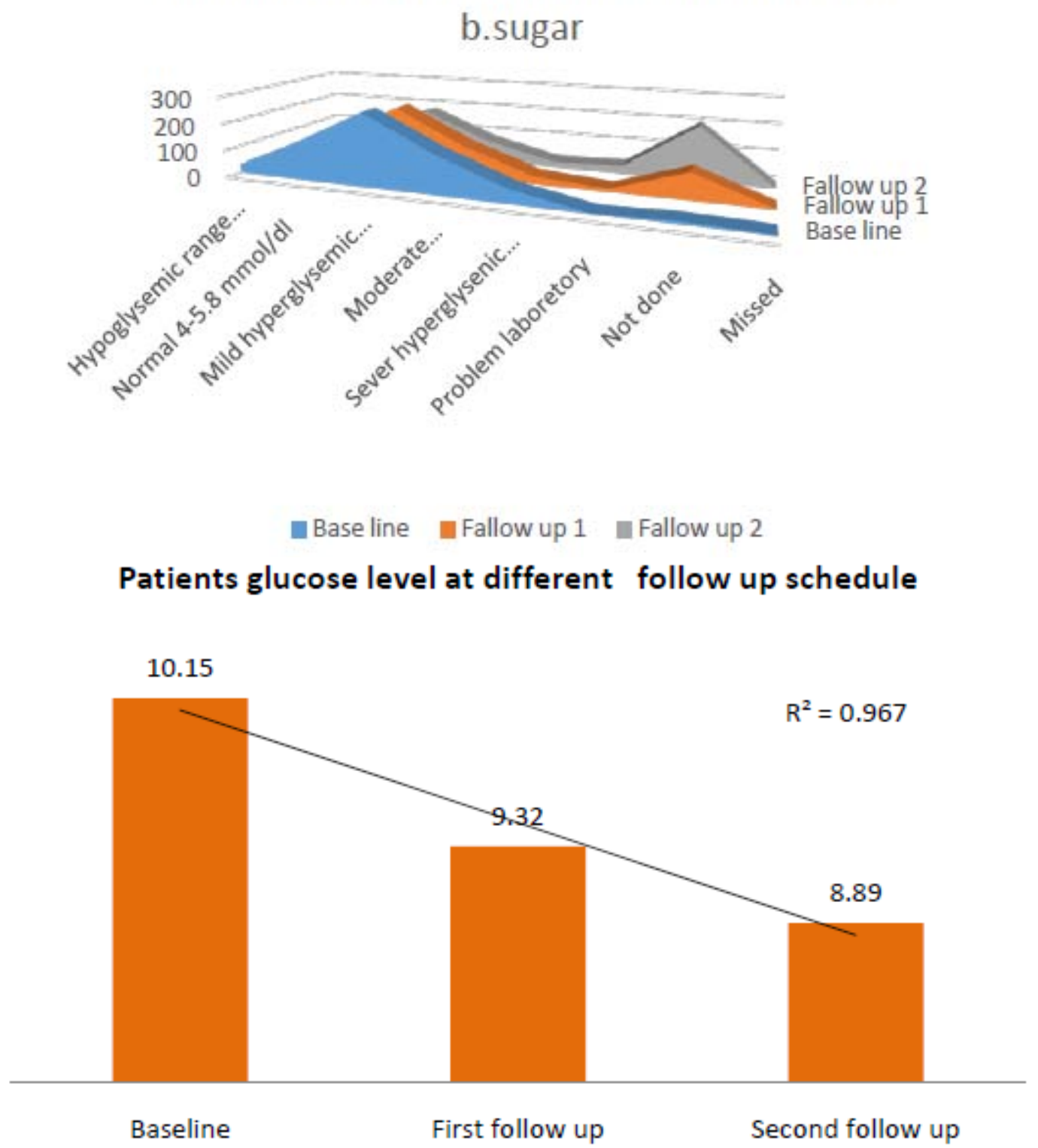

Figures 4. Pie chart, bar chart and linear chart: In the above charts we see the distribution of comparing fasting blood sugar scores at baseline, first follow up, and second follow up after diabetes education among participants.

\section{Summary table of descriptive statistics mean and standard deviation}

A sample of 648 patients with diabetes mellitus, who had participated in educational sessions regarding diabetes, was taken for study in order to determine the effect of education on improving outcomes in diabetes. The mean and standard deviation were calculated using plan coding, without grouping into categories. For the evaluation of the average systolic blood pressure baseline was $131.02 \mathrm{mmHg}(\mathrm{SD}=24.35 \mathrm{mmHg})$, and the average diastolic blood pressure baseline was $71.73 \mathrm{mmHg}(\mathrm{SD}=14.66 \mathrm{mmHg}$ ). The average systolic blood pressure at the first follow up was $121.98 \mathrm{mmHg}(\mathrm{SD}=22.01 \mathrm{mmHg}$ ) with an average diastolic blood pressure at the first follow up of $68.26 \mathrm{mmHg}(\mathrm{SD}=12.83 \mathrm{mmHg}$ ). The average systolic blood pressure at the second follow up was $120.95 \mathrm{mmHg}(\mathrm{SD}=19.95 \mathrm{mmHg})$, with an average diastolic blood pressure at the second follow up of $68.79 \mathrm{mmHg}(\mathrm{SD}=11.33 \mathrm{mmHg}$ ). As seen from baseline to the second follow up, a gradual decrease in both systolic and diastolic blood pressure was observed. When comparing the average serum creatinine concentrations from 
baseline to the second follow up, the baseline average was $93.62 \mathrm{umol} / \mathrm{l}(\mathrm{SD}=61.19 \mathrm{umol} / \mathrm{l})$, with an average of $89.83 \mathrm{umol} / \mathrm{l}(\mathrm{SD}=52.64 \mathrm{umol} / \mathrm{l})$ at the first follow up and $88.03 \mathrm{umol} / \mathrm{l}$ $(\mathrm{SD}=43.44 \mathrm{umol} / \mathrm{l})$ at the second follow up. Therefore, a gradual fall in serum creatinine from baseline to the second follow up was observed. When comparing the average blood urea concentration from baseline to the second follow up, the average urea concentration was found to be $4.66 \mathrm{mmol} / \mathrm{l}(\mathrm{SD}=4.14 \mathrm{mmol} / \mathrm{l})$ at baseline, $4.86 \mathrm{mmol} / \mathrm{l}(\mathrm{SD}=4.86 \mathrm{mmol} / \mathrm{l})$ at the first follow up and $4.30 \mathrm{mmol} / \mathrm{l}(\mathrm{SD}=1.80 \mathrm{mmol} / \mathrm{l})$ at the second follow up. Therefore, a small rise in the blood urea concentration was initially seen, which was then followed by a decrease in average concentration at the second follow up. The average fasting blood glucose concentration at baseline was $10.15 \mathrm{mmol} / \mathrm{dl}(\mathrm{SD}=6.00 \mathrm{mmol} / \mathrm{dl})$, at the first follow up 9.32 $\mathrm{mmol} / \mathrm{dl}(\mathrm{SD}=5.17 \mathrm{mmol} / \mathrm{dl})$, and at the second follow up $8.89 \mathrm{mmol} / \mathrm{dl}(\mathrm{SD}=5.19 \mathrm{mmol} / \mathrm{dl})$. Therefore, a gradual decrease in the fasting blood glucose concentration was observed from baseline to the second follow up.

Table 6. Descriptive statistics mean and standard Deviation of variables

\section{Descriptive Statistics Mean and standard Deviation}

\begin{tabular}{lll} 
& Mean & Std. Deviation \\
\hline Systolic blood pressure base line & $131.02 \mathrm{mmHg}$ & $24.35 \mathrm{mmHg}$ \\
Diastolic blood pressure base line & $71.73 \mathrm{mmHg}$ & $14.66 \mathrm{mmHg}$ \\
Systolic blood pressure first fallow up & $121.98 \mathrm{mmHg}$ & $22.01 \mathrm{mmHg}$ \\
Diastolic blood pressure first fallow up & $68.26 \mathrm{mmHg}$ & $12.83 \mathrm{mmHg}$ \\
Systolic blood pressure second follow up & $120.95 \mathrm{mmHg}$ & $19.95 \mathrm{mmHg}$ \\
Diastolic blood pressure second follow up & $68.79 \mathrm{mmHg}$ & $11.33 \mathrm{mmHg}$ \\
Blood glucose base line & $10.15 \mathrm{mmol} / \mathrm{dl}$ & $6.00 \mathrm{mmol} / \mathrm{dl}$ \\
Blood glucose first follow up & $9.32 \mathrm{mmol} / \mathrm{dl}$ & $5.17 \mathrm{mmol} / \mathrm{dl}$ \\
Blood glucose second follow up & $8.89 \mathrm{mmol} / \mathrm{dl}$ & $5.19 \mathrm{mmol} / \mathrm{dl}$ \\
Serum creatinine base line & $93.62 \mathrm{umol} / \mathrm{l}$ & $61.19 \mathrm{umol} / \mathrm{l}$ \\
Serum creatinine first follow up & $89.83 \mathrm{umol} / \mathrm{l}$ & $52.64 \mathrm{umol} / \mathrm{l}$ \\
Serum creatinine second follow up & $88.03 \mathrm{umol} / \mathrm{l}$ & $43.441 \mathrm{umol} / \mathrm{l}$ \\
Blood urea base line & $4.66 \mathrm{mmol} / \mathrm{l}$ & $4.14763 \mathrm{mmol} / \mathrm{l}$ \\
Blood urea first follow up & $4.86 \mathrm{mmol} / \mathrm{l}$ & $4.55 \mathrm{mmol} / \mathrm{l}$ \\
Blood urea second follow up & $4.30 \mathrm{mmol} / \mathrm{l}$ & $1.80 \mathrm{mmol} / \mathrm{l}$ \\
\hline
\end{tabular}

\section{ANOVA and regression analysis}

In order to examine the effect of diabetes education on the control of diabetes a multiple linear regression was conducted. This allowed an assessment of the control of fasting blood sugar concentrations at baseline as a dependent variable, with the independent variables of baseline blood pressure, blood urea, and creatinine.

The results of the linear regressions were significant $(\mathrm{F}(7,637)=2.44, \mathrm{P}=.018$, $\mathrm{R} 2=.026$ ), suggesting that fasting blood sugar levels at baseline and baseline blood pressure, accounted for $2.6 \%$ of variance in the control of fasting blood sugar levels. The individual predictors were then examined; it was found that fasting blood sugar level was a significant predictor for diabetic control $(\mathrm{B}=1.94, \mathrm{P}<.001)$, suggesting that for each unit increase in baseline fasting blood sugar concentration, the other variables of baseline urea increased by 1.94 units. Baseline post-test score was not found to be significant predictors for the control of fasting blood sugar levels. 
Texila International Journal of Medicine Volume 4, Issue 2, Dec 2016

A post hoc Turkey test showed that baseline BMI when compared with the dependent variable, were significant $(\mathrm{P}=.05)$ at baseline and follow up for fasting blood sugar levels 
:

पै त

콣ำ

营目

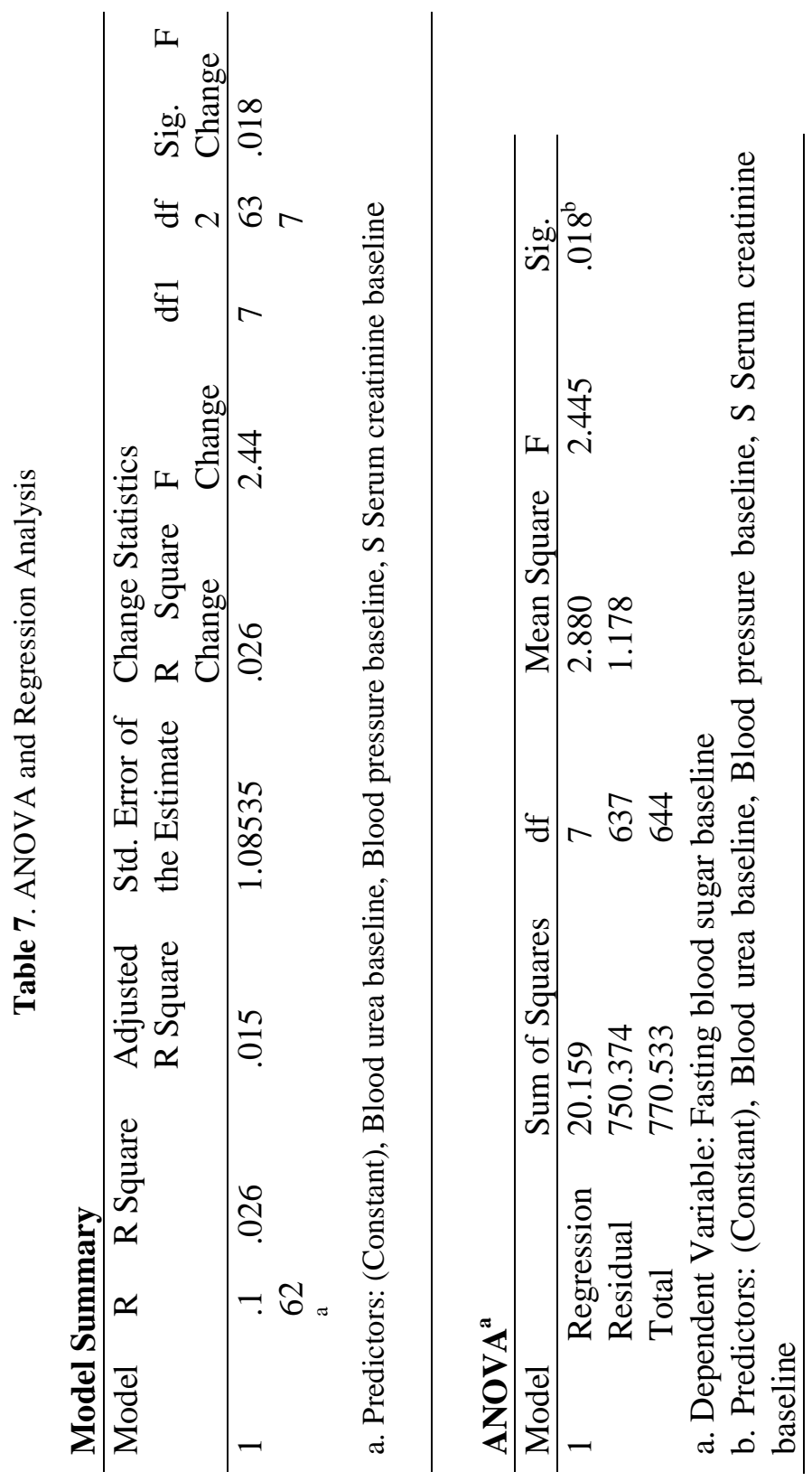


Texila International Journal of Medicine

Volume 4, Issue 2, Dec 2016

\section{Baseline session}

\section{First follow up}

In order to examine the effect of diabetes education on the control of diabetes mellitus and on the occurrence of complications, a multiple linear regression was conducted to assess the control of fasting blood sugar levels at the first follow up as a dependent variable with the independent variables blood pressure at the first follow up.

The result of the linear regression was significant $(F(7, .673)=52.34, P<.001$, $\mathrm{R} 2=.365$ ), suggesting that blood pressure, blood urea and creatinine accounted for $36.5 \%$ of the variance observed in the control of fasting blood sugar levels at the first follow up. The individual predictors examined further revealed that fasting blood sugar was a significant predictor for diabetic control $(\mathrm{B}=0.42, \mathrm{P}<.001)$, suggesting that for each unit increase at the first follow up of fasting blood sugar levels, the other variables of blood pressure, blood urea and creatinine, increased by 0.42 units at the first follow up. The post-test score was not found to be significant predictors for the control of fasting blood sugar.

A post hoc Turkey test showed that, at the first follow up, blood pressure, blood urea and creatinine, when compared with the dependent variable of blood sugar concentration at the first follow up were significant $(\mathrm{P}=.005)$. 


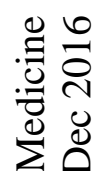

पै

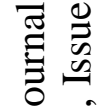

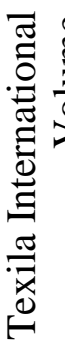

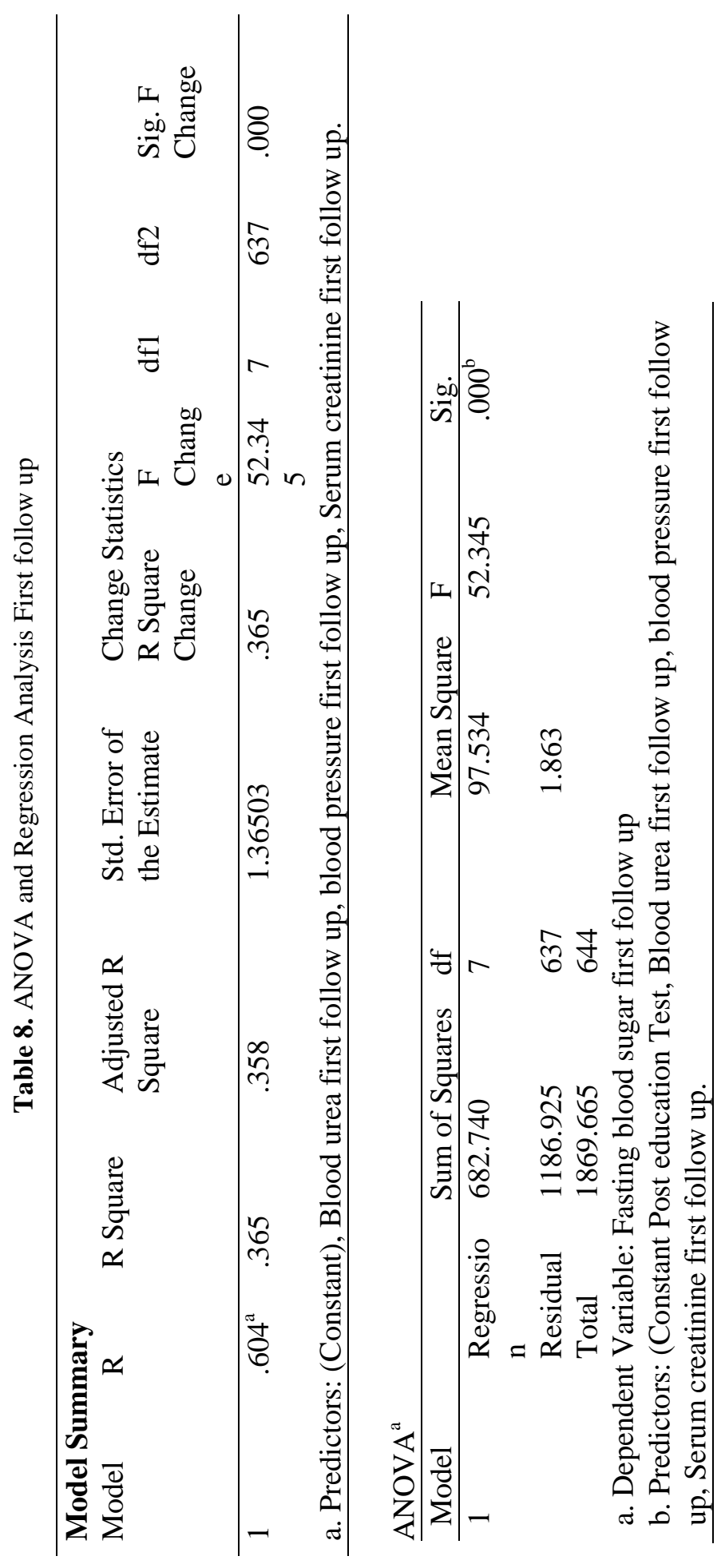


Texila International Journal of Medicine

Volume 4, Issue 2, Dec 2016

\section{Second follow up}

In order to examine the effect of diabetes education on diabetes control and on the incidence of complications, a multiple linear regression was conducted. This allowed the assessment of the control of fasting blood sugar levels at the second follow up as a dependent variable with the independent variables at the second follow up of blood pressure, blood urea and creatinine.

The results of the linear regression were significant $(F(8,632)=66.37, P<.001$, $\mathrm{R} 2=.450$ ), suggesting that at the second follow up, blood pressure, blood urea and creatinine accounted for $45 \%$ of the variance in the control of fasting blood sugar levels. The individual predictors examined further identified fasting blood sugar as a significant predictor for diabetic control $(\mathrm{B}=-.165, \mathrm{P}<.001)$, suggesting that for each unit decrease at the second follow up of fasting blood sugar concentration, the other variables of blood pressure, blood urea and creatinine, decreased by -.165 units at the second follow up.

A post hoc Turkey test showed that, at the second follow up, blood pressure, blood urea and creatinine when compared with the dependent variable of fasting blood sugar concentration at the second follow up, were significant $(\mathrm{P}=.005)$. 


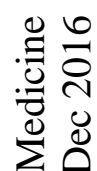

ชิ

㽬

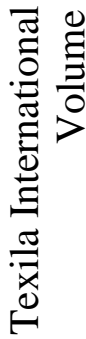

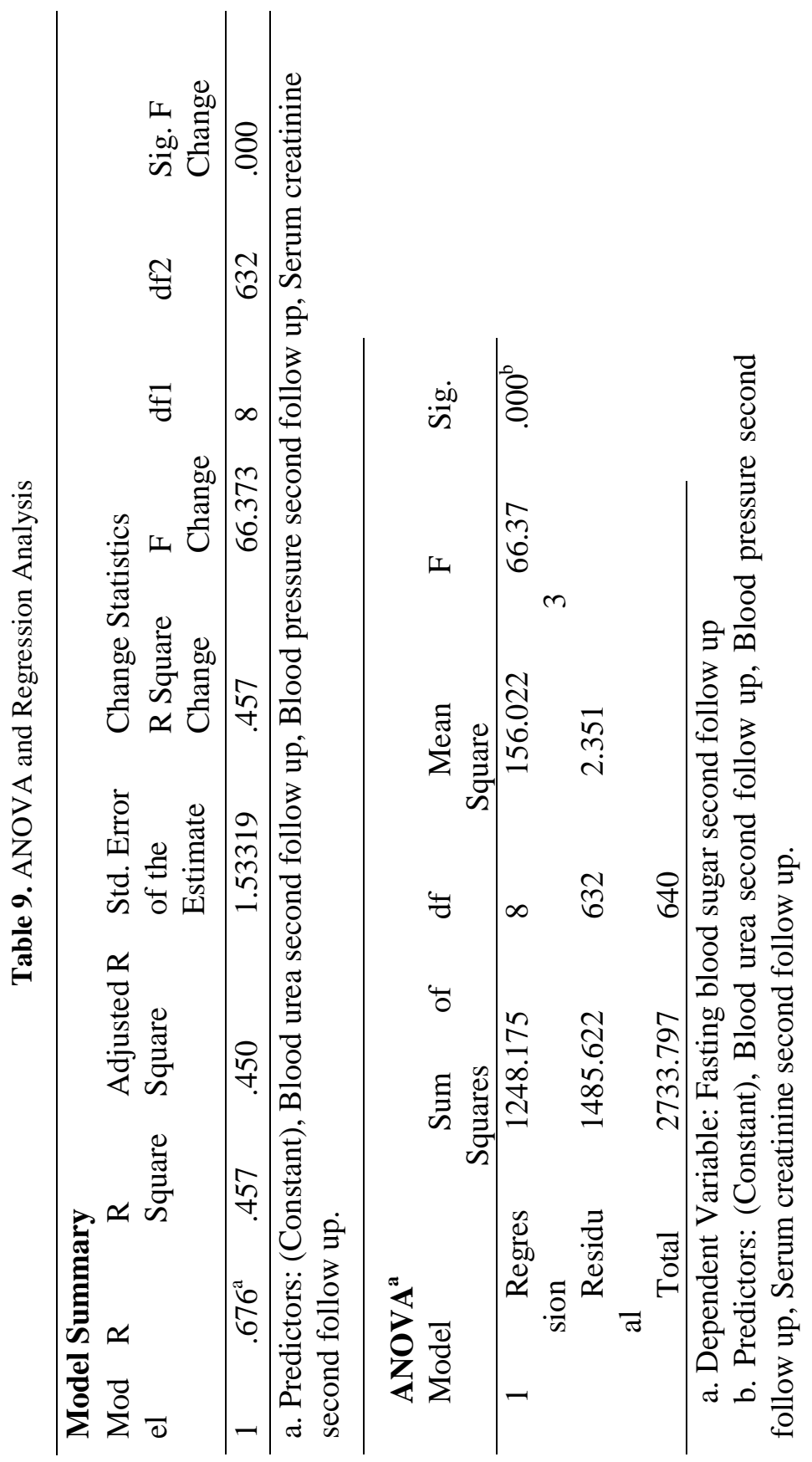


Texila International Journal of Medicine

Volume 4, Issue 2, Dec 2016

\section{Summary of main findings}

A sample of 648 participants was taken for this study. This study was conducted on regular patients of the diabetic outpatient department of the Central Hospital of Nampula. The study investigated the effects of three sessions of the diabetes education program (baseline, first follow-up and second follow-up) on each patient at one-month intervals. The inclusion criteria for participating in the diabetes education program dictated that patients should be in the OPD, willing to participate in the education sessions and willing to give consent to be included in the study. Participants were excluded if they had already completed three sessions of education or if they lived in a district that made it impossible for them to return within one month to the next education session. Amongst the group instructors were a diabetologist, dietician, psychologist, physiotherapist, and diabetic nurse. There was a pre-test questionnaire that aimed to assess the existing knowledge of diabetes before starting the baseline education session. The same questions were asked after the completion of the second follow-up education session. There were various variables to assess from baseline to second follow up education session. The variables were assessed age groups, body mass index, and fasting blood sugar.

Table 10. Regression, ANOVA analysis and post hoc Turkey test:

\begin{tabular}{|c|c|}
\hline \multicolumn{2}{|l|}{ Base line } \\
\hline linear regression & $\begin{array}{l}\text { Significant } \mathrm{F}(7,637)=2.44, \mathrm{P}<=.018, \mathrm{R} 2= \\
.026\end{array}$ \\
\hline The individual predictor & $\begin{array}{l}\mathrm{B}=1.94 \mathrm{P}<.000 \text { suggest that for every one } \\
\text { unit increase of baseline fasting blood sugar, } \\
\text { the other variables baseline increase } 1.94 \\
\text { Unit, }\end{array}$ \\
\hline Post hoc Turkey test & $\begin{array}{l}\text { Baseline compared with dependent variable } \\
\text { baseline follow up fasting blood sugar } \\
\text { significant } \mathbf{P}<.05 \text {. }\end{array}$ \\
\hline \multicolumn{2}{|l|}{ First follow up } \\
\hline linear regression & $\begin{array}{l}\text { significant, } \mathrm{F}(7, .673)=52.34, \mathrm{P}<=.000, \mathrm{R} 2= \\
.365 \mathrm{R} 2=.365\end{array}$ \\
\hline The individual predictor & $\begin{array}{l}\mathrm{B}=0.42 \mathrm{P}<.001 \text { suggest that for every one } \\
\text { unit increase of first follow up fasting blood } \\
\text { sugar, the other variables first follow up } \\
\text { Blood pressure, blood creatinine and urea } \\
\text { increase } 0.42 \text { Unit, }\end{array}$ \\
\hline Post hoc Turkey test & $\begin{array}{l}\text { Blood pressure, blood creatinine and urea } \\
\text { compared with dependent variable first } \\
\text { follow up blood sugar are significant } \mathbf{P}< \\
\mathbf{. 0 0 5} \text {. }\end{array}$ \\
\hline \multicolumn{2}{|l|}{ First follow up } \\
\hline linear regression & $\begin{array}{l}\text { significant, } \mathrm{F}(7, .673)=52.34, \mathrm{P}<=.000, \mathrm{R} 2= \\
.365 \mathrm{R} 2=.365\end{array}$ \\
\hline
\end{tabular}




\begin{tabular}{|c|c|}
\hline The individual predictor & $\begin{array}{l}\mathrm{B}=-.165 \mathrm{P}<.001 \text { every one unit decrease of } \\
\text { second follow up fasting blood sugar, the } \\
\text { other variables second follow up Blood } \\
\text { pressure, blood creatinine and decrease }-.165 \\
\text { Unit } \\
\text { Blood pressure, blood creatinine and urea } \\
\text { compared with dependent variable first } \\
\text { follow up blood sugar are significant } \mathbf{P}< \\
\mathbf{. 0 0 5} \text {. }\end{array}$ \\
\hline \multicolumn{2}{|l|}{ Second follow up } \\
\hline linear regression & $\begin{array}{l}\text { significant, } \mathrm{F}(8,632)=66.37, \mathrm{P}<=.000, \mathrm{R} 2= \\
.450\end{array}$ \\
\hline The individual predictor & $\begin{array}{l}\mathrm{B}=0.42 \mathrm{P}<.001 \text { suggest that for every one } \\
\text { unit increase of first follow up fasting blood } \\
\text { sugar, the other variables first follow up } \\
\text { Blood pressure, blood creatinine and urea } \\
\text { increase } 0.42 \text { Unit, }\end{array}$ \\
\hline Post hoc Turkey test & $\begin{array}{l}\text { Second follow up Blood pressure, blood } \\
\text { creatinine compared with dependent variable } \\
\text { second follow up fasting blood sugar are } \\
\text { significant } \mathbf{P}<\mathbf{. 0 0 5} \text {. }\end{array}$ \\
\hline
\end{tabular}

\section{Discussion}

The present study found that educational intervention was highly effective in controlling blood pressure, as these had significantly decreased from baseline at the second patient follow up visit. Metabolic control (blood sugar, urea and creatinine) also showed a significant positive improvement from baseline at the second follow up visit. The knowledge provided by the education helped the participants to improve and change their lifestyle, especially their dietary and exercise habits, their psychological adjustment and their attitude to living with diabetes.

Similar studies have previously been performed, with some comparable findings being reported. Newly diagnosed diabetic patients need self-management education, as this helps to increase their level of knowledge of diabetes and to provide them with skills to manage their diabetes life long, as it is a chronic condition (American Diabetes Association, 2014). A Cochrane review (Deakin, 2009) concluded that a reduction in blood sugar concentrations, and increased knowledge of diabetes. A Cochrane review (Deakin, 2009) concluded that through group education of diabetes patients get motivated, start adherence to treatment and understand diabetes. Meta analyses and the outcome of various studies have shown positive impacts after receiving diabetes education, and enhanced knowledge of diabetes has been presented by Ricci-Cabello et al. (2014). In order to promote diabetes awareness, self-care behaviors can be useful. Choi et al. (2016) described innovative strategies for the improvement of diabetic control and glycemic improvement in Chinese patients through the continuing education of diabetes mellitus during patient examination and by increasing family involvement via diabetic knowledge. Mollaoğlu et al. (2009) emphasized repeated diabetic education sessions to control and improve metabolic parameters. Salinero-Fort et al. (2011), using experimental and control groups regarding diabetes education. Salinero-Fort et al., 
Texila International Journal of Medicine

Volume 4, Issue 2, Dec 2016

(2011), taken an experimental and control group, pre and post education of diabetes, effects which showed reduced in Systolic and diastolic blood pressure. Pereira et al., (2014), explained that education of diabetes assists in controlling metabolic control, reduction of blood pressure in the intervention group.

\section{Conclusion}

Diabetes mellitus is a chronic and progressive disease, the prevalence of which is rapidly increasing. Uncontrolled diabetes mellitus may cause severe and irreversible untreatable complications, such as cardiovascular disease, retinopathy, nephropathy and cataract development. There is therefore a need to control anthropometric and metabolic parameters within an acceptable range in order to avoid the development of complications.

Currently, it is not only wealthy countries that have a high prevalence of diabetes mellitus; low and mid-level economic counties are also progressively showing an increase in the prevalence of diabetes mellitus. This includes Mozambique, which shows a progressive increase in the number of patients with diabetes mellitus due to the lack of a healthy diet, a sedentary life style and urbanization. Regarding patients with diabetes mellitus in a central hospital in Nampula, it was recognized that there was a need to organized education concerning diabetes, such as regarding the diabetic diet, increasing patient knowledge of diabetes to avoid the risks of complications, physical activity and its importance, and the psychological motivation to live with diabetes.

Diabetes education was performed with general and specific groups of patients according to the needs of the patients, the complications of the diabetes mellitus and other diseases associated with them. Three education sessions were organized, at an interval of one month (baseline, first follow up and second follow up). Each participant was evaluated in each session regarding their blood pressure, blood sugar, urea and creatinine. The statistical analysis showed strong significantly positive effects on controlling each of these parameters.

\section{Motivational quote}

"Exercise and diet can help prevent or even totally reverse metabolic conditions like diabetes and cardiovascular disease - only thing is you've got to catch them young... You know, while these conditions are still of 'impressionable minds'!”

- Deepak 'The Fitness Doc' Hiwale

There is currently a need to design a national policy and program for diabetes education. Clinicians and health educators should continue to reemphasize that patients with diabetes mellitus make healthy behavioral changes in order to control their diabetes and reduce the occurrence of complications.

The limitations of this study include that some of the diabetic patients used traditional medications, some did not adhere to treatment, and some were lost to follow up, all of which can cause uncontrollable diabetes and increase the incidence of complications. Patients were very interested in taking medicine free of charge in a government hospital. Limitations were also found here, such as the intermittent non-availability of the results of blood sugar, urea and creatinine results due to a lack of laboratory reagents. Patients who lived district, distance from the hospital, were not able to regularly attend three education sessions. Patients were more interested in obtaining medication than on lifestyle modification. Patients were generally from a poor or lower income group, and were unable to buy the recommended food. It was also noted that some patients had an insufficient economic condition to take small and frequent meals. Some of the patients presented with a delayed diagnosis, with irreversible complications.

One of the strengths of this study is that patients, at the commencement of educational sessions, were encouraged to participate and to bring laboratory results and other activities to the follow up sessions by reminding them that they would receive prescription medicine at the end of the successful completion of all of the essential activities involved in the education sessions. This encouraged patients to take a further interest in the study, and the majority of 
these patients then implemented the required changes in their lives and achieved positive significant outcomes in controlling their diabetes.

\section{Contribution to knowledge}

This study adds to the current body of knowledge regarding lifestyle modification and patient knowledge of diabetes. The education provided in this study allowed patients to understand diabetes and to control and minimize related complications.

\section{Suggestion for future research}

However, a need remains to involve other departments in future studies, for example emergency and intensive care medicine, district hospitals and effect of education of diabetes of family members to control the diabetic of patient, in order to see effect of education of diabetes to improve the knowledge of diabetes in public for primary prevention of diabetes in society.

\section{References}

[1]. Association, A. D. (2002). Standards of medical care for patients with diabetes Mellitus. Diabetes Care, 25(suppl 1), 33-49. doi:10.2337/diacare.25.2007.S33In-line Citation:(Association, 2002)

[2]. Abdullah M., 2012, 'Effects of the diabetes education program on metabolic Control among Saudi type 2 diabetic patients', Pakistan Journal Medical Science 2012 Vol. 28 No. 5 www.pjms.com.pk 925930 (2012), viewed pjms.com.pk/index.php/pjms/article/view File//954

[3]. Braun, A., Sämann, A., Kubiak, T., Zieschang, T., Kloos, C., Müller, U.A., Oster, P., Wolf, G. and Schiel, R. (2008) 'Effects of metabolic control, patient education and initiation of insulin therapy on the quality of life of patients with type 2 diabetes mellitus', Patient Education and Counseling, 73 (1), pp. 50-59. doi: 10.1016/j.Pec.2008.05.005. In-text citations: (Braun et al., 2008)

[4]. Burke, S., Sherr, D. and Lipman, R. (2014) 'Partnering with diabetes educators to improve patient outcomes', Diabetes, metabolic syndrome and obesity: targets and therapy., 7, pp. 45-53. In-text citations: (Burke, Sherr, and Lipman, 2014)

[5]. BJMP (2009) Impact of diabetes education and peer support group on the metabolic parameters of patients with diabetes Mellitus (type 1 and type 2). Available at: http://www.bjmp.org/content/impactdiabetes-education-and-peer-support-group-metabolic-parameters-patients-diabetes-mellitus-type-1and-type-2 (Accessed: 14 August 2016). In-text citations: (BJMP, 2009)

[6]. Chrvala, C., Sherr, D. and Lipman, R. (2015) 'Diabetes self-management education for adults with type 2 diabetes mellitus: A systematic review of the effect on glycemic control', Patient education and counseling., 99 (6), pp. 926-43. In-text citations: (Chrvala, Sherr, and Lipman, 2015)

[7]. Choi, T.S.T., Davidson, Z.E., Walker, K.Z., Lee, J.H. and Palermo, C. (2016) 'Diabetes education for Chinese adults with type 2 diabetes: A systematic review and meta-analysis of the effect on glycemic control', Diabetes Research and Clinical Practice, 116, pp. 218-229. doi: 10.1016/j.diabres.2016.04.001.In-text citations: (Choi et al., 2016)

[8]. Center, J. D. (2016, August 14). Diabetes education: Why it's so crucial to care. Retrieved August 14, 2016, from http://www.joslin.org/info/diabetes_education_why_its_so_crucial_to_care.htmlIn-line Citation: (Center, 2016)

[9]. Diabetes Education Study Group (1977) History. Available at: http://www.desg.org/desg/about/history/ (Accessed: 14 August 2016). In-text citations: (DESG, 1977)

[10]. Disclaimer, I. D. F. (2015). Mozambique. Retrieved August 29, 2016, from http://www.idf.org/membership/afr/mozambiqueIn-line Citation:(Disclaimer, 2015)

[11]. Ellis, S.E., Speroff, T., Dittus, R.S., Brown, A., Pichert, J.W. and Elasy, T.A. (2004) 'Diabetes patient education: A meta-analysis and meta-regression', Patient Education and Counseling, 52 (1), pp. 97-105. doi: 10.1016/S0738-3991(03)00016-8. In-text citations: (Ellis et al., 2004)

[12]. 5.5 general diabetes self-management and education (2016) Available at: https://www.icsi.org/guideline_sub-pages/diabetes/55_general_diabetes_self-

management_and_education/ (Accessed: 14 August 2016).In-text citations: (5.5 general diabetes selfmanagement and education, 2016) 
Texila International Journal of Medicine

Volume 4, Issue 2, Dec 2016

[13]. Kent, D., Melkus, D., Stuart, P., McKoy, J., Urbanski, P., Boren, S., Coke, L., Winters, J., Horsley, N., Sherr, D. and Lipman, R. (2013a) 'Reducing the risks of diabetes complications through diabetes self-management education and support', Population health management., 16 (2), pp. 74-81. In-text citations: (Kent et al., 2013a)

[14]. Moattari, M., Ghobadi, A., Beigi, P. and Pishdad, G. (2012) 'Impact of self management on metabolic control indicators of diabetes patients', Journal of Diabetes \& Metabolic Disorders, 11 (1), p. 6. doi: 10.1186/2251-6581-11-6. In-text citations: (Moattari et al., 2012)

[15]. Mollaoğlu, M. and Beyazıt, E. (2009) 'Influence of diabetic education on patient metabolic control', Applied Nursing Research, 22 (3), pp. 183-190. doi: 10.1016/j.apnr.2007.12.003. In-text citations: (Mollaoğlu and Beyazit, 2009)

[16]. MakkiAwouda, F., Elmukashfi, T. and Al-Tom, H. (2014) 'Effects of health education of diabetic patient's knowledge of diabetic health centers, Khartoum State, Sudan: 2007-2010', Global journal of health science, 6 (2), pp. 221-6. In-text citations: (MakkiAwouda, Elmukashfi, and Al-Tom, 2014)

[17]. Merakou, K., Knithaki, A., Karageorgos, G. and Theodoridis, D. (2015) 'Group patient education: Effectiveness of a brief intervention in people with type 2 diabetes mellitus in primary health care in Greece: A clinically controlled trial', Health Education Research, 30 (2), pp. 223-232. doi: 10.1093/her/cyv001.In-text citations: (Merakou et al., 2015)

[18]. Mash, B., Levitt, N., Steyn, K., Zwarenstein, M. and Rollnick, S. (2012) 'Effectiveness of a group diabetes education program in underserved communities in South Africa: Pragmatic cluster randomized control trial', BMC Family Practice, 13 (1). doi: 10.1186/1471-2296-13-126. In-text citations: (Mash et al., 2012)

[19]. Mendes, G., Nogueira, J., Reis, C., Meiners, D. and Dullius, J. (2016) 'Diabetes education program with emphasis on physical exercise promotes significant reduction in blood glucose, HbA1c and triglycerides in subjects with type 2 diabetes: A community-based quasi-experimental study', The Journal of sports medicine and physical fitness., In-text citations: (Mendes et al., 2016)

[20]. Norris, S., Lau, J., Smith, S., Schmid, C. and Engelgau, M. (2002) 'Self-management education for adults with type 2 diabetes: A meta-analysis of the effect on glycemic control', Diabetes care., 25 (7), pp. 1159-71. In-text citations: (Norris et al., 2002)

[21]. Pereira, D.A., Ma, N., Costa, S.C., Luíza, A., Sousa, L., César, P., Jardim, V., Sanches, L. and Jardim, S. (2014) 'Effect of an educational intervention on the metabolic control of people with type 2 diabetes’, Journal of Diabetes Nursing, 18. In-text citations: (Pereira et al., 2014)

[22]. Ricci-Cabello, I., Ruiz-Pérez, I., Rojas-García, A., Pastor, G., Rodríguez-Barranco, M. and Gonçalves, D.C. (2014)`Characteristics and effectiveness of diabetes self-management educational programs targeted to racial/ethnic minority groups: A systematic review, meta-analysis and metaregression', BMC Endocrine Disorders, 14 (1), p. 60. doi: 10.1186/1472-6823-14-60. In-text citations (Ricci et al., 2014)

[23]. Retrieved August 29, 2016, from https://en.wikipedia.org/.../Geography_of_Mozambi. NDEP program overview. (2016, June 24). Retrieved August 29, 2016, from https:/www.niddk.nih.gov/health-information/health-communication-programs/ndep/about-ndep/ndepoverview/Pages/ndep-overview.aspxIn-line Citation:(“NDEP program overview,” 2016)

[24]. Salinero-Fort, M., Santa, C., Arrieta-Blanco, F., Abanades-Herranz, J., Martín-Madrazo, C., Rodés-Soldevila, B. and Burgos-Lunar, de (2011) 'Effectiveness of PRECEDE model for health education on changes and level of control of HbA1c, blood pressure, lipids, and body mass index in patients with type 2 diabetes mellitus', BMC public health., 11. In-text citations: (Salinero-Fort et al., 2011)

[25]. Tidy, C. (2014b) Diabetes education and self-management programs. Patient. Available at: http://patient.info/doctor/diabetes-education-and-self-management-programmes (Accessed: 14 August 2016). In-text citations: (Tidy, 2014b)

[26]. zareban, I., Niknami, S. and Rakhshani, F. (2013) 'The effect of the self-efficacy education program on reducing blood sugar levels in patients with type 2 diabetes', Health Education \& Health Promotion, 1 (1), pp. 67-79. In-text citations: (zareban, Niknami, and Rakhshani, 2013) 


\title{
Efficacy of Sympathetic Radiofrequency in CRPS 1 Satellite Ganglion Block VS T2-T3 Sympathetic Block
}

\author{
Article by Jayesh Thakrar \\ Ph.D in Medicine by Research in Anesthesiology, Texila American University, India \\ Email:dr_thakrarjayesh@yahoo.co.in
}

\begin{abstract}
Background: This study is performed to evaluate the treatment of complex regional pain syndrome CRPS type 1 with radiofrequency thermo coagulation of stellate ganglion block and T2-T3 sympathetic block.

Material and methods: We performed diagnostic stellate ganglion block in all patient with CRPS TYPE 1 in one hand. Those patients reduce 50\% in pain score e.g. VAS SCORE, was considered for RF stelleate ganglion block after 1 week and this is GROUP 1. Those patients reduce less than 50\% pain score was considered for diagnostic T2-T3 sympathetic block after 1 week. Those patients reduce 50\% in pain score e.g. VAS SCORE, was considered for RF T2-T3 sympathetic block after 1 week and this is GROUP 2. Pain intensity using a visual analog score also assessed usage of analgesic dosages before and after RF in both groups.

Results: Treatment produced a significant decrease in pain score, VAS value in both groups and significant reduce the dosages of analgesic drugs in both groups.

Conclusion: The study of these 17 patients shows that there is chance of inadequate pain relief after satisfactory stellate ganglion block because of KUNTZ'S nerve and giving T2-T3 sympathetic block among this gives good pain relief. Also RF in stellate ganglion and T2-T3 sympathetic ganglion block gives long term pain relief and decrease analgesic dosages and thus improves quality of life.
\end{abstract}

Keywords: Complex regional pain syndrome type 1, Stellate ganglion block, T2-T3 sympathetic block, RF-radiofrequency, VAS score, analgesic drugs

\section{Introduction}

Complex Regional Pain syndrome (CRPS) 1 arises following trauma to a limb and is characterized by functional impairment in the affected body segment. It is associated with intense sensory, autonomic, motor and trophic changes, which are disproportionate to the inciting event and cannot be accounted for by other causes of chronic pain (1). Despite recent advances in the understanding of its pathophysiology, pain relief in CRPS remains a major challenge. This is partly due to the complexity of the mechanism underlying the maintenance of pain and the functional impairment present in this syndrome, but it is also related to the lack of evidence-based treatment trial specific for this condition (2). Most interventions used for CRPS relief are not supported by high quality evidence-based data (3). It is mainly diagnosed by IASP criteria (11)

\section{IASP diagnostic criteria for CRPS}

- The presence of an initiating noxious event or a cause of immobilization.

- Continuing pain, allodynia or hyperalgesia with which the pain is disproportionate to any inciting event.

- Evidence at some time of edema, changes in skin blood flow, or abnormal sudomotor activity in the region of pain.

- This diagnosis is excluded by the existence of conditions that would otherwise account for the degree of pain and dysfunction.

- TYPE I: Without obvious nerve damage \{aka RSD\}.

- TYPE II: With obvious nerve damage \{aka Causalgia\}. 
Texila International Journal of Medicine

Volume 4, Issue 2, Dec 2016

\section{Budapest diagnostic criteria for CRPS}

General Definition of the Syndrome

CRPS describes an array of painful conditions that are characterized by a continuing

(spontaneous and/or evoked) regional pain that is seemingly disproportionate in the time or degree to the usual course of any known trauma or other lesion. The pain is regional (not in a specific nerve territory or dermatome), but may spread, and usually has a distal predominance of abnormal sensory, motor, sudomotor, vasomotor, and/or trophic findings. The syndrome show variable progression over time.

To make clinical diagnosis, the following criteria must be met:

- Continuing pain, which is disproportionate to any inciting event.

- Must report at least one symptoms in 'three of the four' following categories:

- SENSORY: Reports of hyperalgesia and/or allodynia.

- VASOMOTOR: Reports of temperature asymmetry and/or skin color changes and/or skin color asymmetry.

- SUDOMOTR/EDEMA: Reports of edema and/or sweating changes and/or sweating asymmetry.

- MOTOR/TROPHIC: Reports of decreased range of motion and/or motor dysfunction (weakness, tremor, dystonia) and/or trophic changes (hair, nail, skin).

- Must display at least one sing at time of evaluation in two or more of the following categories:

- SENSORY: Evidence of hyperalgesia (to pinprick) and/or allodynia (to light touch and/or deep somatic pressure and/or joint movement).

- VASOMOTOR: Evidence of temperature asymmetry and/or skin color changes and/or skin color asymmetry.

- SUDOMOTR/EDEMA: Evidence of edema and/or sweating changes and/or sweating asymmetry.

- MOTOR/TROPHIC: Evidence of decreased range of motion and/or motor dysfunction (weakness, tremor, dystonia) and/or trophic changes (hair, nail, skin).

- There is no other diagnosis that better explains the signs and symptoms.

According to Sandroni incidence of CRPS I 5.46 new cases/100000 annually (18). According to IASP incidence is 25.2 new cases/100000 annually (18). Period prevalence is 20.57/100000 (18). Female: male was 4:1, mostly 50-70 year age with median age of 46 years at onset (19). Upper limb was affected twice as commonly as lower limb (19).

Even though the pathophysiology is not clearly defined (20). The syndrome may be mainly a systemic disease involving the central and peripheral nervous system, yet the specific interaction between the central and peripheral mechanisms is unclear 8 . The postulated mechanisms includes: Inflammation, Afferent dysfunction, Central dysfunction \& Sympathetic dysfunction.

CRPS is diagnosed by IASP Diagnostic criteria for CRPS \& "Budapest" Diagnostic criteria (11)

Limited understanding of the pathophysiology mechanism involved in the develop of CRPS and absence of clear objective diagnostic criteria, multimodal, multidisciplinary approaches requires to treat CRPS (19). Effective pain control: (1) pharmacologic (2) interventional methods by IVRA, Sympathetic nerve blocks and Spinal cord stimulation, Functional restoration, Rehabilitation-Based Treatment Modalities, Psychologic Interventions \& Other Therapeutic Modalities (5, 6, 7, 19)

Sympathetic nerve block has been used for treatment of CRPS since the beginning of the $20^{\text {th }}$ century (4). The technique that is most commonly used to target sympathetic innervations of the upper limbs is the stellate ganglion block (6, 8, and 10). Anatomical and clinical studies have suggested that this may not the most effective technique for upper limb sympathetic block 
$(4,12,13)$. Second order neurone cell bodies that supply the upper limb are located in the intermediolateral horn of the thoracic spinal cord. Preganglionic fibers ascend cephalad and synapse on postganglionic fiber, primarily in the $2^{\text {nd }}$ (and to a lesser extent in the 3rd) thoracic sympathetic ganglia, before ascending and passing through the stellate and the middle cervical ganglia, en route to the upper limb $(14,15)$. However, in $20 \%$ of the individual, nerves from these two thoracic sympathetic ganglia projects directly to the brachial plexus, by passing the upper stellate and middle cervical ganglia (14, 15, and 9). Thus different from SGB, which only influences nerve that actually passes through this structure before reaching the upper limb, TSB act directly on the main synapse site of most sympathetic fibers innervating this body segment $(14,15\}$. Despite this potential relevant anatomical information, TSB has rarely been evaluated in CRPS patients $(16,17)$.

\section{Methods}

This study is consisted of 15 patients attending to the Advance Pain Care Clinic, Surat, Gujarat, India from July 2015 to December 2015 with diagnosis of CRPS 1 in one hand.

The diagnosis is based on IASP-BUDAPEST criteria (11) with VAS $>4 / 10$ with failed conservative management (6weeks).

All 15 patients were examined and diagnosis of CRPS type 1, right side 8 and 7 left were included. 9 patients were women and 6 were men. Age of patients were between 18-85 years were included. The conditions associated with development of CRPS 1 includes lower end radius fracture, hand trauma, metacarpal fracture, soft tissue excision, carpel tunnel release and crush injury hand. All 15 patients are assessed and then explain about the procedure. Written informed consent was taken and all 15 patients were given diagnostic sympathetic block mainly stellate ganglion block. Pain intensity was evaluated before and after diagnostic block using a $10 \mathrm{~cm}$ VAS in which 0 means no pain and 10 represented most severe pain. More than 50\% reduction in VAS SCORE for at least 6 hours was considered as positive diagnostic block.

Among 18patients, 8 patients having positive stellete ganglion block, so these patients was considered for RF stellate ganglion block after 1 week and this consider as GROUP 1. 7 patients had negative stellate ganglion block so these 8 patients consider for T2-T3 sympathetic diagnostic block after one week. Among 7 patients, 3 patients having positive T2-T3 diagnostic block, so these patients was considered for RF T2-T3 sympathetic block after 1 week and this consider as GROUP 2. 4 patients had negative T2-T3 Sympathetic block, so these patients are considered as a sympathetic independent and these patients are exclude from the study. Selection of patients for RF for stellate ganglion block \& for T2-T3 sympathetic block was done after 1 week after the positive diagnostic block. In both group RF procedures were done same as diagnostic block.

All patients experienced more than 50\% pain relief after RF after 2 weeks and 1 month follow up. All patients were able to decrease their oral analgesic drugs dosage more than $50 \%$ after 1 month of RF and improved range of movement of wrist joint after 1 month of RF

No complications attritubuted to procedure were noted.

\section{Inclusion criteria}

- H/O trauma or surgery: Presence of regional pain and sensory changes following a noxious event, pain associated with finding such as abnormal skin, color, temperature changes, abnormal sudomotor activities or edema, no distribution of pain of a single nerve in extremities, The combination of these finding exceeding their expected magnitude in response to known physical damage during and following the inciting event.

- Patient had taken conservative treatment e.g. medication, physical therapy, rehabilitation programmed but failed to have pain relief.

- Any age

- Any sex 
Texila International Journal of Medicine

Volume 4, Issue 2, Dec 2016

- Patient is selected on basis of history, clinical examination, clinical diagnostic criteria and diagnostic block.

- Study is done for interventional pain management by RF, other modalities/therapies are not considered in comparison of two groups.

\section{Exclusion criteria}

- Upper limb CRPS II and lower limb CRPS.

- H/O nerve injury.

- Patient having other neuropathy like DM or other.

- Patients who has not taken conservative treatment.

- False negative block.

- Use of tobacco products or any medication that could affect sympathetic function

- Active infection at injection site

- Allergy to medication

- Previous neck surgeries, Reynaud's disease or phenomenon

- coagulopathy

Table 1. patient demographic values and etiologies

\begin{tabular}{|l|l|l|l|l|l|}
\hline No. & Age & Gender & Initial trauma & Side & $\begin{array}{l}\text { Duration } \\
\text { (weeks) }\end{array}$ \\
\hline 1 & 47 & F & Carpel tunnel release & L & 10 \\
\hline 2 & 56 & F & \# Lower end radius & L & 10 \\
\hline 3 & 48 & F & \#Lower end radius & L & 12 \\
\hline 4 & 85 & M & \#Lower end radius & R & 12 \\
\hline 5 & 52 & F & Radial distal end \# & L & 16 \\
\hline 6 & 62 & F & Carpel tunnel release & R & 22 \\
\hline 7 & 58 & M & Hand trauma & R & 26 \\
\hline 8 & 29 & M & Crush injury hand & R & 28 \\
\hline 9 & 32 & M & Metacarpal hand \# & R & 30 \\
\hline 10 & 73 & F & \#Lower end radius & L & 32 \\
\hline 11 & 43 & F & \#Lower end radius & R & 32 \\
\hline 12 & 74 & M & Metacarpal fracture & L & 33 \\
\hline 13 & 38 & F & Soft tissue release & L & 40 \\
\hline 14 & 45 & M & Hand trauma & R & 46 \\
\hline 15 & 70 & F & Radial distal end \# & R & 52 \\
\hline
\end{tabular}

\section{Results}

Table 2. vas score

\begin{tabular}{|l|l|l|l|}
\hline No. & Before block & After diagnostic SGB & After diagnostic TSB \\
\hline 1 & 7 & 2 & ----- \\
\hline 2 & 7 & 3 & ------ \\
\hline 3 & 8 & 4 & ------ \\
\hline 4 & 8 & 3 & ------ \\
\hline 5 & 8 & 4 & ------ \\
\hline 6 & 8 & 3 & ----- \\
\hline 7 & 9 & 3 & ----- \\
\hline 8 & 9 & 4 & ----- \\
\hline 9 & 8 & 6 & 3 \\
\hline 10 & 9 & 7 & 3 \\
\hline 11 & 10 & 8 & 3 \\
\hline 12 & 7 & 5 & 5 \\
\hline
\end{tabular}




\begin{tabular}{|l|l|l|l|}
\hline 13 & 9 & 6 & 6 \\
\hline 14 & 9 & 7 & 8 \\
\hline 15 & 8 & 6 & 7 \\
\hline
\end{tabular}

Table 3. shows patient's vas score rf stellet ganglionic block.

\begin{tabular}{|l|l|l|l|}
\hline PATIENT NO. & INITIAL VAS & 2 WEEKS AFTER RF & 1 MONTH AFTER RF \\
\hline 1 & 7 & 3 & 3 \\
\hline 2 & 7 & 3 & 2 \\
\hline 3 & 8 & 4 & 2 \\
\hline 4 & 8 & 3 & 2 \\
\hline 5 & 8 & 4 & 2 \\
\hline 6 & 8 & 2 & 3 \\
\hline 7 & 9 & 4 & 3 \\
\hline 8 & 9 & 3 & 3 \\
\hline
\end{tabular}

Table 4. shows patient's vas score rf t2-t3 sympathetic block.

\begin{tabular}{|l|l|l|l|}
\hline PATEINT NO. & INITIAL VAS & 2 WEEKS AFTER RF & 1 MONTH AFTER RF \\
\hline 1 & 8 & 3 & 2 \\
\hline 2 & 9 & 3 & 3 \\
\hline 3 & 10 & 3 & 1 \\
\hline
\end{tabular}




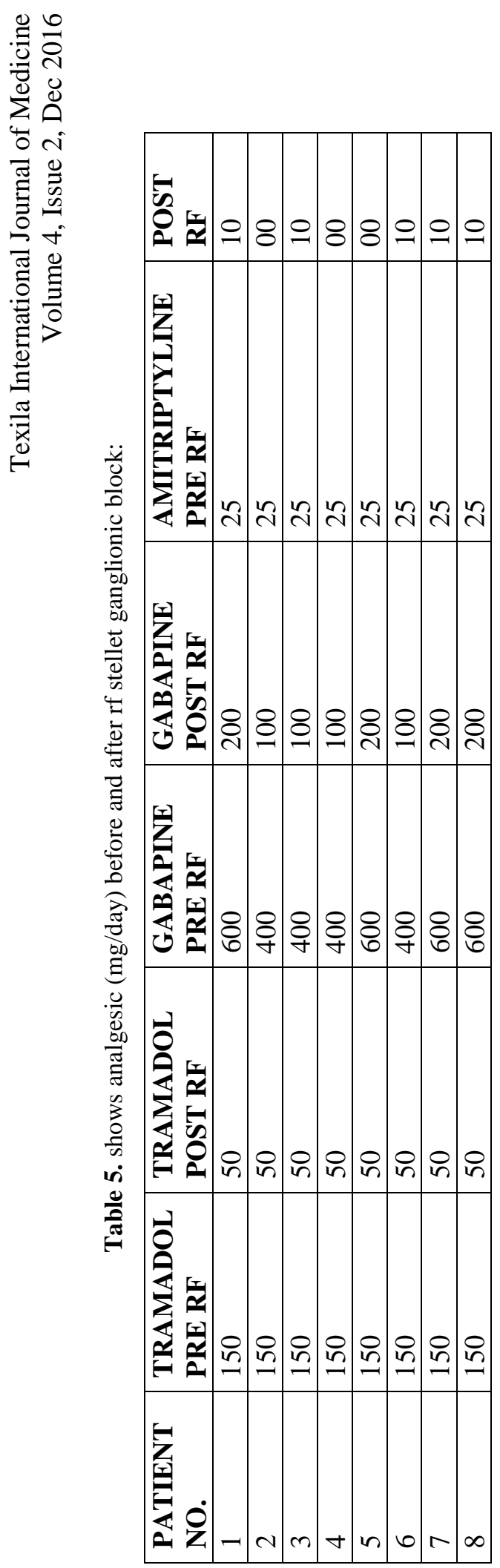




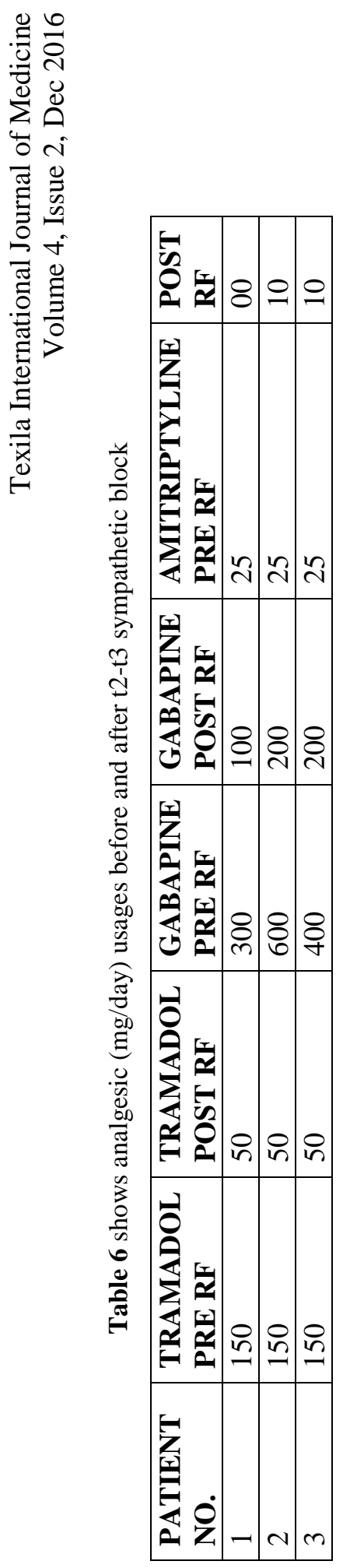


Values VAS score pretreatment and after diagnostic block are shown in table 1. Values VAS score after RF in both groups after 2 weeks and 1 month follow up are shown table 2 and table 3. Blockade significantly improved VAS values in all patients and in both groups, however there was difference in VAS value those patients in diagnostic T2-T3 sympathetic block where diagnostic stellate ganglion block was not effective. Values of analgesic dosages before and after RF in both groups are shown in table 4 and table 5. The blockade was significantly reduced in analgesic dosages in all patients in both groups.

Though it is not included in my study, I observed that wrist movement ROM was improved in all patients that are taken in study under all review article.

Limitation:

1. Comparison between Stellate Ganglion Block and T2-T3 block is not taking in study but efficacy is taken in study.

2. False positive and false negative block should not take in consideration.

3. Negative diagnostic block not take study

4. Long term follow up more than one month is not taken in study.

\section{Discussion}

- Invasive procedure, including nerve block, spinal cord and peripheral stimulation, chemical and surgical sympathetictomy and deep brain stimulation have been used to manage CRPS type 1 . Sympathetic nervous system dysfunction is presumed to be an essential component of the syndrome and sympathetic blockage has been recommended as early as possible to interrupt and reverse the process.

- The primary goal of study was to evaluate efficacy of sympathetic block in CRPS 1 and comparison among stellate ganglion block with T2-T3 block.

- Although several studies have indicated that conventional RF is good option for long term pain relief for upper limb CRPS I. Many studies support that sympathetic block is more superior in pain relief for CRPS I than somatic block, but very few studies were done regarding efficacy between two SYMPATHETIC BLOCK for upper limb CRPS I.

- According to sympathetic pain pathway and previous studies, suggestive that many patients of upper limb CRPS 1, having “Kuntz' nerves” that leads to limitation in pain relief after successful stellate block those patients are treated with successful T2-T3 block and thus decreases false negative results.

- Therefore comparative trials of two sympathetic blocks enhance scope to see pain relief and improvement quality of life of patients.

\section{Conclusion}

Invasive procedure, including nerve block, spinal cord and peripheral stimulation, chemical and surgical sympathetictomy and deep brain stimulation have been used to manage CRPS type 1.(11) Sympathetic nervous system dysfunction is presumed to be an essential component of the syndrome and sympathetic blockage has been recommended as early as possible to interrupt and reverse the process. Sympathetic block treatment may be particularly helpful in cases in which, despite adequate doses of oral medication, pain limits a patient participation in physical and occupational therapy.

Some study suggested that stellate ganglion may not be the most suitable target for upper limb sympathetic block in CRPS 1 . $(4,6,8,13)$. This suggestion is mainly due to fact that SGB may miss the sympathetic nerve fibers travelling to the upper limb in a significant proportion of individual (9). Thus by blocking T2-T3 sympathetic ganglion can cover all sympathetic fibers. In fact, Hogan(13) showed that in 100 consecutive technically well-performed SGB procedure monitored by papillary and hand temperature change, the clinically signs of upper limb sympathetic blockage were only detected after 27 of the procedure(13). Kuntz(9) has demonstrated that in $20 \%$ of individuals the ganglion sympathetic fibers 
projected to upper limb directly, thus bypassing the stellate ganglion after synapsing in the upper thoracic ganglia $(6,14,15)$ This is important given the major difference between TSB and SGB.

The study shows that there is chance of inadequate block after satisfactory stellate block and giving T2-T3 block among this gives good relief in such patients (19). Though posterior approach T2-T3 is more technically difficult than anterior stellate block, KUNTZ'S nerve can be reliably blocked only by a posterior approach $(14,19)$

I observed in my all study that pain score, dose of analgesic and wrist joint movement was significantly reduced in both group after RF but in comparison of both, reduction in VAS score almost similar after RF though RF T2-T3 may gives good and long term pain relief than anterior stellate block. But these require large sample size and long study period. Also CRPS is diagnosed only clinically. No laboratory test currently provides a gold standard for the diagnosis of CRPS. Following a thorough history and examination, test such as those testing for difference in skin temperature help to confirm diagnosis. But those patient having failed stellate ganglion block, T2-T3 sympathetic block gives good pain relief.

Conservative treatment like anticonvulsant and antidepressants should first line and opoids should be second line treatment to enhance pain control. Sympathetic block is more superior for pain relief in CRPS I and improve quality of life.

\section{References}

[1.] Agarwal-Kozlowski K, Lorke DE, Habermann CR, Schulte am Esch J, Beck H. Intervetnional management of intractable sympathetically mediated pain by CT guided catheter implantation for block and neuroablation of thoracic sympathetic chain: technical approach and review of 322 procedures. Anaesthesia 2011, 66. Pages 699-708.

[2.] Boas RA. Sympathetic nerve blocks: in search of a role: Reg Anasth Pain Med. 1998 May-June;23(3): 292305. Review.

[3.] Becker DE. Basic and clinical pharmacology of glucocorticosteroids. Anaesth Prog 2013 Spring; 60(1):2531; Review.

[4.] Bonica JJ, editor: The Management of Pain. Philadelphia, Lea \& Febiger, 1953 \& $4^{\text {th }}$ edition 2010.

[5.] Bonica JJ SCOTT editor, 4th edition 2010

[6.] Day M. Sympathetic blocks: the evidence Pain Pract. 2008 Mar-Apr; 8(2):98-109.

[7.] Elias M. Cervical sympathetic and stellate ganglion blocks. Pain physician. 2000. Jul; 3(3):294-304.

[8.] Fischer SG, Zuurmond WW, Birklein F, Loer SA, Perez RS. Anti-inflammatory treatment of Complex Regional Pain Syndrome. Pain 2010 Nov; 151(2) 251-256.

[9.] Goebel A. Complex regional pain syndrome in adults. Rheumatology (oxford). 2011 oct; 50(10):1739-1750.

[10.] Hogan QH, Erickson S J, Haddox JD, Abram SE. The spread of solution during stellate ganglion block. Reg. Anaesth 1992:17:78-83.

[11.] Hogan QH, Taylor ML, Goldstein M, Steven R, Kettler R. Success rates in producing sympathetic blockade by paratracheal injection. Clin J pain 1994 Jun; 10(2) 139-145

[12.] Harden RN, Oaklander AL, Burton AW, Perez RS, Richardson K, Swan M, Barthel J, Costa B, Graciosa JR, Bruehl S; Reflex Sympathetic Dystrophy Syndrome Association, Complex regional pain syndrome: practical diagnostic and treatment guidelines, $4^{\text {th }}$ edition. Pain Med. 2013 Feb; 14(2):180-229.

[13.] Kunzt A. Distribution of the sympathetic rami to the brachial plexus its relation to sympathectomy affecting the upper extremity. Arch Surg 1927:15:871-877.

[14.] Munts AG, van der Plas AA, Ferrari MD, Teeps-Twiss IM, Marinus J, Van Hilten JJ. Efficiency and safety of a single intrathecal methylprednisolone bolus in chronic complex regional pain syndrome. Eur J Pain. 2010 May;14(5):523-528.

[15.] O’Connell NE, Wand BM, McAuley J, Marston L, Moseley GL. Interventions for treating pain and disability in adults with complex regional pain syndrome. Cochrane Database Sys Rev. 2013 Apr 30;4:CD009416.

[16.] Raj PP, Lou L, Erdine S, Staats PS, Waldman SD: T2 \& T3 sympathetic nerve block and nerolysis, ch 22, pp 132-137, in Radiographic Imaging for Regional Anaesthsia and Pain Management 2003. 
Texila International Journal of Medicine Volume 4, Issue 2, Dec 2016

[17.] Rmsaroop L, Partab P Singh B, Satyapal KS. Thoracic origine of a sympathetic supply to the upper limb: the 'nerve of Kuntz' revisited J Anat 2001:199:675-682.

[18.] Raj's practicle management of pain 4th edition 2008

[19.] Shfali A, Broatch J, RAJA SN: Web-based epidemiological survey for CRPS-1 (poster). The American Society of anaesthesiologists, New Orleans, 2005.

[20.] Yoo HS, Nahm FS, Lee PB, Lee CJ. Early thoracic sumpathetic block improves the treatment effect for upper extremities neropathic pain. Anesth Analg. 2011 Sept;113(3):605-609. 


\title{
Hematoma Localization under Ultrasound-Guidance for Excision (HUGE) of Impalpable Breast Lesions, a Modification to make Screening Effective in Nigeria: Pilot study
}

\author{
Article by Agodirin SO ${ }^{1,2}$, Olatoke $\mathrm{SA}^{2}$, Rahman $\mathrm{GA}^{2}$, Akande $\mathrm{HJ}^{3}$, Habeeb OG ${ }^{2}$ \\ ${ }^{1}$ School of clinical research, Texila American University, Guyana, South America \\ ${ }^{2}$ Department of Surgery University of Ilorin Teaching Hospital \\ ${ }^{3}$ Department of Radiology University of Ilorin Teaching Hospital \\ Email: Cancer1992@yahoo.com ${ }^{1}$
}

\begin{abstract}
Background: Diagnosing and treating impalpable breast lesions is one of the greatest gains of screening and it is a game changer in winning against breast cancer. Screening must be complemented with availability of methods to handle impalpable lesions. At the least, impact of screening is considerably diminished and at worst, screening will be counterproductive or downright unethical if detected lesions cannot be diagnosed and treated, yet standard methods of handling impalpable lesions are not available or not sustainable in lowincome centers.

Objective: To make screening effective by finding cheap and sustainable method of localizing, diagnosing and treating impalpable breast lesions.

Method: Intra-operative ultrasound (USS) directed biopsy of impalpable breast lesions was modified so that the localization and operative procedure can be dissociated and performed with limited facility; Under USS-guidance at the radiology department, hematoma was formed around impalpable lesions by injecting 3-4mls of patient's own blood into them and incision placement was planned at the same time. Two to 3 days later, during open surgical procedure without intra operative USS-facility, the iatrogenic hematomas were found and excised. Primary measures of outcome were achievement of successful excision and histological diagnosis.

Result: Following walk-in screening, 5impalpable breast lesions visible to mammography and ultrasound were included. All 5 were successfully localized and excised. Histological diagnosis was reached in all 5 lesions.

Conclusion: This small volume pilot experience demonstrated how impalpable lesions can be handled in poor resource centers. The HUGE method allows flexibility of scheduling and lowers dependence on high technology.
\end{abstract}

Keywords: Hematoma localization, Impalpable, breast lesion, low-income

\section{Background}

Modern surgical practice of breast cancer management is witnessing detection and diagnosis of majority of lesions when they are still impalpable (1-3). The gains of diagnosing impalpable lesions includes reduction in the cost of treatment, availability of wider array of surgical treatment, minimization of trauma of treatment and remarkable increment in the chances of cure. These are incentives which will make orthodox care attractive.

Diagnosis and treatment of impalpable breast lesion is one of the major factors revolutionizing the outcome of breast cancer treatment in developed centers because of high rate of screening backed by facilities for excision of impalpable lesions such as wire localization biopsies, ultrasound guided biopsies, and various tissue marking guided biopsies(1-7).

In contrast, centers in developing countries are deficient in the capability to detect, localize, diagnose or treat impalpable lesions(8). The unfortunate implication of not possessing the capability to handle impalpable lesion(s) is having to wait until the lesions are 
Texila International Journal of Medicine

Volume 4, Issue 2, Dec 2016

clinically palpable, at which time the treatment becomes more difficult, more expensive, more mutilating and unattractive to patients(8) thus fueling vicious cycle of late presentation (912).

It is imperative that we find and demonstrate acceptable and attractive treatment options in order to reverse the trend of late presentation in developing centers(13). In addition to helping to tackle the poor trend of management outcomes, presence of effective and acceptable treatment options is a prerequisite before rolling out screening programs.

Therefore, a pilot research was designed with the goal of finding a relatively cheap and sustainable method of localization, diagnosis and treatment of impalpable breast lesions in a resource poor center. Success in our quest will make screening more effective and orthodox care more appealing. This article is a report of our experience in the pilot research; Hematoma localization under Ultrasound Guidance for Excision (HUGE) of impalpable breast lesions, a modification of hematoma directed ultrasound guided biopsy.

\section{Setting and method}

This pilot research was conducted in General surgery II division, department of Surgery and Radiology department of the University of Ilorin teaching Hospital, Ilorin Nigeria after satisfying ethical requirements.

Following walk-in breast screening using sonography (USS) and/or mammography (mammo), impalpable but sonographically detectable lesions adjudged to be suspicious were included in the research if diagnosis could not be reached by USS-guided fine needle biopsy(FNB). Patients whose lesions were palpable or whose diagnosis could be reached by FNB were excluded. Pregnant and lactating females were also excluded. One patient whose BI-RADS score was not suspicious but who had a family history of carcinoma of the breast in two siblings and one parent was included because she preferred excision of the lesion and to have a pathologic diagnosis rather than reassurance of sonographic score.

\section{Preoperative hematoma localization under sonographic guidance}

This was carried out in the radiology department with the surgeon in attendance 2-3 days before the proposed day of surgical excision. This flexibility of localization day fitted with the schedule of the sinologists (USS day) and the surgeon (surgical outpatient clinic day). The USS machine used was SONOACE X4 with probe frequency 7.5MHz. After US localization of the lesion, in terms of location in the breast when the areola was likened to the face of a clock, depth from the skin and distance from the areola, 3-4 mls of patient's own venous blood was injected into and around the lesion using the hollow trocar of an 18G intravenous cannula. The point of insertion was cleansed with alcohol and numbed with lidocaine injection. Antiseptic lotion was used to reduce contamination and as an acoustic coupling agent. Prophylactic antibiotics were not given.

\section{Surgical localization and excision technique}

All excisions were performed under local anesthesia with adrenaline containing lidocaine injection. A transverse directly overlying skin incision was placed based on the prior planning during the sonographic localization 2-3days earlier. After making appropriate length incision on the skin, 2-3 cm of skin flap was raised in all directions, subcutaneous layer and superficial breast parenchyma was parted or cleared (figure1) after sagittal and cruxiate incisions were made to access the deeper tissue and visualize the area of hematoma formation. The identified hematoma was completely excised with a rim of normal tissue (figure2). The specimen was tagged for appropriate orientation and sent for histology.

Attempt was made to reconstruct the normal contour of the breast by local tissue advancement flap. Hemostasis was secured, the skin was close with nylon 2/0 interrupted mattress suturing and firm bandaging was applied for 3days. All cases were performed as day case, none of the patients had prophylactic antibiotic and drains were not inserted in any of 
the patients. The wounds were inspected on day 3, sutures were removed on $10^{\text {th }}$ postoperative day

Measures of Outcome. The primary measures of outcome was "yes" or "no" response to whether the surgeon was able to find and excise the hematoma (lesion) without USS-guidance and whether histologic diagnosis was reached. The occurrence of postoperative complications was secondary measure of outcome

\section{Results}

Between July 2014 and August 2016, 5 patients fit the inclusion criteria. The age range was 38-53. Four lesions were on the left while one was on the right. Excision was successful in all cases. Histologic diagnosis was reached in all cases and excision was therapeutic in all cases. Early postoperative complications ensued in 4 of the 5 patients, one had late complication (mild distortion of the areola). None of the lesions was malignant. (table 1)

Table1

\begin{tabular}{|c|c|c|c|c|c|}
\hline Age & Side & location & Clinical comments & histology & $\begin{array}{l}\text { Postoperative } \\
\text { complications }\end{array}$ \\
\hline 38 & Right & central & $\begin{array}{l}\text { ?Genetic predisposition; } \\
\text { Mother and one sibling } \\
\text { died of CAB } \\
\text { Living sibling } \\
\text { diagnosed of CAB } \\
\text { Ultrasound detected } \\
\text { lesion } \\
\text { BI-RADS III (excision } \\
\text { preferred) }\end{array}$ & $\begin{array}{l}\text { Fibrocystic } \\
\text { changes }\end{array}$ & $\begin{array}{l}\text { SSI } \\
\text { Wound } \\
\text { dehiscence } \\
\text { Mild distortion }\end{array}$ \\
\hline 50 & left & UOQ & $\begin{array}{l}\text { Blood discharge } \\
\text { Mammographic } \\
\text { calcifications } \\
\text { Architectural distortion } \\
\text { BI-RADS IV } \\
\end{array}$ & $\begin{array}{l}\text { Intra-ductal } \\
\text { papilloma } \\
\text { Fibrocystic } \\
\text { changes }\end{array}$ & Nil \\
\hline 53 & left & UOQ & $\begin{array}{l}\text { BIRAD IV } \\
\text { Excision advised }\end{array}$ & Fat necrosis & $\begin{array}{l}\text { SSI } \\
\text { Wound } \\
\text { dehiscence }\end{array}$ \\
\hline 49 & left & UOQ & $\begin{array}{l}\text { BI-RADS IV } \\
\text { Excision advised }\end{array}$ & $\begin{array}{l}\text { Fibrocystic } \\
\text { changes }\end{array}$ & SSI \\
\hline 43 & left & UOQ & $\begin{array}{l}\text { BI-RADS IV } \\
\text { Excision advised }\end{array}$ & $\begin{array}{lr}\text { Breast cyst lined } \\
\text { with chronic } \\
\text { inflammatory cells }\end{array}$ & Bruising \\
\hline
\end{tabular}

$\mathrm{CAB}=$ Carcinoma of the breast 
Texila International Journal of Medicine

Volume 4, Issue 2, Dec 2016

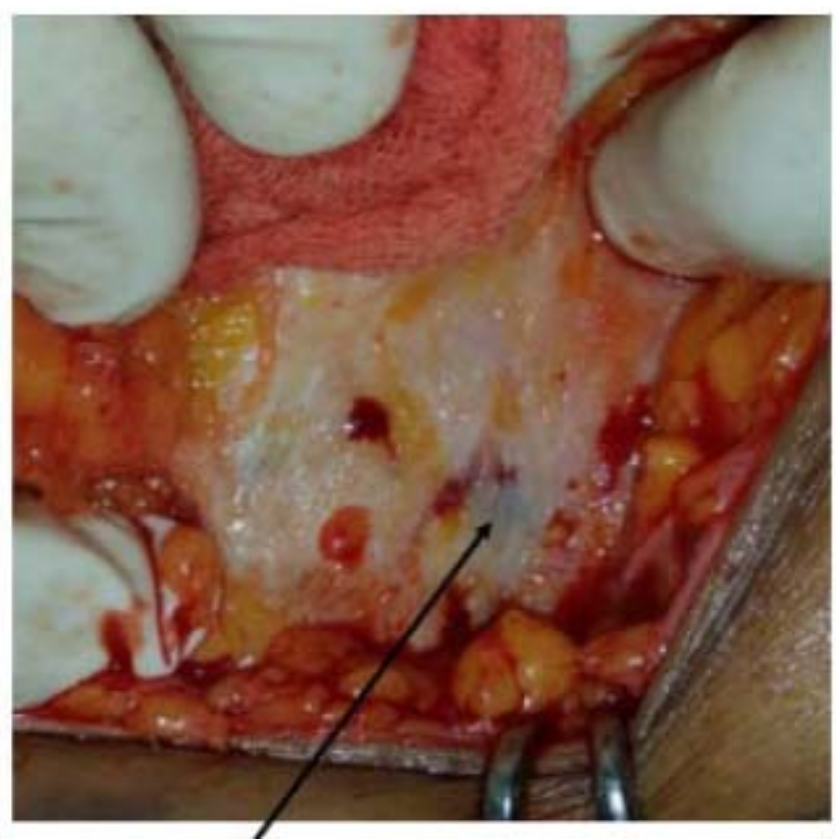

Figure1

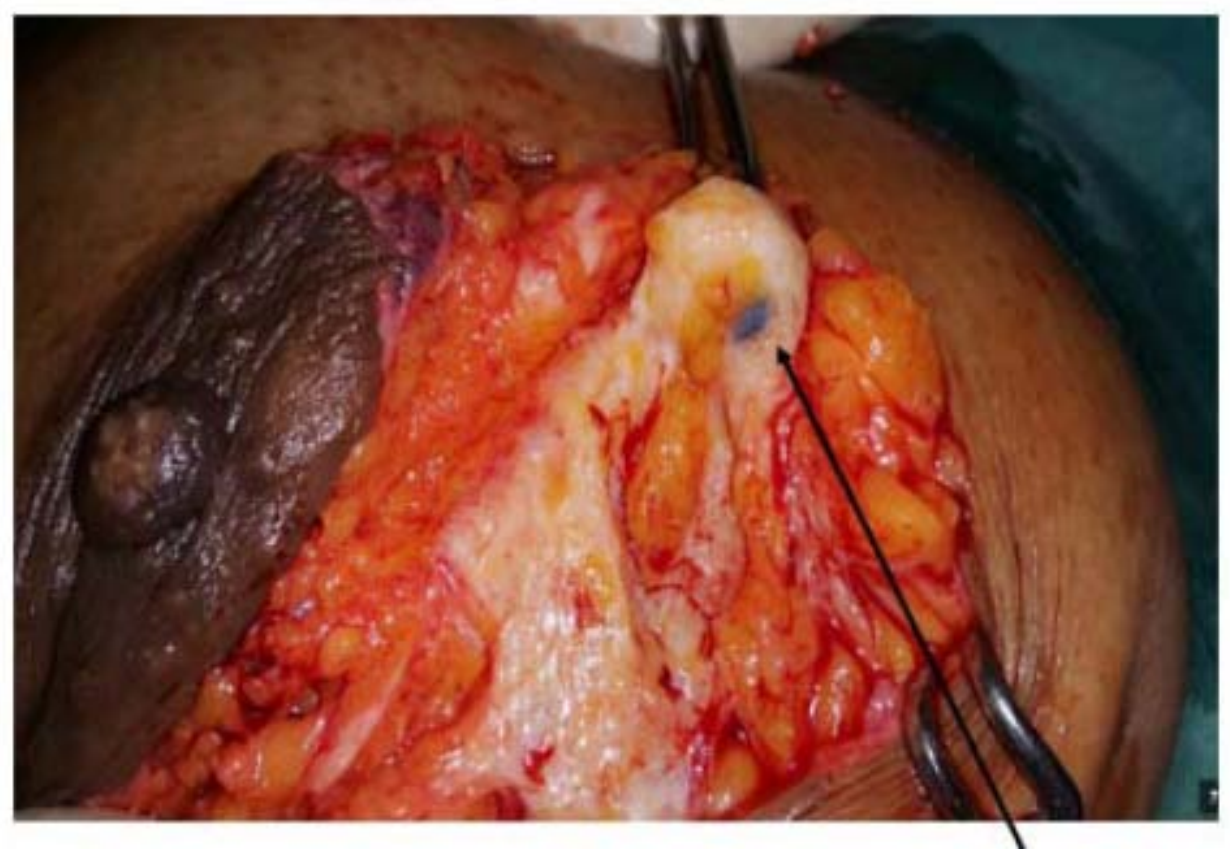

Figure 2

\section{Discussion}

Screening to diagnose and treat impalpable lesions is a game changer in winning against breast cancer. Screening should be complemented with ability to diagnose and treat detected lesions. At the least, the impact of screening is diminished and at the worst, screening will be counter-productive or downright unethical if detected lesions cannot be correctly diagnosed and treated. Sensitive screening will increase diagnosis of suspicious and impalpable lesions and create the need to localize them for planned surgical removal. The need to find means of handling impalpable lesions combined with the goal of achieving breast conservation to complement screening in low in-come centers necessitated this study.

Wire localized biopsy is the gold standard for handling impalpable lesions, other methods of handling impalpable lesions are ultrasound directed biopsies and use of various tissue 
staining techniques. The standard methods which require sophisticated facilities and tight coordination of multiple specialists are not yet achievable nor sustainable in most resource poor centers. Previously documented less demanding techniques of excising impalpable lesions which can be implemented in developing centers include the use of methylene blue and the use of charcoal suspension (5). Both methods do not require intraoperative ultrasound. The methylene blue method still relies on a rather tight schedule while the charcoal suspension gives a lot of room (5). Both methods have the advantage of leading a trail to the lesion in contrast to the active search described for HUGE in this study, but both staining methods will not unmask the location of impalpable mammographically detected lesion(s) to sonography.

Advances in the USS techniques should be priority in resource poor countries where mammography, MRI and stereotactic procedures are not readily available. The increased utility of breast conserving surgery as fallout of these small facets of advancement in developing centers will aid acceptance of orthodox treatment. However, concern remains over the specificity of patient selection and risk of over treatment as was demonstrated in this study. Capacity building and researches centering on correlation between clinical, radiologic and pathologic features should reduce risks of these concerns. Nonetheless, we should note that over-diagnosis/over-treatment are forced compromises and are challenges in the management of impalpable breast lesions in many places where mammographic screening take center stage $(7,14)$

In this study, impalpable breast lesions were excised from the breasts of 5 women. four of the lesions had BI-RADS IV score by mammo and USS assessment, one of the lesions scored BI-RADS III but had a strong family history of breast cancer and wished to have pathologic diagnosis. All excised lesions were benign on histology. The HUGE method was successful in non-technologically aided surgical excision of the impalpable lesions. Pathologic definitive diagnosis was reached in all cases and excision was therapeutic in all cases. There is however a need to improve specificity of patient selection. The complication rate in this study was high, this is likely to improve on the learning curve and with addition of adjuncts such as prophylactic antibiotics.

In this pilot study, the volume of patients used was small. This was because of our stringent selection criteria and the underutilization of screening facilities by the populace. One other demerit of the technique is that it was a relatively blind. Even though the hematomas were formed in and around the lesions and were completely excised with rim of normal tissue, there was no immediate confirmation of complete excision.

An invaluable merit we identified is the decentralization or dissociation of the process. The flexibility whereby localization can be concluded at a separate time and in a separate space and then excision can be completed at another time and space with allowance of 2-3 days interval addresses the problem of limited time allowable on the limited space and facility. This makes it easier to achieve multidisciplinary care without clash of schedules and without owning the space, facility or expertise. This is a significant advantage over the requirements of wire localized biopsy we reported in Nigeria previously (15). In the later, after wire localization, the excision must be immediately performed and the radiologist will be on standby for immediate repeat mammography to confirm excision.

Although this was a pilot study of an evolving method, there are areas of prospect. The immediately foreseeable prospect it holds is possibility of unmasking mammographically detectable but sonographically undetectable lesions. In this scenario, a small unmaskinghematoma may be created stereotactically (at mammography), the small hematoma will reveal the location of the lesion to sonography and then the HUGE process can proceed on the unmasking-hematoma.

The cause of poor outcome of breast cancer management in developing centres is hydraheaded. However, a major contributory factor is aversion for mastectomy $(12,16)$. Hence, locally sustainable methods which promote less mutilating surgical intervention will 
Texila International Journal of Medicine

Volume 4, Issue 2, Dec 2016

undoubtedly support the necessary changes required to improve the outcome of care in developing centers.

\section{Conclusion}

This small volume pilot experience demonstrated how impalpable lesions can be detected, localized, diagnosed and treated in poor resource centers. The HUGE method uncouples the process so that flexibility is possible in scheduling and intraoperative high technologic facilities are not absolute requirements.

\section{References}

[1]. Adamczyk B, Murawa P. Preoperative localization of nonpalpable breast nodules-which method to choose? Reports of Practical Oncology and Radiotherapy. 2008:201-4.

[2]. Ahmad S, Ginawi AE, Sabbagh S. DEDICATED BREAST CANCER MANAGEMENT CENTRES WITH. FACILITIES FOR FULL IMAGE-GUIDED ASSESSMENT AND IMAGEGUIDED SURGERY IN THE DEVELOPING AREAS OF PAKISTAN--A LONG OVERDUE NECESSITY. Journal of Ayub Medical College, Abbottabad : JAMC. 2015;27(1):251-4.

[3]. Agodirin O, Olatoke S, Rahman G, Adeoti M, Oyeyemi G, Durojaiye A, et al. How effective is the treatment of locally advanced and metastatic breast cancer in Developing centers; A retrospective review Ethiop J Health Sci. 2015;25(4):338-44.

[4]. Anyanwu SN, Egwuonwu OA, Ihekwoaba EC. Acceptance and adherence to treatment among breast cancer patients in Eastern Nigeria. Breast. 2011;20 Suppl 2:S51-3.

[5]. Alikhassi A, Ahmadinejad N, Sedighi N, Najafi M. Stereotactic breast core needlel biopsy in a tertiary breast center of tehran University of Medical sciences Arch Breast Cancer. 2015;2 (1):21-6.

[6]. Agodirin SO, Ojemakinde OM, Bello TO, Oguntola AS, Aremu AA, Ojemakinde KO, et al. Ultrasound-guided wire localization of lesions detected on screening mammography in Osogbo, Nigeria and its impact on breast conservative surgery. Ann Afr Med. 2012;11(2):91-5.

[7]. Akanbi oO, A. Adeoti, M. Aderounmu, A. Idris, O. Abayomi, O. Delay presentation of breast cancer: A study among south western Nigerian women. International Journal of Current Research. 2015;7.

[8]. Blumencranz PW, Ellis D, Barlowe K. Use of hydrogel breast biopsy tissue markers reduces the need for wire localization. Ann Surg Oncol. 2014;21(10):3273-7.

[9]. Chan BK, Wiseberg-Firtell JA, Jois RH, Jensen K, Audisio RA. Localization techniques for guided surgical excision of non-palpable breast lesions. The Cochrane database of systematic reviews. 2015 (12):Cd009206.

[10]. Egwuonwu O, Anyanwu S, Ihekwoaba E, Chianakwana G, Iloabachie I. Pattern of presentation and adherence to treatment in young breast cancer patients Orient Journal of Medicine. 2013;25 (12):14-8.

[11]. Ko K, Han BK, Jang KM, Choe YH, Shin JH, Yang JH, et al. The value of ultrasound-guided tattooing localization of nonpalpable breast lesions. Korean Journal of Radiology. 2007; 8 (4):295-301.

[12]. Mascaro A, Farina M, Gigli R, Vitelli CE, Fortunato L. Recent advances in the surgical care of breast cancer patients. World J Surg Oncol. 2010;8:5.

[13]. Memon MA, Berstock DA. Ultrasound-guided excision of impalpable mass breast lesion. Annals of The Royal College of Surgeons of England. 1996;78 (1):61-2.

[14]. Masroor I, Afzal S, Shafqat G, Rehman H. Usefulness of hook wire localization biopsy under imaging guidance for nonpalpable breast lesions detected radiologically. International Journal of Women's Health. 2012;4:445-9.

[15]. Ogundiran TO, Ayandipo OO, Ademola AF, Adebamowo CA. Mastectomy for management of breast cancer in Ibadan, Nigeria. BMC Surgery. 2013;13:59.

[16]. Sule E. Breast conservation for T3/T4 Tumors in a developing country. wjpmr. 2016;2 (4):39-42. 


\title{
Duodenal Carcinoid with Cystic Hepatic Metastasis Presenting with Severe Anemia and Heart Failure
}

\author{
Article by Chenna Keshava BG ${ }^{1}$, KNN Anand ${ }^{2}$, Ashwin Kulkarni ${ }^{3}$, Anil Kumar T ${ }^{4}$, \\ ${ }^{1}$ Consultant Intensivist, ${ }^{2}$ Post graduate student Dept. Of Medicine, ${ }^{3}$ Asst. Professor, \\ ${ }^{4}$ Professor of Medicine, M.S. Ramaiah Medical College Bangalore, Karnataka, India \\ E-mail: ${ }^{1}$ ckeshava7@gmail.com
}

\begin{abstract}
Introduction: Carcinoid tumours are neoplasms of neuroendocrine cells with varying symptoms and malignant potential. Cystic hepatic metastasis secondary to carcinoids is a rare entity. There are very few reports in literature (around four as of date) and all have been in relation to ileal carcinoid or post chemotherapy. Most of the carcinoids present with diarrhoea, flushing, pruritis. Severe anemia as presenting symptom is rare.

Case report: Herein we describe a 66 year old gentleman who presented with severe anemia and heart failure. An OGD (Oesophago gastro duodenal endoscopy) done as part of anemia work-up revealed multiple, duodenal, centrally umbilicated nodules. Histopathology and special stains (chromogranin \& synaptophysin) confirmed it to be Grade 1 Neuroendocrine tumour (carcinoid) with a Ki-67 index of less than 2\%. CECT abdomen showed two small cystic lesions, the largest one measuring $2 \times 3 \mathrm{cms}$. Anemia was corrected and patient improved symptomatically. He was placed on conservative management for Neuroendocrine tumours and is on regular follow up.

Discussion: In this case patient presented with severe anemia and heart failure. He had no other symptoms like flushing, diarrhoea. The rarity of this case is the presence of cystic hepatic metastasis and presentation with severe anemia. This is the first case reported in which a duodenal carcinoid is diagnosed during the workup for anemia. Here another interesting and rare feature is the presence of cystic hepatic metastasis which is quite unusual.

Case report: A 66 year old male, known case of CVA not on treatment, hypertensive on treatment admitted with history of progressive easy fatigability, progressive bilateral lower limb swelling, decreased appetite for 15 days. Patient denied history of diarrhea, vomiting, melena or hematochezia, diabetes, hypertension or cardiac problems .Physical examination revealed pallor, bilateral pitting pedal oedema, raised JVP, with pansystolic murmur at tricuspid area, S3 with bilateral basal crepitations and rhonchi with tender right hypochondrium. His initial workup revealed hemoglobin of $4.3 \mathrm{gm} / \mathrm{dl}$ and peripheral blood smear showed microcytic hypochromic anaemia. Liver and kidney functions were within normal limits with a serum albumin of $3.4 \mathrm{mg} / \mathrm{dl}$. $2 D$ ECHO revealed dilated $R A, R V$ with a severe tricuspid regurgitation (TR) with PASP of $70 \mathrm{mmHg}$. LVEF 56\%,No RWMA, mild MR \& AR. Oesophago-gastro duodenoscopy(OGD) revealed multiple duodenal nodules with central umbilication in D1,D2,D3 with largest measuring $2 \times 3 \mathrm{~cm}$ (?Carcinoid) and was biopsied for histopathological examination(HPE) (fig 1). Contrast enhanced computerised tomography $(C E-C T)$ thorax and abdomen revealed enlarged liver $(15.5 \mathrm{~cm})$ with two well defined non enhancing cystic lesions in segments $4 A$ of liver (measuring 36x31×32 mm and $8 \times 9 \times 4 \mathrm{~mm}$ ) and pyloric and duodenal wall thickening suggesting a possibility neoplastic etiology(fig 2). HPE (Fig 3) revealed well differentiated neuroendocrine tumor (WHO grade1) with EMA, synaptophysin, chromogranin positive and a Ki-67 index: of 2\%. Patient transfused with three pint of packed RBC and was symptomatically better, In view of the low grade of the NETs patient is on regular follow up
\end{abstract}

\section{Discussion}


Texila International Journal of Medicine

Volume 4, Issue 2, Dec 2016

Neuroendocrine tumors (NETs), also known as Carcinoids, originally Karzinoide in 1907; (=Cancer like, not the preferred terminology anymore except in case of NETs of lung and thymus) are a heterogeneous group of relatively rare neoplasms arising from the diffuse neuroendocrine system. The clinical and pathologic features resemble both the organ of origin and neuroendocrine neoplasms. WHO (2010) has classified (Table 1) NETs based on site of origin, clinical syndrome and differentiation(1). They are classified as functional and nonfunctional, based on their secreted products. Nearly two-thirds are functional NETs and the classical example is carcinoid tumors. The other examples of functional NETs is insulinomas, gastrinomas, VIPomas (vasoactive intestinal peptide), glucagonomas and somatostatinomas (2). The classical midgut NETs was referred to as carcinoid which is now referred to as neuroendocrine tumors. The diagnosis is reliant on either positive histology, or elevated 24hour urinary 5-HIAA levels. The latter test has a sensitivity of $75 \%$ and a specificity of up to $100 \%$, provided that the use of certain drugs and foods are excluded. Most NETs express synaptophysin (a synaptic vesicle glycoprotein present in neuroendocrine cells) and chromogranin-A by immune-histochemistry. Chromogranin-A by contrast, is a nonspecific marker, and is often raised in patients with a carcinoid tumor. Depending on the cut-off values and assays used, its sensitivity and specificity are $75 \%$ and $84 \%$, respectively. $(3,4)$.

NETs can arise anywhere in the body but the most common site of origin is the gastrointestinal tract (GIT-67.5\%), since it is the largest reservoir of neuroendocrine cells followed by the broncho-pulmonary system (25.3\%). In the GIT most of them occur in the small intestine (41.8\%), rectum(27.4\%), and stomach(8.7\%). These tumors have a female preponderance and most frequently seen in fifth to seventh decades. NETs may secrete as many as forty secretory products (vasoactive substances), the most prominent being 5hydroxytryptamine (5-HT=serotonin). These tumor products are usually inactivated by the liver but when the production exceeds the capacity for degradation, the classical carcinoid syndrome (CS) ensues (10-15\% of all carcinoids). The triad of CS is cutaneous flushing, bronchospasm with wheezing and. It is a well known fact that only one third of carcinoids present with the typical triad (5). Most patients with NETs have metastatic disease at diagnosis, with regional or distant metastasis observed in $50 \%$ of patients (6). Duodenal tumors $<1 \mathrm{~cm}$ rarely metastasize, whereas $33 \%$ of those $>2 \mathrm{~cm}$ do. Liver metastases are usually solid and vascular which on CT and magnetic resonance (MR) scans are accentuated with contrast. Primarily cystic appearance is exceedingly rare in untreated duodenal NETs and all the reports are in association with ileal NETs.(7) Cystic changes due to central tumor necrosis, are described in hepatic metastases after chemotherapeutic treatment.

Carcinoid heart disease (CHD-Hedinger syndrome) is a rare and unique manifestation seen in up to $60 \%$ of patients with NETs, typically inducing abnormalities of the right side of the heart. CHD is associated most frequently with NETs originating in the small bowel (72\%). A slight male preponderance $(60 \%)$ has been reported, with a mean age at diagnosis of 56-63 years.(8)

Our patient being a male patient, in his late sixties presented with features of severe anemia (hb-4.4gm\%), bilateral pitting pedal edema, severe TR and weight loss. The TR was not explained by his co-morbidities and was presumed to be related to the carcinoid. It could have been a mild TR secondary to carcinoid accentuated by the severe anemia. A urinary HIAA level was not done as the invasive workup confirmed the diagnoses in a very short time.

In conclusion, carcinoid known for its varied sites of origin can be confusing, but a high index of suspicion with an early HPE helps in confirming the diagnoses and early plan of care. Based on this report we can safely conclude that carcinoid should be considered in differential diagnoses of all anemias.

1. Klimstra D, Modlin I, Coppola D, Lloyd R, Suster S. The Pathologic Classification of Neuroendocrine Tumors. Pancreas. 2010; 39(6):707-712.

2. National Comprehensive Cancer Network. NCCN clinical practice guidelines in oncology: neuroendocrine 
tumors.http://www.nccn.org/professionals/physician_gls/f_guidelines.asp. Accessed August 9, 2011.

3. Wiedenmann, B., Franke, W., Kuhn, C., Moll, R. and Gould, V. (1986). Synaptophysin: a marker protein for neuroendocrine cells and neoplasms. Proceedings of the National Academy of Sciences, 83(10), pp.3500-3504.

4. Ma, J. (2014). Detection of serum chromogranin A for diagnosis and evaluation of prognosis of gastrointestinal and pancreatic neuroendocrine tumors. World Chinese Journal of Digestology, 22(28), p.4352.

5. Modlin I, Oberg K, Chung D, Jensen R, de Herder W, Thakker R et al. Gastroenteropancreatic neuroendocrine tumours. The Lancet Oncology. 2008; 9(1):6172.

6. Yao JC, Hassan M, Phan A et al. One hundred years after 'carcinoid': epidemiology of and prognostic factors for neuroendocrine tumors in 35 825cases in the United States. J Clin Oncol 2008; 26: 3063-3072.

7. Fiori S, Del Gobbo A, Gaudioso G, Caccamo L, Massironi S, Cavalcoli F et al. Hepatic pseudocystic metastasis of well-differentiated ileal neuroendocrine tumor: a case report with review of the literature. Diagnostic Pathology. 2013; 8(1):148.

8. Grozinsky-Glasberg S, Grossman A, Gross D. Carcinoid Heart Disease: From Pathophysiology to Treatment - Something in the Way It Moves'. Neuroendocrinology. 2015;101(4):263-273.

Table 1. Who 2010 Classification of Carcinoid

\begin{tabular}{|c|c|c|c|}
$\begin{array}{l}\text { Histological } \\
\text { Classification }\end{array}$ & $\begin{array}{l}\text { Well Differentiated } \\
\text { (Low Grade, G1) }\end{array}$ & $\begin{array}{l}\text { Moderately } \\
\text { Differentiated } \\
\text { (Intermediate } \\
\text { Grade, G2) }\end{array}$ & $\begin{array}{l}\text { Poorly } \\
\text { Differentiated (High } \\
\text { Grade, G3) }\end{array}$ \\
\hline Appearance & $\begin{array}{c}\text { Monomorphic } \\
\text { population of small, } \\
\text { round cells }\end{array}$ & $\begin{array}{c}\text { Cellular } \\
\text { pleomorphism }\end{array}$ \\
\hline Prognosis & Prolonged survival & Intermediate & $>20$ \\
\hline Mitotic Rate & $<2$ & $2-20$ & $>20 \%$ \\
\hline Ki-67 Index & $<3 \%$ & $3-20 \%$ & Poor \\
\hline Necrosis & Absent & $*$ & Present
\end{tabular}

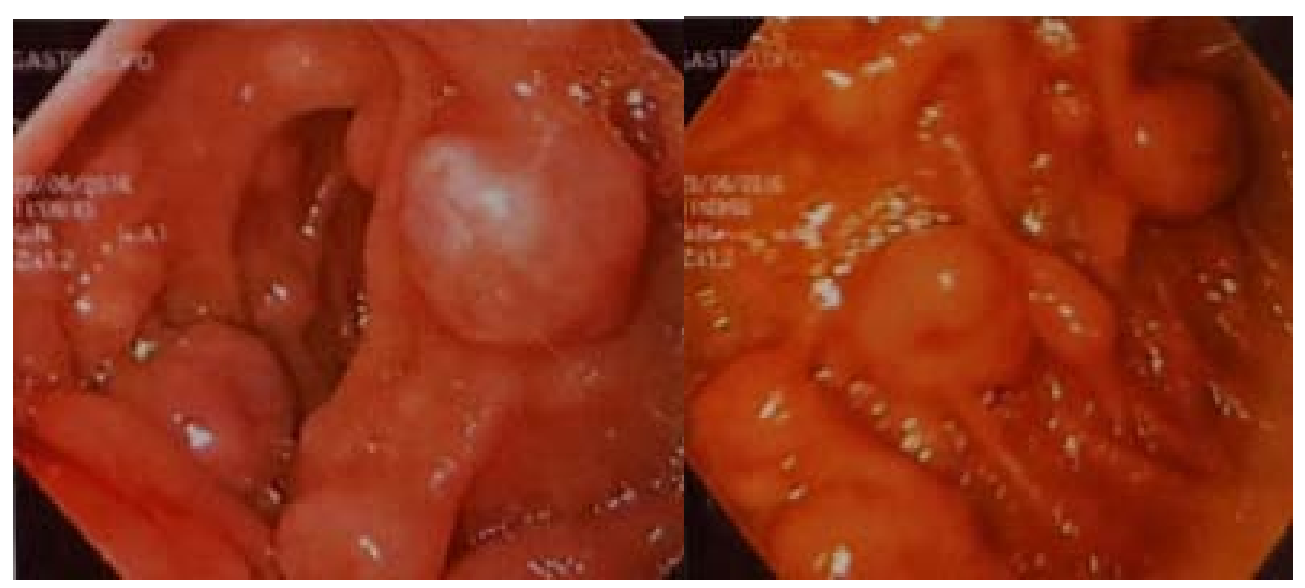


Texila International Journal of Medicine

Volume 4, Issue 2, Dec 2016

Fig 1. Multiple duodenal nodules with central umbilication in D1, D2 D3.

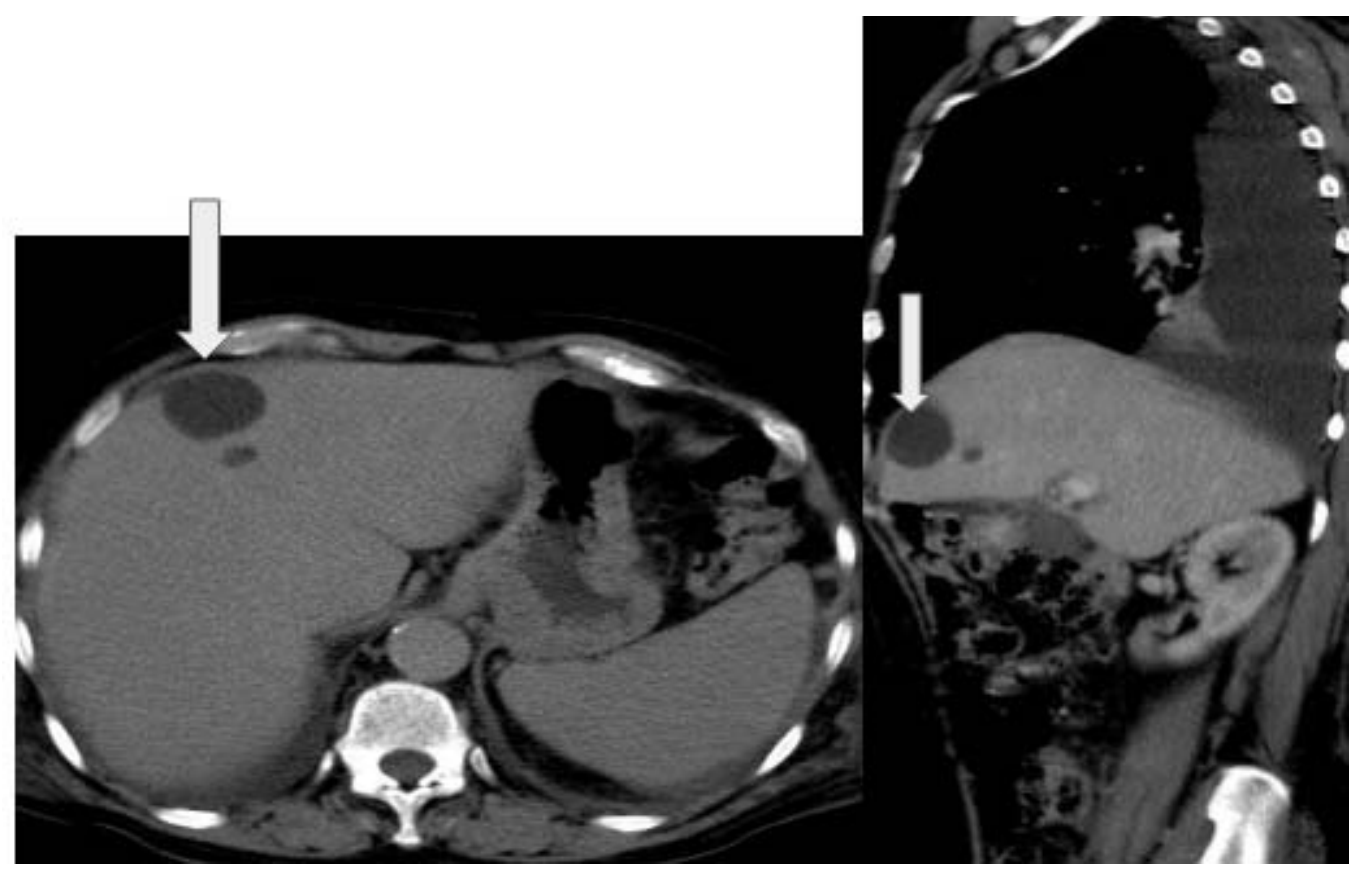

Fig 2. Transverse and longitudinal CT showing cystic lesions

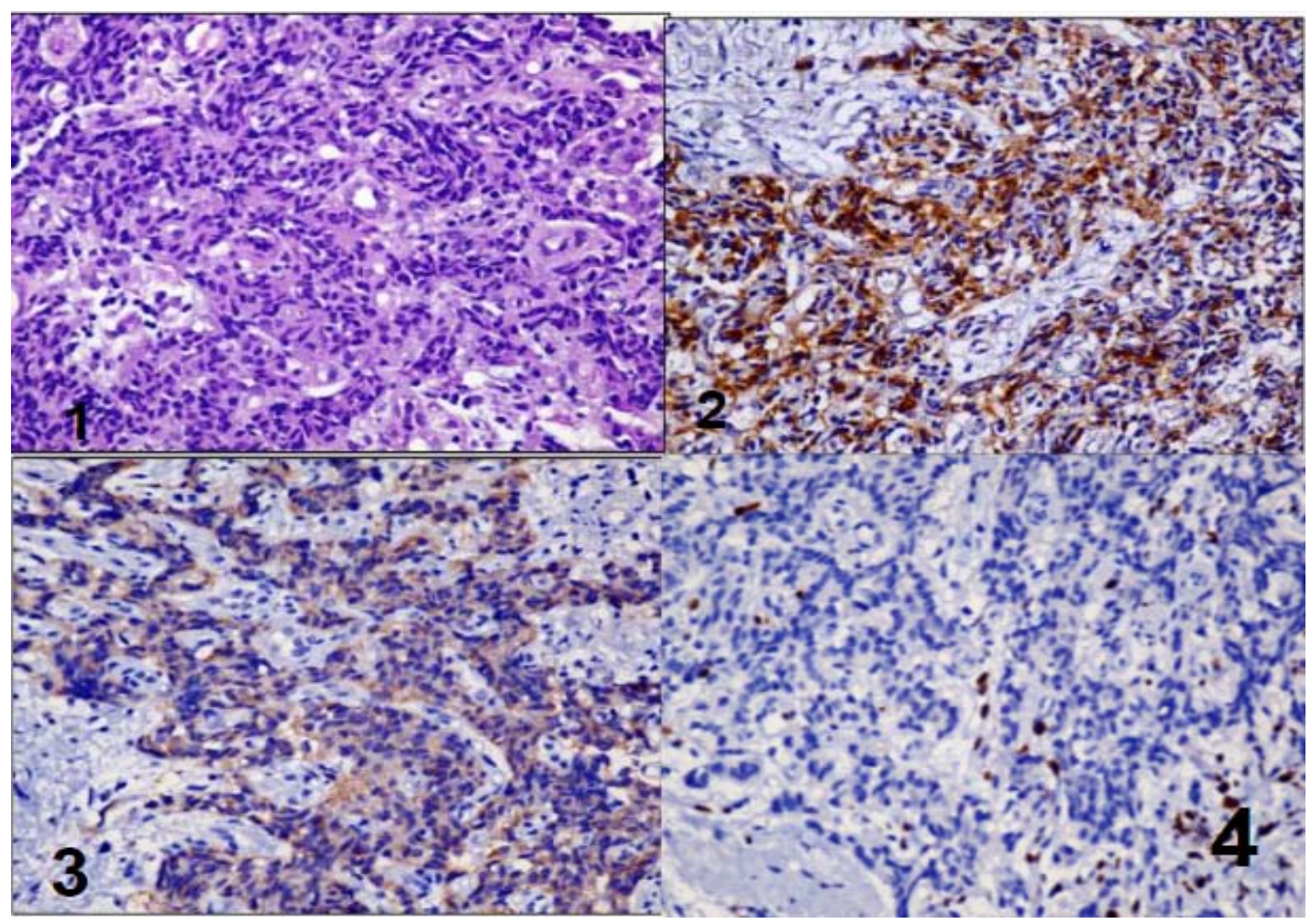

Figure 3. H\&E stain showed glands, trabecula and small solid nests of medium-sized polygonal cells with rather uniform nuclei and eosinophilic granular cytoplasm (a-c). IHC stain showed the tumor cells with positive reaction to chromogranin (2). Synaptophysin positive (3) and Ki 67 index<2\% (4). 


\title{
Management of a suspected case of Monkeypox at Vanga Hospital, Kwilu, Republic Democratic of Congo
}

\author{
Article by Mudji e’kitiak \\ M.Sc Clinical Research, Texila American University, Congo \\ E-mail:mudjimedecin@yahoo.fr
}

\section{Introduction}

Monkeypox disease is a zoonosis caused by monkeypox virus, a member of the genus orthopoxvirus, subfamily Chordopoxvirinae, family Poxviridae. It is a virus very similar to the smallpox virus. It is a disease that occurs in tropical Africa, in the Congo Basin. The Congo is the country where you meet the most cases of monkeypox. The disease was first identified in 1958 but the first cases were observed after the eradication of smallpox in 1977, the disease was confused with smallpox for several years (1).

\section{Motivation}

Dermatological diseases are very common in the tropics and children are no exception. A doctor working in an isolated corner is faced with multiple problems including identifying rare diseases which it will be difficult to diagnose and treat.

Monkeypox disease is a zoonosis caused by monkeypox virus, a member of the genus orthopoxvirus, subfamily Chordopoxvirinae, family Poxviridae. It is a virus very similar to the smallpox virus. It is a disease that occurs in tropical Africa, in the Congo Basin.

Monkeypox, a rare disease, occurs with a frequency of two to three cases per year in Evangelist Hospital of Vanga Democratic Republic of Congo. The Congo is the country where you meet the most cases of monkeypox. The disease was first identified in 1958 but the first cases were observed after the eradication of smallpox in 1977, the disease was confused with smallpox for several years (1).

Management is done by both groping especially regarding measures to be taken for the protection of health care, other inpatient and the entire community, knowing that monkeypox is an infectious disease of viral etiology contagious between humans (2). So we reviewed the medical literature about patients with monkeypox and report our experience with a patient admitted with monkeypox in the pediatric ward of the Evangelical Hospital of Vanga.

\section{Patient presentation}

\section{a) Subjectively}

The patient is a 9 years old male that was brought to the hospital pediatric ward for fever and skin rash lasting for about a week.

A week before the start of the fever, the boy used a trap to catch a wild rodent. The local name for this rodent is $M w e p u$. The rodent was noted to have a skin eruption but the boy went ahead and began to roast and it over the fire. His mother upon returning from the field decided that the rodent should not be eaten. One week later, the child presented with fever, dysphagia, asthenia intense physical pain in the mouth, pain in the back and hip. Two days after the onset of fever, parents noticed early macular rash with cervical and submandibular lymphadenopathy. Parents consulted the local health post in Kapimbi in the Vanga health zone. The child visited the Kapimbi health post for two days without improvement so the parents decide to come to the hospital Evangelical vanga for further evaluation.

This child has seven siblings of which two died of according to the parent of unknown cause. The child has not been fully immunized according to the locally recommended schedule. (Did the child not get any shots or do you know which shots the child did not receive?) This index case was associated with two household contacts also presenting with 
Texila International Journal of Medicine

Volume 4, Issue 2, Dec 2016

symptoms suggestive of monkeypox, a fever, rash, and dysphagia and the second child presented with fever, dysphagia but without its eruptions. The sibling with a rash was hospitalized in the same isolation room his sibling. The mother also presented with fever and dysphagia, arthralgia but without skin rash.

Family lives in a town of about 1000 inhabitants. No other children developed similar symptoms in the village. The child attends primary school Kapimbi and no children at that school came down with a similar illness. Mom was afraid of losing her three children especially it has already lost two children in the past.

Community members in the village believe the cause of this family outbreak was a curse because this family has already lost two children. The community leaders did not believe this dangerous disease could be a risk for other members of the community.

\section{b) Objective}

The child weighed $16 \mathrm{~kg}$ to a height of $105 \mathrm{~cm}$ with $\mathrm{P} / \mathrm{T}$ in the middle, with a temperature $38^{\circ} \mathrm{C}$, a heart rate of 100 beats per minute, respiratory rate of 28 cycles per minute. Palpebral and bulbar conjunctiva normal colored and anicteric.

Lymphadenopathy was noted in the posterior cervical sub- mandibular and inguinal regions

Cardiac exam revealed mild tachycardia, normal S1 and S2 with no murmur.

Chest was symmetrical with clear respirations and normal tympani to percussion.

Abdomen was soft, non-tender without organomegaly.

He noted tall umbilicated papules scattered throughout most of the body. Some of these lesions showed secondary infection with honey colored crusting. These lesions were all in similar stage of eruption and showed no surrounding erythema. The rash was most prominent in the trunk, thighs, legs, palms and soles. During hospitalization, the lesions evolved from popular lesions, to vesicle/pustules, then crusts and have finally sloughed.

\section{C) Review of laboratory}

White blood cell count: 16000 élts/mm3

Leukocytes: N 67\%, L 43\%

Blood sedimentation rate: $20 \mathrm{~mm} / \mathrm{H}$

Hemoglobin: 12 gr\%

\section{d) Assessment}

1. Clinical

Monkeypox disease with secondary case of a sibling.

\section{E) Management}

1. Clinic

We immediately isolated the patient

Have limited medical visits to a doctor and a nurse who wore masks and gloves while providing care.

$\mathrm{R} /$ Ampicillin $1 \mathrm{~g} 2$ times a day for 7 day

$\mathrm{R}$ / Paracetamol $500 \mathrm{mg}$ in the case of the mouth

We reassured the child may return to school it once it is healthy because it can infect her friends from school.

We isolated in the same room as the other suspect child and mother, and we reassured and give clear instructions that they should remain in the isolation room until the rash has resolved.

A team Part of the area is to the village of Akimbo and awareness throughout the population risk of the disease by showing them that it was very important to report any person presenting with fever and rash. Particular emphasis was placed on the community had ideas that it is a curse and this concerned only the family there. They showed that it could happen to 
anyone because everyone is hunting. Stigma family should end, had told a member of the team area. The central office has worked closely with the hospital on the plan above all monitoring and follow-up.

\section{Review of the literature}

\section{History and character epidemiological}

In Africa, monkeypox has probably existed for several years in sub-Saharan Africa since humans have contracted the virus through contact with infected animals. The reservoir of monkeypox virus is still unknown; however, the data suggest that monkeys, rodents or squirrels or more who live in the forests in Central Africa are the reservoir (3). In our case, the child identified the rodent as a rat locally called Menu. (See picture)

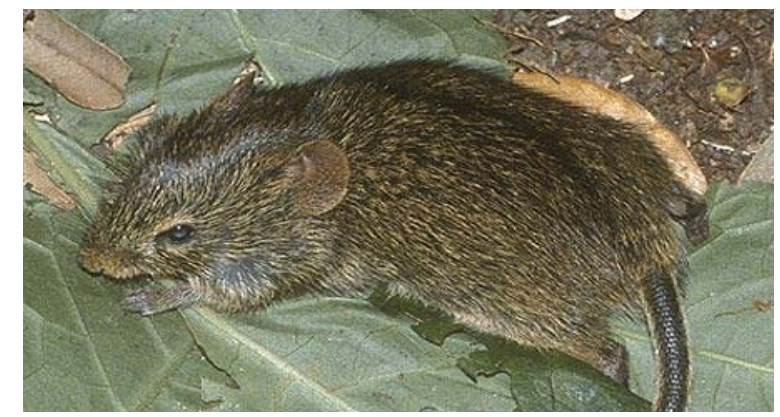

This rat's scientific name is Lemniscomys Rosalia

This is the rat that children identified when we presented with various photos of different rodent species.

Monkeypox was not considered as a separate disease from smallpox until 1970 when, after the elimination of the latter, we continued to have a disease resembling smallpox in rural areas of DR CONGO (4). We are in rural areas where there is most often the case of monkeypox. The virus was first identified in 1958 but the first case was observed in 1970 in Democratic Republic of Congo in a child of 9 months (5-6). Vaccination scale in Central Africa during the global campaign eradication has probably reduced the incidence of monkeypox but the lack of immunity in the generations born since that time and the dependence of the population to feed hunting products explains the resurgence of the disease(4). Early epidemiological studies conducted during the period 1970-1979 detected a total of 47 cases of monkeypox in rainy areas of sub-Saharan Africa, 38 in DR Congo and the rest in Cameroon, Central African Republic, Gabon, Côte d'Ivoire, Liberia and Sierra Leone. (2)

All cases in DR Congo occurred in the rainforests and animal contact was strongly suspected. Secondary transmission has been considered the most likely cause of infection in 4 cases with a secondary attack rate of $7.5 \%$ in the immediate family or member living under the same roof. (7)

Since 1980, the vast majority of cases were reported in DR Congo.

example, to determine whether the monkeypox had the potential to emerge in Central Africa and occupy areas left by smallpox, WHO conducted a monitoring program for the period from 1981 -1986 where 338 of the 404 cases were identified as cases of monkeypox in the period 1970 to 1986 (8).

An animal source was suspected in 245 of 338 cases. Secondary transmission from a human source was assumed in the remaining 93 cases. The majority of cases occurred in children less than 4 years and this distribution suggests waning immunity from small pox vaccination.

Since the end of the monitoring of the WHO, there were some items that were interested in monkeypox. During the period 1986-1992, only 13 items were reported in the literature and none was observed during the period 1993-1996 (9). However, between 1996 and 1997, over 
Texila International Journal of Medicine

Volume 4, Issue 2, Dec 2016

500 cases were suspected as cases of monkeypox in Kasai Oriental, but only a small number were laboratory confirmed.

No reports new suspected cases of monkeypox were published until 2001, the year which 31 patients with monkeypox were diagnosed in Equateur province in DRC (4).

Political instability, lack of resources does not allow continuous monitoring of the disease. The disease frequently occurs when cases are not reported.

Between January 1998 and 31 December 2002, a total of 1265 cases were reported to the Ministry of Public Health of the Congo. Samples of 215 cases were analyzed and 88 were due to monkeypox. A monitoring system was installed in Kasai Oriental, with the aim to improve data collection. (4)

In the United States of America, in 2003, cases of monkeypox were reported. 72 cases, 37 were confirmed monkeypox in the laboratory. Prairie dogs or rodents from Africa were suspected source. (10)

\section{Monkeypox Virus}

\section{TRANSMISSION}

The virus is transmitted to humans through the handling of infected animals, as in our case, by direct contact with infected animals or contact with blood, serum or other blood-derived. The transmission is also possible with aerosolized droplets. Human to human transmission is possible but prolonged close contact.

\section{B. Clinical manifestations}

The clinical manifestations of monkeypox are similar to those of smallpox. There is a ten to fourteen day incubation period. The first symptoms appear about two weeks after contact with the virus. The disease begins with fever, malaise, dysphagia, sore mouth, lymph nodes before the rash appears. These macules, papules, pustules and gallbladder, it will form scabs and dander will end (4). Other symptoms may be chills, sweating, headache, back pain and dyspnea. Lymph nodes were observed in approximately $90 \%$ of patients, which is not the case with smallpox and can help in the differential diagnosis are latérocervicales lymphadenopathy, inguinal or submandibular (4). Prodromal stage lasts 1-3 days before appear as rashes. During the first week of the rash, the patient is highly contagious and must be isolated. The diameter of the lesions ranged from 0.5 to $1 \mathrm{~cm}$ and disease progression is almost identical to smallpox. For a period of 2 to 4 weeks, the lesions progress from macules, papules, vesicles, pustules, dry, peel off and become scabs.

Lesions begin to spread to the trunk palm of hands, soles of feet. The lesions may be observed in the mucous membranes of the mouth, tongue and genitals. Other manifestations are soft tissue infection, pneumonia, encephalitis and ocular complication (9).

\section{Diagnosis}

As the clinical manifestations of monkeypox are similar to those of chickenpox and smallpox, accurate diagnosis is crucial for the control of these diseases. A summary table summarizes the situation. 
Table 1. Evaluation criteria for the differential diagnosis of patients with monkeypox, smallpox, and chickenpox.

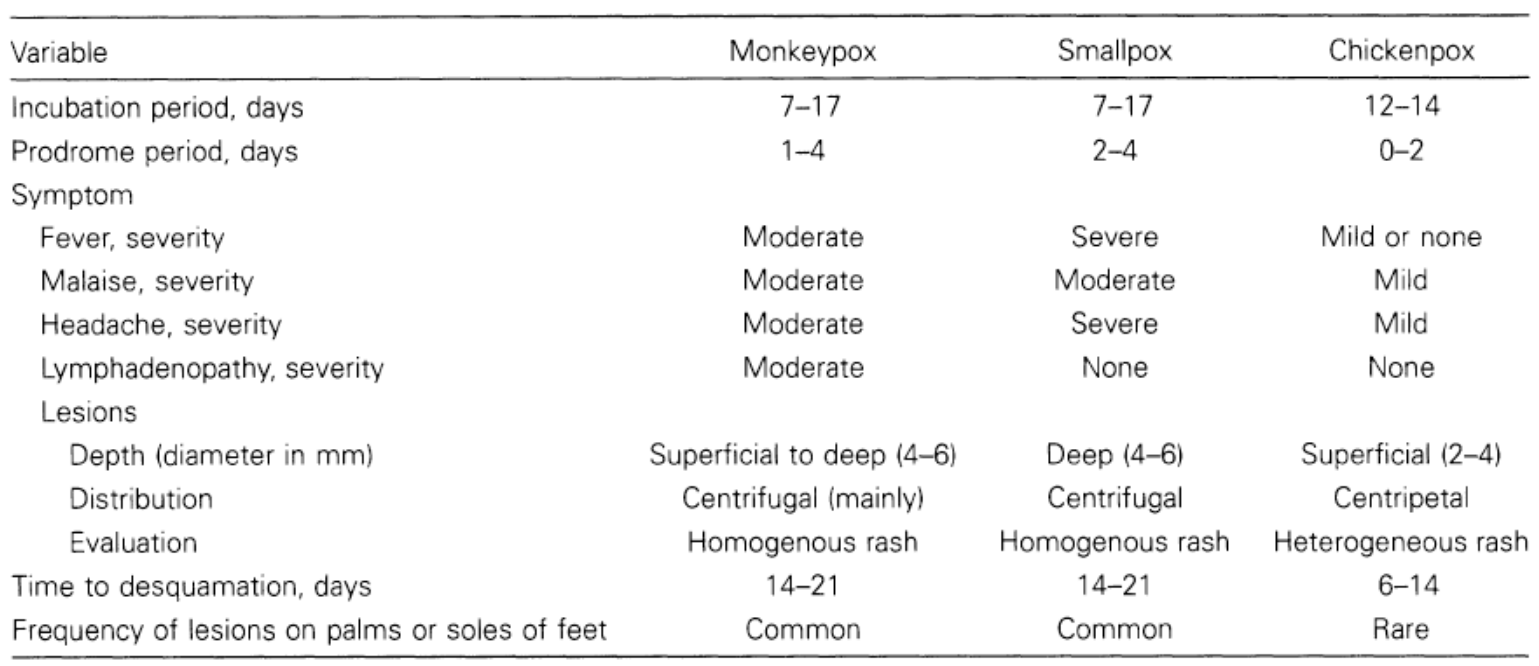

NOTE. Signs and symptoms of the diseases are not age-specific.

(Site souce of this table)

In the United States, electron microscopy has been used to distinguish between monkeypox and bovine stomatitis.

Thus, although the clinical features are useful in the diagnosis and may help to distinguish the disease, confirmation laboratory is essential for definitive diagnosis. We can try to isolate the virus or use the PCR, ELISA, immunofluorescence test and even histopathological analysis. Unfortunately, many of these methods are relatively nonspecific and are unable to tell the difference between monkeypox virus and other virus's poxvirus. However, immunohistochemically analysis with polyclonal and monoclonal directed against orthopoxviruses, can make the difference between herpes and infections poxvirus. In the past, electron microscopy has played an important role in the diagnosis (11).

Electron microscopy can be a method of choice for the laboratory diagnosis of poxvirus infections, and can provide one of the first clues the cause of a rash illness unknown. This method, however, cannot differentiate between species.

Virus isolation in culture of mammalian cells and characterization techniques of CPR followed by fragment analysis or sequences are considered the definitive means for identifying monkeypox virus (11).

Unlike regions outside Africa where it is essential to distinguish between monkeypox and the deliberate introduction of smallpox, the main diagnostic problem in sub-Saharan Africa is to distinguish monkeypox from chickenpox.

During active disease, laboratory confirmation can be performed by PCR analysis made from liquid vesicles, whereas after the resolution of the disease, serum samples for research IGM antibodies to chickenpox virus can be achieved.

Antipoxivirus The presence of antibodies in unvaccinated individuals with a history of skin rash illness confirms the diagnosis.

\section{Support cases of monkeypox}

For proper treatment, we must define the case.

\section{Definition of case}

Clinical criteria:

Skin rash (macule, papule, vesicle, and pustule) generalized or localized, discrete or congruent.

Fever greater than $37,4^{\circ} \mathrm{C}$.

Other signs include chills, headache, backache, lymphadenopathy, cough, and dyspnea 
Texila International Journal of Medicine

Volume 4, Issue 2, Dec 2016

Epidemiological criteria:

Exposure to a mammal with signs of illness such as rash, respiratory symptoms, or others.

Exposure to a mammal with or without clinical signs but was in contact with an animal or a human with monkeypox.

Exposure to a probable or confirmed case of suspected monkeypox

Laboratory criteria:

Isolation of monkeypox virus in culture

Presence of virus DNA PCR monkeypox in a clinical specimen.

Demonstration of a morphology resembling a virus an orthopoxvirus by electron microscopy in the absence of exposure to other orthopoxviruses.

Demonstrated presence of an orthopoxvirus in tissue used for the method immunohistochemically test in the absence of exposure to another orthopoxvirus.

\section{Classification of cases}

\section{Suspected case}

Epidemiological criteria skin rash with fever or unexplained two or more symptoms appear in a period less than 21 days

\section{Probable case}

Epidemiological criteria met include fever, rash vésicopustuleuse more skin with onset of symptoms less than 21 days after the last exposure or if rash but not typical elevation IGM antibodies reactive with orthopoxviruses between 7 and 56 days after the early eruptions

\section{Case confirmed}

Those who are included in the test lab

\section{Exclusion criteria}

Another diagnosis can exclude or monkeypox,

The case was reported on the basis of primary or secondary exposure to a wild animal or a human being and who subsequently did not present symptoms or epidemiological or other criteria,

A suspect without developing rashes within ten days following the onset of clinical symptoms consistent with monkeypox.

Cases with undetectable levels of IGM during the period of 7 to 56 days after the rash appear.

INFECTION CONTROL: GENERAL PRECAUTIONS

Anyone who comes to the hospital with fever and rash, a history should look well-made if the person is in contact with the monkey, dog and rat. Once this is proven, measures must be taken to protect health care workers and the public.

Measures to be taken are:

Hygiene hands after contact with an infected patient or environment in which care is provided.

Gowns and Use gloves for contact with the patient.

Protection against the virus by droplets or aerosols. We use the N95 NIOSH certified to filter the air and should be discarded immediately after leaving the room. If the N95 is not available, a surgical mask should be worn to protect against the transmission through contact with droplets. The mask must be worn before entering the patient's room.

Eye protection if splashing through the glasses.

Though managing contaminated waste

Use caution when handling soiled linen to avoid contact with exudates lesions. Dirty laundry should not be shaken or otherwise handled as infectious particles spray.

Treating the patient avoiding contamination of the skin or clothing. Ensure that the equipment has been cleaned and adjusted accordingly. 


\section{Placement of sick}

Patient who presents to the emergency room with fever and rash, maculo papular or vesicular should be immediately placed in isolation as soon as possible. If a negative pressure room is available, it should be used. If this is not available in the next few minutes, to the surgical mask on the patient, covering the patient's skin lesions with clean cloths.

In the hospital, the majority of patients with monkeypox have no need to be hospitalized for medical treatment.

Patients who require hospitalization should be placed in a negative pressure room. If the negative pressure room is not available, a private room should be used.

Vaccination of family caregivers and contacts presumed cases of monkeypox

Vaccination smallpox vaccine is recommended for persons providing care to patients or contacts family of monkeypox. It is better for the caregivers suspected to be vaccinated. The vaccine can be given even before the diagnosis is confirmed if available. Caregivers and family members of suspected cases must comply with the recommendations and precautions to avoid disease.

Monitoring of personal caregiver or other person exposed exposed

Health workers exposed must be followed. Symptoms should be monitored including measurement of body temperature twice a day for 21 days after exposure. Before coming to work each day, the caregiver should be questioned about fever or rash.

Patients who do not require hospitalization for medical indication can be isolated at home. The ability to implement control measures and isolation at home and it varies depends on whether the patient is a child or an adult with monkeypox, if several people in the house are infected, and the number of people who reside in this house, the nature, the extent of damage in each case.

Following principles should be considered and adopted to the extent possible within the family:

1. Isolation at home

People with signs should not leave the house, except as required for follow-up medical care. Should avoid going outside and coming into contact with wild or domestic mammals.

Unexposed persons who do not have a basic need to be at home should not visit the sick. Household members who are not sick should avoid contact with the sick person.

Individuals with extensive lesions that cannot be easily covered with respiratory symptoms should be isolated in a separate room or area member's family whenever possible.

2. The person with a sign must wear a surgical mask in particular that this respiratory signs. If this is not possible, other members of the household should consider wearing a surgical mask in the presence of the person with symptoms.

3. Skin lesions should be covered to the extent possible to minimize the risk of contact with others.

4. Disposable gloves should be worn for direct contact with oozing lesions and discard after use.

5. The hand hygiene (washing hands with soap or other disinfectant) must be performed by person's infected household contacts after touching contaminated areas of the body, clothing or environment that may have contact with infectious lesions.

6. Bedding, towels, clothes can be washed in a standard washing machine with warm water and detergent, bleach can be added. Precautions should be used when handling soiled linen and avoid contact with other materials. The cloths must not be shaken or otherwise manipulate to spray the infectious particles.

7. Dishes and other utensils should not be shared, but the segregation of specific utensils for use by an infected person is not necessary. Dirty dishes and utensils should be washed in a dishwasher or by hand with warm water and soap

8. Contaminated surfaces should be cleaned and disinfected. Disinfectants can be used.

9. Contaminated materials must be bagged and placed in a container for disposal with household garbage. 
Texila International Journal of Medicine

Volume 4, Issue 2, Dec 2016

\section{Period of isolation}

decisions relating to discontinuation of isolation precautions should be taken after consultation with all services health.

For people with a rash vésiculopustuleuse, isolation measures should be continued until the lesions become scabs.

Precautionary shutdown after isolation, affected individuals should avoid close contact with immunocompromised people until all lesions that disappear. This applies to the case of HIV, diabetes, cancer, emphysema.

For people who develop symptoms such as fever, sore throat, cough without rash, isolation precautions should be continued for 7 days after the onset of fever. If the rash does not develop during this time, isolation measures may be interrupted. Those affected must continue to monitor symptoms for 14 days. If symptoms recur or if a rash develops, the health department must be notified.

Affected individuals should not donate blood, cells, tissues, organs, breast milk, semen or while they are sick or during monitoring.

Contacts asymptomatic animals or humans suspected of having monkeypox should be placed under surveillance for 21 days symptoms bitter their latest exhibitions. It monitors fever, sore throat, cough, and rash. Closer monitoring is desirable.

Asymptomatic contacts should continue their daily activities (go to school, work) but should stay close to home throughout the duration of the surveillance. However it may be prudent to exclude preschoolers to gardiennerie or other group.

\section{Conclusion}

Monkeypox is a viral disease although rare but present in our area. Two to three cases are reported each year in the hospital Vanga. No protocol or concrete plan of care does not exist in our area.

Recognition of the disease by thorough anamnesis, physical examination and thorough epidemiological data are tools for health personnel.

Rats in our case are clearly defined as a reservoir of the disease from clear and reliable evidence of the family.

Once diagnosed, the measures detailed above should be switched to the management of the disease.

\section{References}

[1]. Aysegul N, Anne W, Sina B, Chris A. Reemergence of Monkeypox: Prevalence, Diagnostics, and Countermeasures. Clin Infect Dis. 2005 Dec 15;41(12):1765-71. Epub 2005 Nov 11

[2]. Foster SO, Brink EW, Hutchins DL, et al. Human monkeypox. Bull World Health Organization 1972;46:569-76.

[3]. Gentile M, Gelderblom HR. Rapid viral diagnosis: role of electron microscopy. New Microbiol 2005; 28:1-12.

[4]. Heymann DL, Szczeniowski M, Esteves K. Re-emergence of monkeypox in Africa: a review of the past six years. Br Med Bull 1998; 54:693-702

[5]. Jezek Z, Arita I, Mutombo M, Dunn C, Nakano JH, M. Szczeniowski Four generation of probable person to person transmission of human monkeypox. Am j Epidemiol 1986; 123:1004-12

[6]. Jezek Z, Fenner F. Human monkeypox. In: Melnick JL, ed. Monographs in virology ol. 17. Basel, Switzerland: Karger,1 988

[7]. Khodakevich L, Jezek Z, Messinger D. Monkeypox virus: ecology and public health significance. Bull World Health Organ 1988; 66:747-52.

[8]. Ladnyj ID, Ziegler P, Kima E. A human infection caused by monkeypox virus in Basankusu Territory, Democratic Republic of the Congo. Bull World Health Organ 1972;46:593-7.

[9]. Multistate outbreak of monkeypox-Illinois, Indiana, and Wisconsin, 2003. MMWR Morb Mortal Wkly Rep 2003; 52:537-40. 
Texila International Journal of Medicine

Volume 4, Issue 2, Dec 2016

[10]. The global eradication of smallpox: final report of the global commission for the certification of smallpox eradication. Geneva, Switzerland: World Health Organization, 1980.

[11]. Inger K. Damon. Status of human monkeypox: clinical disease, epidemiology and research. Vaccine. Dec. 30 2011, 29 Suppl 4: D54-9. Epub 2011 Dec 18. 


\title{
Yoga Concepts in Real Life
}

\author{
Article by Anitha Bobba \\ Ph.D in Alternative Medicine, History \& Philosophy of an Alternative Medicine, \\ Major Yoga Concepts in Real life, India \\ Email: acunaturecare@gmail.com
}

\begin{abstract}
The process of individual spirit Union with the Supreme Being, or any practice that makes such union is expounded by Sage Patanjali. Here are 10 major concepts associated with Yoga which can be implemented for overall quality of our life style in real world (Fitness Health, 2016).
\end{abstract}

\section{Yoga concepts}

\section{Karma}

This concept refers to any type of mental or physical action which deals with consequences of each action. We can expect every action that you force on another person can be expected in our future life.

Past karmas have effect on current life, overlapping into your present and effecting your present. Actually it is us effecting our reality creating by doing that creating from past (wisdomsdoor, 2016). As past karmas have effect on current life, in order to undo all karmic knots that we have made over the years need to use Worming technique. With vigilant use of Worming Technique, we can take seven year karmic period to one year. This creeping-in reminds you of past actions, so that you can gauge your future actions in accordance with Universal Laws.

According to Indian spirituality karma is a physical, mental, verbal and social activity which has impressions which cannot be erased before creating reaction. Contemplation on Karma principle finds unity with cosmic law by Meditating on idea of cosmos as a doer causing positive effects in Cosmos, see yourself in every being. Personal effort is required the concept of karma can't be experimented to find out workings of Law of Karma (Coghlan\&Miller, 2014).

As Karma is a physical, mental, verbal and social activity which has impressions and which cannot be erased before creating reaction. To work for selfish reasons as to get stature in society leads to bad karma this will restrict one to grow spiritually. Good Karma advances through knowledge and helps in getting job done in selfless manner. One who does his daily duties in tune with nature will have Good karma which in turn leads to God realization (Kramer, 2011).

\section{Dharma}

This concept deals with correct way to live our life and receive good karma. This concept also helps to achieve enlightenment and union with supreme power.

The concept of Dharma in Indian philosophy and religion has multiple meanings depending on the various religions; in common it means 'right way of living and path of righteousness' (Wikipedia, 2016). This right path shows way to right living to the people as per Universe and provide guidance to them. Similarly if it is not supported according to the nature or Universe these differences in laws cause opposite reaction by leading to accumulation of bad karmas. Also multiple religions even though base is common, due to misinterpretation of their religious laws are leading to lot of confusion.

The Research done among Pasters and Hindu leaders by using methodology called Ethnography whose main focus is to understand perceptions, views, fears and aspirations in 
Texila International Journal of Medicine

Volume 4, Issue 2, Dec 2016

divergent cultural context of India. Example of Sanata Dharma is they may participate in multiplicity of truths but they must participate in common duties of Dharma (James, 2010).

In the modern world people are not thinking about Dharma which are the root cause for all sufferings. In reality people who follow Dharma will never fail in anything in the world. The person who follows Dharma realizes Self, under the nature and does all works perfectly with broad ambition and lives a full life with success. Everyone should follow the four fold path; life means existence, knowledge, bliss and absolute, in order to have completeness or fulfillment in life. In practical life one should avoid clashes and create remarkable changes in life for betterment of world and to achieve one human world with peace, unity and international brotherhood (Ramesh, 2006).

\section{Manah}

This concept is word for your Mind. The Manah is the portion of Mind which receives sensory signals from other portions of the body. This is the metaphysical ability for the mind to receive signals from the spirit.

This concept of Manah is the one of the three fold inner organ - thinking. If we are a good spirit, we will have good thinking and it gives results of Asha, justice and conscience (James, 2011) If we are a evil spirit, we will have evil thinking and it gives results of lie, darkness, bad thinking. Basically the force of light in us needs to fight against the force of darkness in us.

The Manomaya means manah or manas or mind; the mind along with five senses is called Manomayakosa. Meditation, tartak, jap and tanmatra are part of Manomaya Kosa-Sadhana. The study was conducted by Shiram Sharma Acharya conducted study with 30 adolescents. Study concluded that Manomaya kosa sadhana is significantly effective for Mental Health of adolescents which helped in building positive feeling, positive attitude and self confidence (Trivedi, 2014).

The Manah with five senses causes all thoughts which leads to action in real world. Controlling Mind can be done only through Sadhanas like Meditation, tartak and jap. Any human being who want to keep his Mind balance need to practice one of these sadhanas keep Mind under control which in turn leads to regulated and rightful thoughts which are useful to our daily life.

\section{Buddhi}

This concept is intelligence, the conscious ability to be able to understand the concepts which are taught to us. It is also an ability to think situations and to use reason when making decisions which are important.

We need to Buddhi Meditation practice to arise conscious and intuitive powers to understand and override challenges before they manifest we are forever healed (Tiwari, 2012). This concept is Buddhi, can be harmful if it is misinterpreted with the individual thoughts with real intuition. It might lead to wrong direction and the person would lose the real awareness of knowledge.

In Human being the great Cosmic mind or Intelligence or Intelligence like a Cosmic computer and stores memories and impressions and also governs senses. Candace Pert's pioneering research in $20^{\text {th }}$ Century demonstrates how we respond to and experience our world through, our internal chemicals, the neuropeptides and their receptors, manifesting themselves as our emotions, beliefs and expectations influenced through biological under pinning of awareness (Venkateswara, 2015).

"As universe evolves, habits of nature evolve", this idea was presented and developed by Rupert Sheldrake and C.S. Pierre. Lynne Me Taggert and Rupert Sheldrake called mental fields as, view of morphic fields, and also called as Quantum Hologram and this 2way communication done through Agna Chakra (Venkateswara, 2015).

Buddhi is knowledge helps to be smart and intelligent in taking decisions. Buddhi is radius of Atman reflection which gives us the power to discriminate and decide what is good for us 
or not. Buddhi influences in the way we understand and interpret our experiences regulate our lives, relationships, behavior and other activities (Jayaram, 2015).

\section{Samskara}

This concept is translated as memories. Every action whether it is good or bad would create an impression. The negative impressions need to be cleansed to obtain immortality.

This concept clearly mentions that as long as we have Samskaras, we will be getting fresh births, this cycle needs to repeat until all samskars exhausted in order to acquire knowledge of self (Sivananda, 2010). If we have bad samskaras the cycle of transmigration keeps on repeating the final destiny would take longer time to achieve.

Indian Philosophy focus on voluntary action that has not cognized before which is generic consciousness, which a generic animal or a human soul wants food and knows where to look in current life proves rebirth based on goal directed activity requires mental dispositions (Samakaras) formed by previous experience. Xenoglossy is similar example as evidence is restricted (Philps, 2009).

Every action what we do creates an impression (Samskara), not only this life what we had in our previous lives also gets accumulated and comes on the whole we have impact on our current life. One can exhaust these Samskaras through Nirbija Samadhi through seclusion of senses and old Samskaras can be destroyed through Vichara (right enquiry of Supreme Self). Actually they are fried out by Jnana (Sivananda, 2010).

\section{Vasana}

This concept is basically group of impressions of actions or memories (samskaras) based on similarities between them. These groups are active even in unconscious state.

According to Bhagavadgita if one works according to his own Vasana is better, so that it helps in exhausting his own Vasanas. If one fail to follow their own Vasanas, they not only fail to exhaust Vasanas but also add more load of Vasanas due to his temperament (Chinmayananda, 1995).

Samkhya \& Yoga Concepts accept the theory of reincarnation, is collation of Samskaras and Vasanas. Our Actions determine our Personality; each action interacts with previous action and personality changes accordingly. Future actions are also determined by our Personality (Dalal \& Misra, 2012).

The Brahman is the Supreme Self, there is no Vasana in Brahman. The seeds of impure Vasana can be fry up through Nirvikalpa Samadhi. The knowledge of Brahman one can extinct all Vasanas. One who aspires higher spiritual planes of Nirvikalpa Samadhi should approach saints who had achieved that level (Sivananda, 2010).

\section{Kriya}

This concept is actually practice or exercise of the techniques found in Yoga. It pertains to correct physical motions involved and also has the skill involved in correcting the incorrect technique while performing each movement.

The study of Kriya Yoga and brain waves published in 1998 in the Magazine Bindu by Psychologist Erik Hoffman. A Researchs is concept is actually practice or exercise of the techniques found in Yoga. It pertains to correct physical motions involved and also has the skill involved in correcting the incorrect technique while performing each movement. The effects of kriya yoga on the EEG(Electro Encephalography) i.e recording the brain waves before and after Kriya was measured, the result was, there was change in brain waves, the alpha and theta activities increased about $40 \%$. Further research findings were that any Kriya method has no direct effects had been proved wrong; the uninformed debasers feel that Kriya is demoniac (Kinnes, 2014).

The six purificatory excercises of Kriya are Dhauti, Basti, Neti, Nauli, Trataka and Kapalbhati. These purification excercises helps in cleaning up the organs, Digestive, 
Texila International Journal of Medicine

Volume 4, Issue 2, Dec 2016

Respiratory and circulatory systems. If one practices Meditation would keep Brain and Nerves system under control(Sivananda, 2011).

\section{Viveka}

This concept is the ability to realize the difference between reality and fantasy of life. It also realizes temporary aspects of life and the permanent aspects of the current and after life.

This concept of viveka is the knowledge shows the difference between knower and knowable which ends the entire knowledge. Knowable is different from its nature and is revealed by consciousness (Elenjimettam, 1974). If one can't see the difference between the knower and knowledge can't realize the difference between reality and fantasy of life.

The Yogic intellectual capacity of Vivek Buddhi (discriminative wisdom) acts as a way to enhance authenticity. In the real world, the ability to concept is the ability to manage wisdom is emotional intelligence. In psychotherapy is often to help clients determine the meaning \& significance of their feelings (Marques\&Dhiman, 2016). One can achieve Viveka meditaion on OM, by doing Nishkamya Karma.

\section{Viragya}

This concept concerns with disinterest anything in current life. This concept expects distance yourself from anything you enjoy in mortal life in order to prepare for after life.

The Viragya means non-attachment and Mind can be controlled by practice and nonattachment. When we can understand Nitya and Anitya, Dharma and Adharma, then Viragya develops through which we can have control of our Mind (Nikhilananda, 2016).

If we have attachment to worldly things, then Viragya can't be developed and can't understand the reality.

This concept expects distance yourself from anything you enjoy in mortal life in order to help other needy people. One should experience in pure giving, for example Traditional healers describes cures for diseases like depression, angst or Vairagya. The UN Holloway's ideas are for resources mobilization is an ongoing and evolving process (Holloway, 2014).

One can achieve Viveka and Vairagya by Chitta-Suddhi. The Chitta-Suddhi is done by Nirguna Dhyana, meditaion on OM, by doing Nishkamya Karma. Along with this approach Sadguru for guidance, by doing this one would realize Vedantic realization which comes through Nididhayasana (Sivananda, 2011).

\section{Sanyasa}

This concept attempts to sum up all of other Yoga concepts which contribute to a well led life. It is the eventual perfection in all aspects of life to attain perfect and healthy after life.

The real meaning of Sanyasa is sacrificing oneself for the sake of doing something, for this you need not be single, you can be householder and still perform the duties of mankind. The aim of Sanyasa is not moksha, doing seva, selfless service. If everyone cultivate the habit of selfless service world would be a peaceful place to live (YOGA, 2016).

On the contrary, if a person is greedy and selfish and act to the world that he is real Sanyasa, he misleads people, so one should be careful in approaching him.

The Sanyasa of Gita will not tolerate complete cessation of activity. All research will be useless if internal research is not allied (Gupta, 2016). Sanyasa means end of life each stage prepares for next stage.

This concept attempts to sum up all of other Yoga concepts which contribute to a well led life, in order to achieve this one should sacrifice oneself for sake of doing something for others or to the world. The modern society should adapt the above concepts to attain Oneness of Mankind (YOGA, 2016).

The Mastery of Mind leads to renunciation (Sanyasa) of all. Renunciation means abnegation of mind from all desires and egoism through which one acquires immortality in life, oneness of all in Brahman. Keep the mind always rooted in God amidst of all activities of life by having confidence in your own faculties and powers (Sivananda, 2011). 


\section{Conclusion}

The Good Karma leads to good Samskaras, one who does his duties according to nature will have good karma. One needs to follow Dharma of God (Divine) in order to follow one human world and to maintain International brotherhood. The Mind has to be zero, in order to achieve truth and rightful thoughts which influences Buddhi through which we understand and experience our lives spiritually and worldly.

The Kriya is used to keep our physical body under healthy condition which acts like a Temple to hold the Atman. All the Samskaras and Vasanas which are the root cause of Avidya needs to be removed by either by undergoing experience (Bhoga) or fried in "Yoga Fire" or can be done both. Samskaras can be scraped by Sahaj Marga Raja Yoga meditation from casual body through Transmission of Pranahuti by Guru (Divine Force of power), then only Supreme Self (Brahman) remains. All the spiritual stages are passed on without even realizing them and achieve the highest spiritual state in this life time itself. One attains renunciation (Sanyasa) from egoism and all desires, finds oneness of all in Brahman, and develops cosmic love for all living beings.

Actually practicing Sahaj Marga Raja Yoga meditation is my own experience. When one Atman is found in all living beings, all life is one. The whole world is one family of God. By living spiritually doesn't mean we run away from our duties of family. We need to live like birds with two wings one with Spiritual life and Worldly life to live peaceful and blissful.

\section{References}

[1]. Chinmayananda, S. (1995). The Holy Geeta from

https://books.google.co.in/books/about/The_Holy_Geeta.html?id=eVw_Rff7m7AC

[2]. Coghlan, D., \& Miller, M.B. (2014). The Sage Encyclopedia of Action Reserach from http://www.ebook777.com/sage-encyclopedia-action-research/

[3]. Dalal, A.K., \& Misra, G. (2012). New Directions in Health Psychology from https://books.google.co.in/books?id=1l_lDAAAQBAJ\&pg=PT215\&lpg=PT215\&dq=current+research + activities+Vasanas\&source=bl\&ots=b25a45RqHZ\&sig=Vwf7iNXsBRwZizNEBp9kHAujmds\&hl=en \&sa=X\&ved=0ahUKEwjj75OStI7QAhUKN48KHZFrCZQQ6AEIITAC\#v=onepage\&q=current\%20re search\%20activities\%20Vasanas\&f=false

[4]. Elenjimettam, A. (1974). The Yoga Philosophy of Patanjali from

https://books.google.co.in/books?id=E8jWAAAAMAAJ

[5]. Fitness Health. (2016). Concepts of Yoga from

http://www.fitnesshealth101.com/fitness/yoga/concepts

[6]. Gupta, P. (2016). Wisdom of Kalam from

https://books.google.co.in/books?id=anhQihB4lKsC\&pg=PA44\&lpg=PA44\&dq=wisdom+of+kalam\& source=bl\&ots=_ylGseTnKC\&sig=_iZhXeQW2U9XKiT7QJzDc5zN3vU\&hl=en\&sa=X\&sqi=2\&ved= 0ahUKEwjsl-

yHuo_QAhXJuo8KHeufCkwQ6AEIUTAM\#v=onepage\&q=wisdom\%20of\%20kalam\&f=false

[7]. Holloway, R. (2014). Towards Financial Self reliance from https://books.google.co.in/books?id=ypRAwAAQBAJ\&pg=PP1\&dq=Towards + financial + self + reliance\&hl=en\&sa $=X \& v e d=0$ ahUKEwi96cL JmY_QAhWIM48KHXaYCSkQ6AEIGjAA\#v=onepage\&q=Towards\%20financial\%20self\%20relianc $\mathrm{e} \& \mathrm{f}=$ false

[8]. James, L. (2011). Philosophy: An introduction to the Art of wondering from https://books.google.co.in/books/about/Philosophy_An_Introduction_to_the_Art_of.html?id=8vw9z_m nzH8C\&redir_esc $=$ y

[9]. James, J.D. (2010). McDonaldisation, Masala McGospel and Om Economics from https://in.sagepub.com/en-in/sas/mcdonaldisation-masala-mcgospel-and-om-economics/book235557

[10]. Jayaram, V. (2015). What is Buddhi? From

http://www.hinduwebsite.com/hinduism/concepts/buddhi.asp

[11]. Kinnes, T. (2014). Kriya Research Findings from http://oaks.nvg.org/kresearch.html

[12]. Kramer, S. H. (2011). Karma Yoga and Practical Spirituality from http://www.susankramer.com/KarmaYoga.html 
Texila International Journal of Medicine

Volume 4, Issue 2, Dec 2016

[13]. Marques, J, \& Dhiman, S. (2016). Leadership Today: Practices for Personal and Professional Performance

https://books.google.co.in/books?id=2LnmDAAAQBAJ\&pg=PA91\&lpg=PA91\&dq=current+research +activities+Vivekam\&source=bl\&ots=QGphLJCmjj\&sig=3fjFVTSOMo_gxRabNfcM0dZ6aEo\&hl=en $\& s a=X \& v e d=0$ ahUKEwjGve6k9o7QAhUIL48KHUbXB1QQ6AEIKDAC\#v=onepage\&q=current\%20 research\%20activities\%20Vivekam\&f=false

[14]. Nikhilanda, S. (2016). Restraining Mind through Abhyasa and Vairagya from

http://www.chinmayamission.com/restraining-mind-abhyasa-vairagya/\#.WBhWOtIrLIU

[15]. Philips, S.H. (2009). Yoga, Karma, and Rebirth: A Brief History and Philosophy from http://www.jstor.org/stable/10.7312/phil14484

[16]. Ramesh, T.A. (2006). Dharma and the Modern World from

http://www.boloji.com/index.cfm?md=Content\&sd=Articles\&ArticleID=2583

[17]. Sivananda, S. (2010). Samskaras from

http://sivanandaonline.org/public_html/?cmd=displaysection\&section_id=871

[18]. Sivananda, S. (2010). Vasanas from

http://sivanandaonline.org/public_html/?cmd=displaysection\&section_id=884\&format=html

[19]. Sivananda, S. (2011). Kriya Yoga Sadhana from

http://sivanandaonline.org/public_html/?cmd=displaysection\&section_id=526\&format=html

[20]. Sivananda, S. (2011). Jnana Yoga Sadhana from http://sivanandaonline.org/public_html/?cmd=displaysection\&section_id=1225\&format=html

[21]. Sivananda, S. (2011). True Renunciation from

http://sivanandaonline.org/public_html/?cmd=displaysection\&section_id=560\&format=html

[22]. Trivedi, I. (2014). Impact of Manomaya kosh sadhana on Adolescent's Mental Health from

http://www.jiarm.com/July2014/paper15812.pdf

[23]. Tiwari, M. (2012). Women's Power to Heal: Through Inner Medicine from https://books.google.co.in/books/about/Women_s_Power_to_Heal.html?id=DHNMxjGnqzQC\&redir_e $\mathrm{sc}=\mathrm{y}$

[24]. Venkateswara, R.K. (2015). Oneness in Science and Spirituality from https://books.google.co.in/books?id=lrhcDQAAQBAJ\&pg=PT69\&lpg=PT69\&dq=current+research+a ctivities+Buddhi(knowledge)\&source=bl\&ots=p4dw294x5I\&sig=x-snJZqJCjyB4hlSXBj3-

46v5gQ\&hl=en\&sa $=X \& v e d=0$ ahUKEwj4zK-

N84zQAhXLL48KHdZSDLwQ6AEIPDAH\#v=onepage\&q=current\%20research\%20activities\%20Bud dhi(knowledge)\&f=false

[25]. YOGA. (2016). Magazine of Bihar School of Yoga published in 1963 from http://www.yogamag.net/archives/2008/lnov08/san.shtml

[26]. Wisdomsdoor. (2016). Karma: Why does it exist? And How can you control it? From http://www.wisdomsdoor.com/rc4/hrc4-05.php

[27]. Wikipedia. (2016). Dharma: from https://en.wikipedia.org/wiki/Dharma 


\title{
Compare the Effect of Thiopental and Propofol on Neonatal and Maternal Outcomes after Caesarean Section: Anon-Systematic Review
}

\author{
Article by Jean Claude Nkola Ndomba \\ Master of Public Health, Texila American University, Congo \\ E-mail:drjcnkola@gmail.com
}

\begin{abstract}
Background: obstetric anaesthesia recommends that caesarean sections are done under regional anaesthesia, but there are conditions for which regional anaesthesia is contraindicated, so in those conditions general anaesthesia is the only choice.

For general anaesthesia thiopental 4-5mg/ $\mathrm{kg} \mathrm{l}$ and propofol 2,5mg/kg are both used for caesarean section.

Methods: we have reviewed articles from 1989 up to 2016 comparing the use of thiopental to propofol in caesarean sections.

Result: a total of 20 published articles and abstracts from 1989 up to 2016 were reviewed. These articles show that propofol was the best alternative drug for general anaesthesia induction in caesarean section and has few disadvantages according to the neonate Apgar score at one minute.

Conclusions: these articles reviewed show that propofol is currently the most commonly used induction agent and alternative for obstetric general anaesthesia and has better neonatal and maternal outcomes post operation than thiopental.
\end{abstract}

Keywords: propofol, obstetric anaesthesia, thiopental, caesarean section

\section{Introduction}

Currently more caesarean sections are done under regional anaesthesia than general anaesthesia. The use of regional anaesthesia is increasing because of failed intubation (Dyer RA 2011) and it has good post-operative analgesia. Currently the use of general anaesthesia in caesarean sections is less than $5 \%$ of caesarean deliveries in the United States and United Kingdom (Gilbert J Gran, up to date).

The type of anaesthesia in $\mathrm{C} / \mathrm{S}$ depends upon the caesarean section indication.

The study compared the effect of thiopental and propofol on neonatal and maternal outcomes. Thiopental and propofol are used for induction in GA for C/S. The purpose of the study was to find which one is the best induction drug in caesarean sections.

\section{Literature review}

\section{Introduction}

A study done comparing the effect of thiopental and propofol on the Apgar score was done in Uganda at Mulago National Referral Hospital and concluded that there was no significant difference between the two drugs used for induction in women undergoing general anaesthesia for a caesarean section (Tumukunde et al. 2015).

Another study done on pregnant women showed that there is some evidence that propofol may exert neuro developmental effects in animals but the effect on a developing human fetus is not clear (McKenzie 2015). Many anaesthetists use propofol for $\mathrm{C} / \mathrm{S}$ at a dosage of $2.8 \mathrm{mg} / \mathrm{kg}$ but a previous study done showed that there is no advantage to neonates in using propofol (Dyer 2011).

Thiopental is no longer available in many western countries. Propofol is the alternative. In China thiopental is not available and ketamine was recommended as the drug of choice for induction in caesarean sections by the Obstetric Anaesthesia Society (Huang, Gao 2016). 
Texila International Journal of Medicine

Volume 4, Issue 2, Dec 2016

Thiopental has been used routinely for caesarean sections since 1930 as an anaesthetic induction agent. It has disadvantages such as hypotension and a potentially reduced Apgar score.

Propofol is widely used for the induction and maintenance of anaesthesia for other types of surgery, but not for caesarean section.

\section{Agents used in general anaesthesia}

\section{Intravenous induction drugs}

These are drugs that, when given intravenously in an appropriate dose, cause a rapid loss of consciousness. This is often described as occurring within "one arm-brain circulation time", which is simply the time taken for the drugs to travel from the site of injection (usually the arm) to the brain, where they take effect. They are used:

- To induce anesthesia prior to other drugs being given to maintain anesthesia.

- As the sole drug for short procedures.

- To maintain anesthesia for longer procedures by intravenous infusion.

- To provide sedation.

The concept of intravenous anesthesia was born in 1932, when Wesse and Schrapff published their report on the use of hexobarbitone, the first rapidly acting intravenous drug. Two years later in 1934, sodium thiopental was introduced into clinical practice by Waters and Lundy, and it is still widely used today. A number of other drugs have come since then. The commonest drugs currently in use can be classified according to their chemical structure and include:

- Barbiturates

- Phenols

- Imidazoles

- Phencyclidines

- Benzodiazepines

Barbiturates and phenols will be discussed below.

\section{Pharmacokinetic}

On entering the blood stream, a percentage of the drug binds to the plasma proteins, with the rest remaining unboundor "free". The degree of protein binding will depend upon the physical characteristics of the drug in question. These include lipid solubility and degree of ionization. The drug is carried in the venous blood to the right side of the heart, through the pulmonary circulation, and via the left side of the heart into the systemic circulation. The majority of the cardiac output passes to the brain, liver and kidney (often referred to as "vessel rich organs"); thus a high proportion of the initial bolusis delivered to the cerebral circulation. The drug then passes along a concentration gradient from the blood into the brain. The rate of this transfer is dependent on a number of factors:

-The arterial concentration of the unbound free drug

-The lipid solubility of the drug

- The degree of ionization.

Unbound, lipid soluble, unionized molecules cross the blood-brain barrier the quickest.

Once the drug has penetrated the CNS tissue, it exerts its effects. Like most anaesthetic drugs, the exact mode of action of the intravenous drugs is unknown. It is thought that each drug acts at a specific receptor - GABA-A, NMDA and acetylcholine receptors have all been studied as potentials it esofaction.

Following the initial flooding of the CNS and other vessel-rich tissues with non-ionized molecules, the drug starts to diffuse through other tissues that do not have such a rich blood supply. This secondary tissue up take, predominantly by skeletal muscle, causes the plasma concentration to fall, allowing the drug to diffuse out of the CNS down the resulting reverse concentration gradient. It is this initial redistribution of the drug in to other tissues that leads to the rapid awakening seen after a single dose of an induction drug. Metabolism and plasma 
clearance have a much less important role following a single bolus, but are more important following in fusions and repeat doses of a drug.

Fat makes little contribution to the early redistribution of free drugs following a bolus due to its poor blood supply (vessel-poor tissues), as seen on the diagram below. However, following repeat doses or in fusions, equilibration with a dipose tissue forms a drug reservoir, often leading to the delayed awakening we observed most with obese patients.

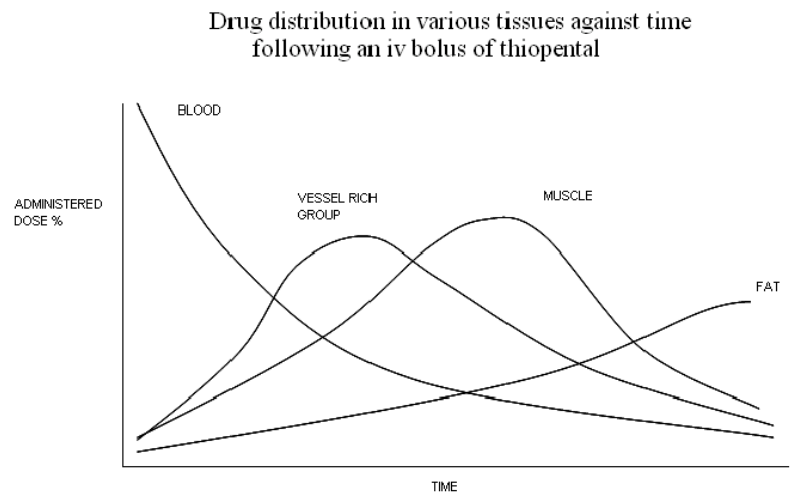

\section{Effect on cardiac output}

In the case of patients in shock, cesare an section (due to physiological changes), and elderly patients, cardiac output is reduced and the body compensates by diverting an increased proportion of cardiac output to the cerebral circulation in order to preserve cerebral blood flow. Thus a greater proportion of any given drug will enter the cerebral circulation. In these situations, the induction drug dose must always be reduced. Furthermore, as global cardiac output is reduced, the time taken for an induction drug to reach the brain and exertits effect is prolonged. The slow titration of a reduced drug dose is the key to safe induction in these patients.

\section{Properties of intravenous induction drugs}

1. Physical properties

- Water soluble and stable in solution

- Stable on exposure to light

- Long shelf life

- No pain on intravenous injection

- Painful when injected in to an artery

- Non-irritant when injected subcutaneously

- Low incidence of thrombo phlebitis

- Cheap

2. Pharmaco kinetic properties

- Rapid on set in one arm-brain circulation time

- Rapid redistribution to vessel-rich tissue

- Rapid clear ance and metabolism

- No active metabolites

3. Pharmaco dynamic properties

- High the rapeutic ratio (ratio of toxic dose : minimally effective dose)

- Minimal cardio vascular and respiratory effects

- No histaminerel ease/hyper sensitivity reactions

- No emetic effects

- No involuntary movements

- No emergence night mares

- No hang over effect

- No adreno cortical suppression 
Texila International Journal of Medicine

Volume 4, Issue 2, Dec 2016

- Safe to use in porphyria

\section{Sodium Thiopental}<smiles>[R1]N1C(=O)N([R1])C(=O)C([Y3])([Y3])C1=O</smiles>

Thiopental (also called thiopentone and pentothal) is a barbiturate, supplied as a pale yellow hygroscopic (attracts moisture from the atmosphere) powder. Ampoules commonly contain $500 \mathrm{mg}$ of sodium thiopental with $6 \%$ sodium carbonate in an inert atmosphere of nitrogen. Reconstituted with $20 \mathrm{ml}$ of water, this yields a $2.5 \%$ solution $(25 \mathrm{mg} / \mathrm{ml})$ with a $\mathrm{pH}$ of 10.8. The alkaline solution is bacteriostatic and safe to keep for 48 hours. The molecular structure of thiopental is based up on the barbiturate ring - as shown above. A sulphur atom at the carbon R2 position confers the short duration of action.

A dose of $4-5 \mathrm{mg} / \mathrm{kg}$ of thiopental produces a smooth on set of hypnosis with good definitive end points within 30 seconds of intravenous injection. Recovery after a single dose is rapid due to redistribution, and there is a low incidence of restlessness, nausea and vomiting.

Thio pentalis $65-85 \%$ protein bound in plasma. Metabolism is slow and occurs in the liver. Excretion of metabolites occurs mainly in the urine. Following repeated doses or infusions of thiopental, metabolism follows zero order kinetics; this means that a constant amount of the drug is being eliminated per unit time, irrespective of the plasma concentration. Some drugs are metabolized by first order kinetics; this means that a constant fraction of the drug is eliminated per unit time, i.e. dependent on plasma concentration. Zero order kinetics occur when the metabolic path ways become saturated, leading to an accumulation of the active drug and delayed recovery.
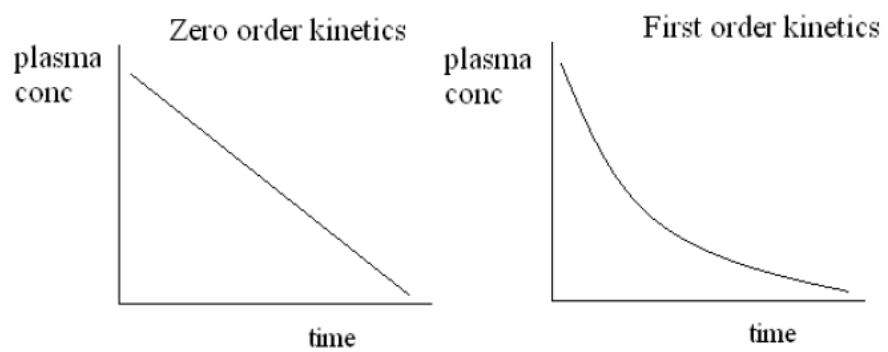

$\mathrm{T}$ Thiopental directly depresses the contractile force of the heart, reducing cardiac output and blood pressure. There may be a compensatory increase in the heart rate. It also decreases venoustone, causing pooling of blood in the peripheral veins, and increasing the degree of hypotension, particularly in patients who are hypovolemic (e.g. following hemorrhage).

Respiratory depression is common and a period of apneais usually seen following abolus dose. Airway reflexes are well preserved in comparison with propofol; as a result, it is unsuitable for use when inserting a laryngeal mask airway (LMA), which may cause coughing and laryngospasm. Histamine release can occur, which may precipitate bronchospasm.

Thiopental reduces cerebral blood flow, cerebral metabolic rate and oxygen demand. It has potent antic on vulsant properties. Following traumatic brain injury, infusion of thiopental to produce a "barbiturate coma" lowers intra cranial pressure and may improve neurological outcome. This is, however, associated with significant accumulation, causing a prolonged effect with multiple complications.

The porphyrias are a group of diseases characterized by over production and excretion of 
porphyrins (intermediate compounds produced during hemo protein synthesis). Acute attacks may be precipitated by drugs, stress, infection, alcohol, pregnancy and starvation. Thiopental may precipitate porphyria due to hepatic enzyme induction in susceptible patients, and therefore should be avoided.

\section{Propofol (2, 6 di-isopropylphenol)}

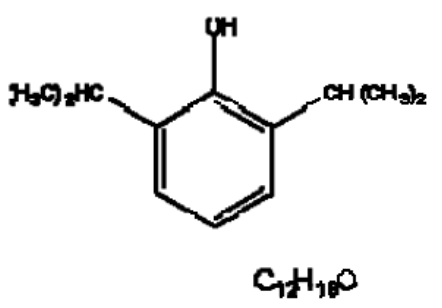

Propofolis usually presented as a 1 or $2 \%$ aqueous mulsion (tiny fat drop lets in suspension, white colour) containing soya oil, egg phosphatide and glycerol. It is otonicto plasma and has a pH of 7.0 - 8.5. It can cause pain on injection in to small veins.

It is a short-acting general anesthetic drug, with an onset of action of approximately 30 seconds. Recovery from anesthesia is usually rapid. A smooth induction of anesthesia usually follows a dose of $2-2.5 \mathrm{mg} / \mathrm{kg}$. Propofol should be titrated against the response of the patient until the clinical signs show the onset of anesthesia. The best end point is loss of verbal contact with the patient.

Following an IV bolus, there is rapid equilibration between the plasma and the highly per fused tissue of the brain as described earlier. Plasma levels decline rapidly as a result of redistribution, followed by a more prolonged period of hepatic metabolism and renal clearance. The initial redistribution half-life is between 2 and 4 minutes. Moderate hepatic orrenalim pairment does not alter the pharmaco kinetics of propofol.

Propofol causes the most marked fall in blood pressure of all the induction drugs. This is mainly due to systemic vasodilatation. There may be an accompanying light increase in heart rate. The fall in blood pressure is dose dependent and is most marked in the elderly and inpatients in shock. This can be minimized by slow injection to avoid in advertent overdose.

With the exception of ketamine, all induction drugs act on the respiratory centre to cause respiratory depression. This effect is the most profound with propofol, and a period of a pnoeais usually seen.

Propofol also markedly reduces airway and pharyngeal reflexes, making it the ideal drug to use with the laryngeal mask.

Propofol has been associated with epileptic form movements, which must not be confused with true seizure activity, on induction and recovery, but it is anti convulsant in normal doses. It has also been shown to reduce cerebral blood flow, metabolic rate and intra-cranial pressure.

An infusion of propofol issued commonly to provide sedation for adult patients undergoing minor procedures and in intensive care units. It is also the most commonly used drug to provide to talintravenous anesthesia.

Experience suggests that propofol is safe to use inpatients susceptible to porphyria and in pregnancy.

\section{Inhalation agents}

The inhalation agents used for the maintenance of GA were analysed and it was found that sevoflurane and desflurane had no adverse maternal or neonatal effects, while sevoflurane was associated with more rapid recovery than isoflurane (Dyer 2011). Sevoflurane has been successfully used for anaesthesia induction in patients with need lephobia.

2.2. Muscle relaxant Suxamethonium has been used successfully for rapid sequence of intubation, but in the case of anaphylactic reaction, rocurronium or sugammadex can be used instead. 
Texila International Journal of Medicine

Volume 4, Issue 2, Dec 2016

Opioid use: a study on remifentanil showed that it is effective for intubation in healthy patients, but neonatal respiratory support may be required, especially in preterm.

2.2.5.100\% oxygenation in GA leads about $50 \%$ and more umbilical venous oxygenation. Endo tracheal Intubation in GA for C/S is standard, but a study shows that a laryngeal mask airway is an alternative to tracheal intubation during elective C/S. Failed intubation delays the surgery and leads to poor oxygenation of the unborn baby, which may yield a poor Apgar score.

Propofol crosses the placenta and can depress neonatal respiration.

Tables of articles reviewed

\begin{tabular}{|l|l|}
\hline $\begin{array}{l}\text { 1. Study Jeffrey } \\
\text { 2016 Methods }\end{array}$ & Survey of current obstetric anaesthesia practiced in China \\
\hline Participants & $\begin{array}{l}\text { 78000 registered anaesthesiologists, members of the New } \\
\text { Youth Anaesthesia Forum, responded by on WeChat to a } \\
\text { questionnaire on agent use in general anaesthesia for } \\
\text { caesarean section. Their response was that propofol is not } \\
\text { licensed by manufacturers for use in obstetric anaesthesia. }\end{array}$ \\
\hline Interventions & $\begin{array}{l}\text { No } \\
\text { The author concluded that anaesthesiologists strongly } \\
\text { supported the use of propofol to replace ketamine as the } \\
\text { induction agent of choice in caesarean sections. } \\
\text { Manufacturers should change the wording of their package } \\
\text { inserts with regard to the use of propofol in obstetric } \\
\text { anaesthesia. }\end{array}$ \\
\hline Notes & $\begin{array}{l}\text { This survey was done in China. Other anaesthetists did not } \\
\text { support the replacement of ketamine by propofol. }\end{array}$ \\
\hline & \\
\hline
\end{tabular}

\begin{tabular}{|l|l|}
\hline $\begin{array}{l}\text { 2. Study Munender } \\
\text { Mamidi et al } 2016 \\
\text { Methods }\end{array}$ & Comparative randomized study \\
\hline Participants & $\begin{array}{l}\text { A sample of } 103 \text { healthy patients were randomized in two } \\
\text { groups. Of these, 51 patients received thiopental and } 52 \\
\text { patients received propofol. }\end{array}$ \\
\hline Interventions & $\begin{array}{l}\text { Term pregnant women received } 5 \mathrm{mg} / \mathrm{kg} \text { of thiopental or } \\
2.5 \mathrm{mg} / \mathrm{kg} \text { of propofol; maintenance was similar. }\end{array}$ \\
\hline Outcomes & $\begin{array}{l}\text { Author concluded that propofol appears to be a suitable } \\
\text { alternative induction agent for obstetric anesthesia. }\end{array}$ \\
\hline
\end{tabular}

3. StudyTumukunde et al. BMC anaesthesiology 2015

\begin{tabular}{|l|l|}
\hline Methods & $\begin{array}{l}\text { Randomised single blinded clinical trial at Mulago } \\
\text { Hospital, in Uganda, ASA1 and } 2 \text { included term pregnant } \\
\text { women. }\end{array}$ \\
\hline Participants & $\begin{array}{l}150 \text { term pregnant women, from November } 2013 \text { to April } \\
2014\end{array}$ \\
\hline Interventions & $\begin{array}{l}\text { Premedication was done with: cimetidine200mg IV, } \\
\text { metoclopramide 10mg IV 1-2hours before operation, } \\
\text { preoxygenate for 3-5 minutes. } \\
\text { General group with thiopental 4mg/kg iv, succinylcholine, } \\
\text { oxygen, isoflurane inhalation, then atracurium, nalbuphine } \\
\text { 10mg was administered, then halothane was discontinued, }\end{array}$ \\
\hline
\end{tabular}




\begin{tabular}{|l|l|}
\hline & $\begin{array}{l}\text { reversal was given: neostigmine } 0.05 \mathrm{mg} / \mathrm{kg} \text { of body weight } \\
\text { plus atropine } 0.02 \mathrm{mg} / \mathrm{kg} .\end{array}$ \\
& $\begin{array}{l}\text { GA group with propofol had } 2 \mathrm{mg} / \mathrm{kg} \text { administered in one } \\
\text { minute intravenously, followed by succinylcholine } \\
1,5 \mathrm{mg} / \mathrm{kg} \text {, oxygen, isoflurane inhalation, then atracurium, } \\
\text { nalbuphine } 10 \mathrm{mg} \text { was given, then halothane was } \\
\text { discontinued, reversal was given: neostigmine } 0.05 \mathrm{mg} / \mathrm{kg} \\
\text { of body weight plus atropine } 0.02 \mathrm{mg} / \mathrm{kg} \text {. Both groups were } \\
\text { intubated. All received 1.5l of crystalloid. }\end{array}$ \\
\hline Outcomes & $\begin{array}{l}\text { The author concluded that maternal recovery was shorter in } \\
\text { the propofol group than in the thiopental group. The Apgar } \\
\text { score did not differ significantly whether thiopental or } \\
\text { propofol was used as an induction agent in women } \\
\text { receiving GA. There was high rate of ICU in the group in } \\
\text { which propofol was used for induction. }\end{array}$ \\
\hline
\end{tabular}

\begin{tabular}{|l|l|}
\hline $\begin{array}{l}\text { 4. Study Vedat et al.2015 } \\
\text { Methods }\end{array}$ & Patients were selected on a randomized basis. \\
\hline Participants & $\begin{array}{l}70 \text { term pregnant women, divided in two groups T (N=35) } \\
\text { and P (N=35), undergoing C/S for any indication. }\end{array}$ \\
\hline Interventions & $\begin{array}{l}\text { Premedication done with: cimetidine200mg IV, } \\
\text { metoclopramide 10mg IV 1-2hours before operation, } \\
\text { preoxygenate for 3-5minutes. } \\
\text { General group had either thiopental 5mg/kg iv and or } \\
\text { propofol 2,5mg/kg then 0,6mk/kg of rocuronium, oxygen, } \\
\text { sevoflurane inhalation for maintenance, 15 unit of oxytocin } \\
\text { infusion then 10unit bolus, reversal was given: neostigmine } \\
\text { 0.05mg/kg of body weight plus atropine 0.02mg/kg. }\end{array}$ \\
\hline Outcomes & $\begin{array}{l}\text { The author concluded that both propofol and thiopental } \\
\text { sodium can be used safely in caesarean sections, and the use } \\
\text { of propofol was more advantageous than thiopental because } \\
\text { it provided adequate anaesthetic depth and more rapid } \\
\text { recovery. }\end{array}$ \\
\hline Notes & \\
\hline
\end{tabular}

5. StudyDadras MM et al. 2013

\begin{tabular}{|c|c|}
\hline & Methods Double-blind clinical trial \\
\hline Participants & $\begin{array}{l}230 \text { healthy women who volunteered to undertake caesarean } \\
\text { operation were selected and then divided randomly into two } \\
\text { equal groups using statistical blocking. }\end{array}$ \\
\hline Interventions & $\begin{array}{l}\text { One group was treated by propofol while other one was } \\
\text { treated by thiopental. }\end{array}$ \\
\hline Outcomes & $\begin{array}{l}\text { Author concluded that after sufficient fluid therapy, propofol } \\
\text { can be a suitable drug to achieve anaesthesia. Moreover, it } \\
\text { exerts less impact on cesarean babies' Apgar and stimulates } \\
\text { lower levels of nausea and vomiting in mothers. }\end{array}$ \\
\hline
\end{tabular}

6. Study Arzu Mercanet al.2012

\begin{tabular}{|l|l|}
\hline Methods & $\begin{array}{l}\text { Prospective, randomized, clinical study was performed } \\
\text { between January 2009 and December 2009 at Saad } \\
\text { Specialist Hospital. }\end{array}$ \\
\hline Participants & $\begin{array}{l}82 \text { term pregnant women. Nulliparity. Sample size was 82 } \\
\text { patients divided in two groups, propofol group (N=42) and }\end{array}$ \\
\hline
\end{tabular}


Texila International Journal of Medicine

Volume 4, Issue 2, Dec 2016

\begin{tabular}{|l|l|}
\hline & $\begin{array}{l}\text { thiopental group (N=40), undergoing elective C/S for any } \\
\text { indication. }\end{array}$ \\
\hline Interventions & $\begin{array}{l}\text { Premedication done with: cimetidine200mg IV, } \\
\text { metoclopramide 10mg IV 1-2hours before operation, } \\
\text { preoxygenate for 3-5minutes. } \\
\text { General group had thiopental } 5 \mathrm{mg} / \mathrm{kg} \text { iv, succinylcholine } \\
1 \mathrm{mg} / \mathrm{kg}, \text { oxygen, isoflurane inhalation, then } \\
\text { atracurium0.5mg/kg, nalbuphine } 10 \mathrm{mg} \text { was given, then } \\
\text { isoflurane was discontinued, reversal was given: } \\
\text { neostigmine } 0.05 \mathrm{mg} / \mathrm{kg} \text { of body weight plus atropine } \\
0.02 \mathrm{mg} / \mathrm{kg}, 100 \% \text { oxygen } 5 \mathrm{mg} / \mathrm{kg} \text { and propofol } 2 \mathrm{mg} / \mathrm{kg} \\
\text { Thiopental 4-5mg/kg. }\end{array}$ \\
\hline outcomes & $\begin{array}{l}\text { The author concluded that induction agent for caesarean } \\
\text { section could be effective in maintaining adequate BIS } \\
\text { (bispectral index) levels until neonate delivery. Furthermore } \\
\text { propofol used as an induction agent was more effective than } \\
\text { thiopental in keeping BIS values levels lower until the } \\
\text { delivery of the newborn. }\end{array}$ \\
\hline
\end{tabular}

7. Study Maziar Mahjoobifard et al. 2011

\begin{tabular}{|l|l|}
\hline Methods & 230 patients selected by randomized prospective study. \\
\hline Participants & $\begin{array}{l}\text { 230 pregnant healthy women, divided in two groups, thiopental } \\
\text { (N=115) and propofol (N=115), undergoing elective C/S for } \\
\text { any indication. }\end{array}$ \\
\hline Interventions & $\begin{array}{l}\text { General group had propofol or thiopental succinyl choline, } \\
\text { oxygen/nitrousoxide, isofluraneat 0.25-0.5\% for maintenance, } \\
\text { reversal given was neostigmine plus atropine. }\end{array}$ \\
\hline Outcomes & $\begin{array}{l}\text { The author concluded that in elective cesarean sections in } \\
\text { which there are no danger to mother and neonate without any } \\
\text { contraindication; propofol may be useful as an anaesthetic } \\
\text { inducing agent. Despite its reduced effect on the neonatal Apgar } \\
\text { score, it induces less post-operative nausea and vomiting for } \\
\text { mothers. }\end{array}$ \\
\hline
\end{tabular}

8. Study Perisa Golfam et al. 2009

\begin{tabular}{|l|l|}
\hline Methods & $\begin{array}{l}\text { Double blinded clinical trial study, done for patients scheduled } \\
\text { for elective caesarean section. }\end{array}$ \\
\hline Participants & $\begin{array}{l}60 \text { term pregnant women, sample size was } 60 \text { patients divided in } \\
\text { two groups, } 1^{\text {st }}\left(\mathrm{N}=30 \text { for propofol) and } 2^{\text {nd }}(\mathrm{N}=30 \text { for }\right. \\
\text { thiopental), undergoing elective } \mathrm{C} / \mathrm{S} \text { for any indication. }\end{array}$ \\
\hline Interventions & $\begin{array}{l}\text { Premedication done with: cimetidine } 200 \mathrm{mg} \mathrm{IV}, \\
\text { metoclopramide } 10 \mathrm{mg} \text { IV } 1-2 \text { hours before operation, } \\
\text { preoxygenate for } 3-5 \text { minutes. } \\
\text { General group had thiopental } 4 \mathrm{mg} / \mathrm{kg} \text { iv, or propofol } 2.5 \mathrm{mg} / \mathrm{kg}, \\
\text { Succinylcholine, oxygen, halothaneinhalation, thenatracurium, } \\
\text { nalbuphine } 10 \mathrm{mg} \text { was given, then halothane was discontinued, } \\
\text { reversal was given: neostigmine } 0.05 \mathrm{mg} / \mathrm{kg} \text { of body weight plus } \\
\text { atropine } 0.02 \mathrm{mg} / \mathrm{kg} .\end{array}$ \\
\hline Outcomes & $\begin{array}{l}\text { The author concluded that propofol had no adverse effect on } \\
\text { either mother's hemodynamic or the clinical status of neonates: it } \\
\text { can be used as an alternative drug to induce anaesthesia. }\end{array}$ \\
\hline
\end{tabular}


9. Study Celleno D et al. 1993

\begin{tabular}{|l|l|}
\hline Methods & Randomized, double-blind study \\
\hline Participants & g0 healthy patients undergoing elective cesarean section with \\
general anesthesia.
\end{tabular}

10. Study M Valtonen et al. 1989

\begin{tabular}{|l|l|}
\hline Methods & Patients were selected by randomized prospective study. \\
\hline Participants & $\begin{array}{l}32 \text { term pregnant women, divided in two groups, A (N = 16) and } \\
\text { B (N = 16), undergoing elective C/S for CPD. }\end{array}$ \\
\hline Interventions & $\begin{array}{l}\text { General group had thiopental } 4 \mathrm{mg} / \mathrm{kg} \text { iv or propofol 2, 5 mg/kg } \\
\text { for induction, other drugs were the same. }\end{array}$ \\
\hline Outcomes & $\begin{array}{l}\text { The author concluded that propofol was found to be similar to } \\
\text { thiopentone in induction characteristics and in the effects on } \\
\text { neonates. Recovery times after anesthesia were shorter with } \\
\text { propofol, and this fact may be advantageous in some situations. } \\
\text { Propofol appears to be a suitable alternative to thiopentone as an } \\
\text { induction agent for anesthesia in elective caesarean sections. }\end{array}$ \\
\hline notes & \\
\hline
\end{tabular}

\section{Methods}

We carried out a non-systematic literature review of articles comparing propofol to thiopental from 1989 to 2016.

\section{Findings}

Out of all the articles read, Celleno et al (1993) said that thiopental remains the first line choice for $\mathrm{C} / \mathrm{S}$ and others concluded that propofol can be used as an alternative in pregnancy for $\mathrm{C} / \mathrm{S}$.

\section{Conclusions}

Most of the studies read show that GA for $\mathrm{C} / \mathrm{S}$ is a challenge for the modern anaesthesiologist, because the physiological changes during pregnancy make the GA difficult. In the case of general anaesthesia, propofol can be used as an alternative, but manufacturers advise against using it in pregnancy.

\section{Recommendations}

Many articles support the use of propofol in pregnancy. This is practice based rather than research based. We are not sure of its safety in obstetric use. Manufacturers still contraindicate it for obstetric use. 
Texila International Journal of Medicine

Volume 4, Issue 2, Dec 2016

It may be that propofol is a suitable agent for obstetric use but available data do not support this assertion nor do 75\% of obstetric anesthetists (Sneyd 2004).

We recommend more clinical studies to compare propofol outcomes on neonate and mothers.

More data is required to conclude if propofol is $100 \%$ suitable for cesarean sections.

\section{References}

[1]. Arzu Mercan et al. A prospective, randomized comparison of the effects of thiopental and propofol on bispectral index during caesarean section till delivery of new-born. 2012.

[2]. Celleno D1 et al.1993 J Clin Anesth. 1993 Jul-Aug; 5(4):284-8.

[3]. Dr Tom Lupton \&Dr Oliver Pratt. Tutorial on: Intravenous drugs used for the induction of anesthesia. Salford Royal Hospitals NHS Foundation Trust, Salford, UK (2003).

[4]. Dadras MM, Mahjoobifard M, Panahipoor A, \&Dadras MA. Comparing propofol with sodium thiopental on neonatal Apgar score after elective cesarean section. Zahedan J Res Med Sci (ZJRMS) 2013; 15(4): 21-24.

[5]. Heather McKenzie et al. The pregnant patient: assessment and perioperative management...2015.

[6]. Mahjoobifard $\mathrm{M}$ et al. The comparison of propofol with thiopental as induction drug on neonatal Apgar during elective cesarean section. Zahedan J Res Med Sci (Zahedan Journal of Research in medical sciences) 2011; 13(4):35-39.

[7]. M. Valtonen et al. Comparison of propofol and thiopentone for induction of anesthesia for elective Caesarean section. 1989.

[8]. M. Mamidi, Shiva Prasad D. Propofol and Thiopentone as induction agents in obstetric anesthesia - A comparative study. IAIM, 2016; 3(4): 111-117.

[9]. Michael A et al. Propofol infusion for cesarean section. 1990; 37:5 pp514-20.

[10]. Perisa Golfam et al. The effect of propofol and thiopental on apgar score during caesarean section. 2009.

[11]. Rob Dyer. Update on general anesthesia for C/S. South African Journal of Anesthesia Analgesia 2011; 17(1).

[12]. South African guidelines for safe use of procedural sedation and analgesia for diagnostic and therapeutic procedures in adults: 2010.

[13]. Tiffany Sun Moon \&Joshua Sappenfield Anaesthesia management and challenges in the pregnant patient. 2016; 6:89-94.

[14]. Tumukunde et al. The effect of propofol versus thiopental on Apgar scores in newborns and perioperative outcomes of women undergoing emergency caesarean section: a randomized clinical trial. 2015.

[15]. Update on use of propofol and thiopental 2016.

[16]. Which induction drug for cesarean section? A comparison of thiopental sodium, propofol, and midazolam.

[17]. Vedat et al. Comparison of the effect of thiopental sodium and propofol on haemodynamics, awareness and newborns during caesarean section under general anaesthesia 2015. Turk Journal of anaesthesia reanimation.

[18]. xJR Sneyd. Recent advances in intravenous anesthesia. British Journal of Anesthesiology 2004; 93: $725-36$ 


\section{PIEXILA JOURNAL}

\section{Texila American University,}

Providence, Georgetown,

Guyana, South America.

Telephone: (+592) 2318118 / (+592) 2318111

E-mail: ejournal.assist@tau.edu.org

Skype: texila.aco32

Whatsapp: +918056580933 